Aus dem Institut für Neuropathologie

(Prof. Dr. med. C. Stadelmann-Nessler)

der Medizinischen Fakultät der Universität Göttingen

\title{
Oligodendrozytenpopulationen in Läsionen der multiplen Sklerose sowie der toxisch- und autoimmun-induzierten Demyelinisierung
}

\author{
INAUGURAL-DISSERTATION \\ zur Erlangung des Doktorgrades \\ der Medizinischen Fakultät der \\ Georg-August-Universität zu Göttingen
}

vorgelegt von

Raein Kordestani Nejad

aus

Teheran, Iran

Göttingen 2020 
Dekan:

\section{Betreuungsausschuss}

Betreuer/in

Ko-Betreuer/in:

\section{Prüfungskommission}

Referent/in

Ko-Referent/in:

Drittreferent/in:
Prof. Dr. med. W. Brück

Prof. Dr. med. C. Stadelmann-Nessler

Prof. Dr. rer. nat. T. Outeiro

Prof. Dr. med. C. Stadelmann-Nessler

Prof. Dr. rer. nat. T. Outeiro

Prof. Dr. med. Ralf Dressel

Datum der mündlichen Prüfung: 27.07.2021 
Hiermit erkläre ich, die Dissertation mit dem Titel "Oligodendrozytenpopulationen in Läsionen der multiplen Sklerose sowie der toxisch- und autoimmun-induzierten Demyelinisierung" eigenständig angefertigt und keine anderen als die von mir angegebenen Quellen und Hilfsmittel verwendet zu haben.

Göttingen, den 


\section{Inhaltsverzeichnis}

Abbildungsverzeichnis ....................................................................................... III

Tabellenverzeichnis ......................................................................................... III

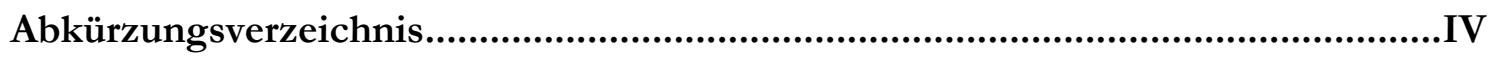

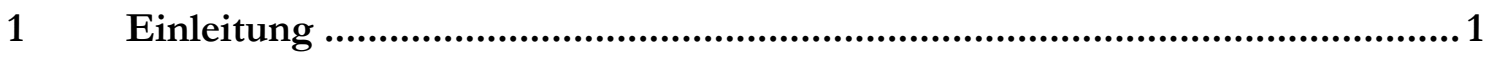

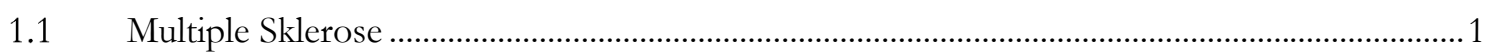

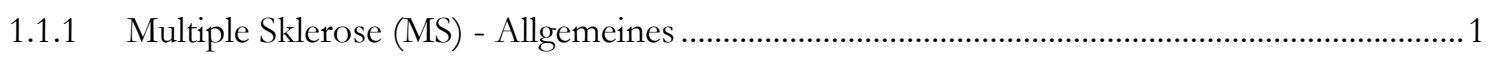

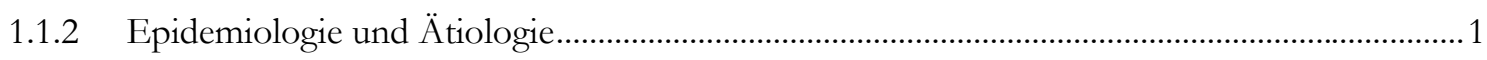

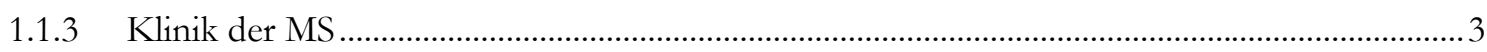

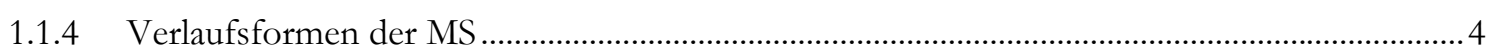

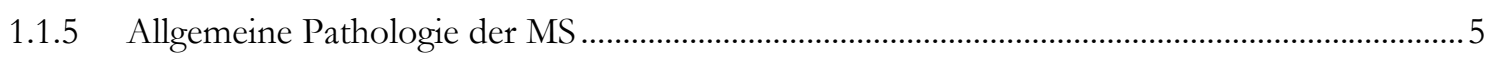

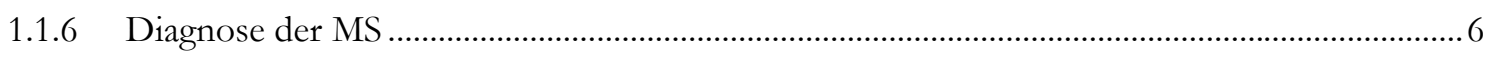

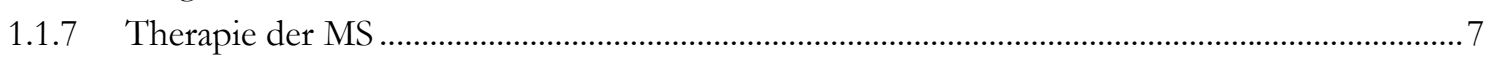

1.2 Oligodendrozyten - Aufgaben und assoziierte Strukturen .........................................................

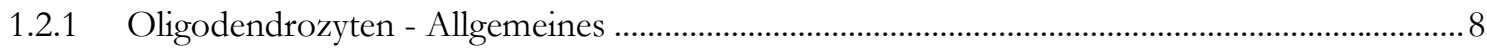

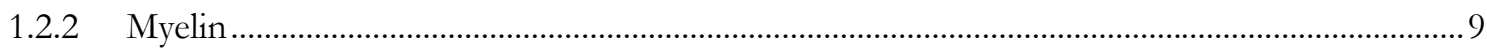

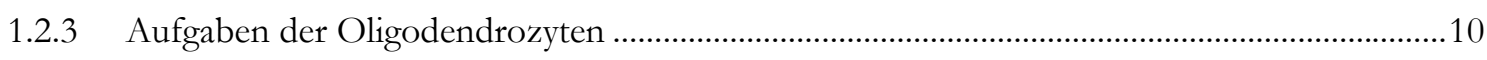

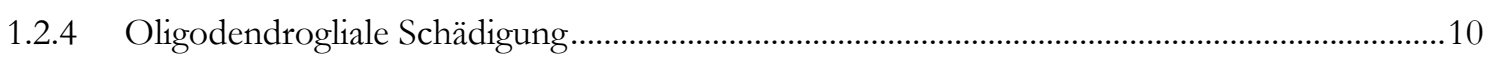

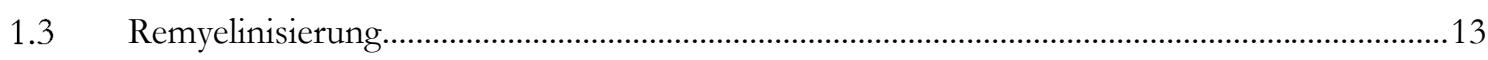

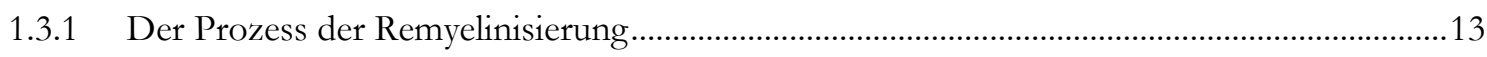

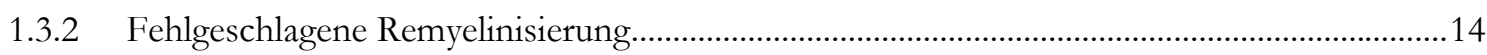

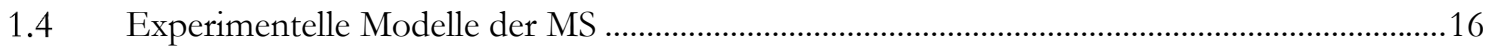

1.4.1 Experimentelle autoimmune Enzephalomyelitits (EAE) .........................................................16

1.4.2 Cuprizoninduzierte Demyelinisierung ...............................................................................

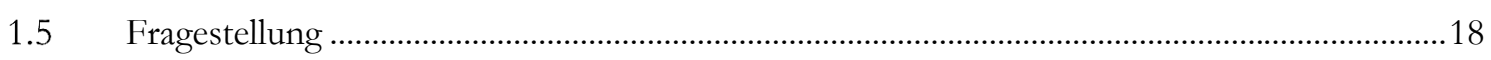

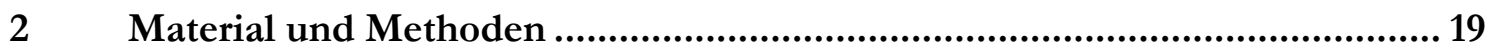

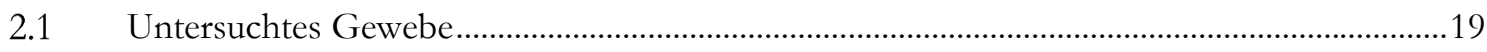

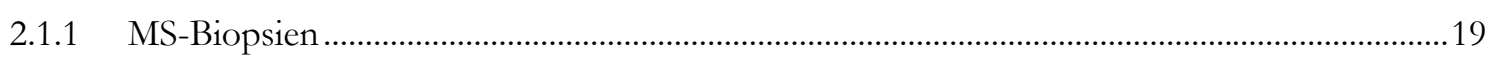

2.1.2 Experimentell erzeugte Proben in Tiermodellen der MS ........................................................2

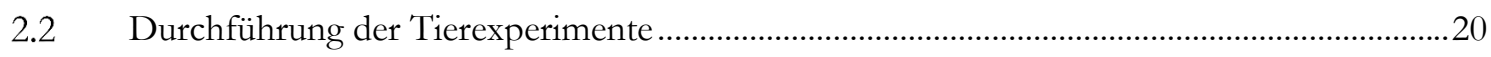

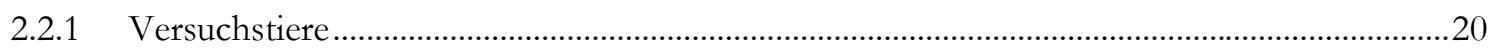

2.2.2 Experimentelle autoimmune Enzephalomyelitis (EAE) .........................................................21

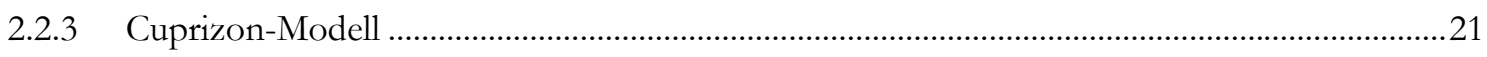

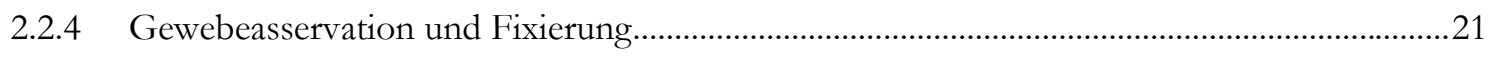

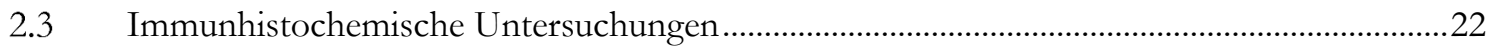

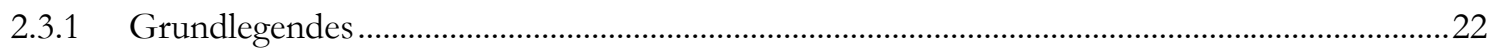

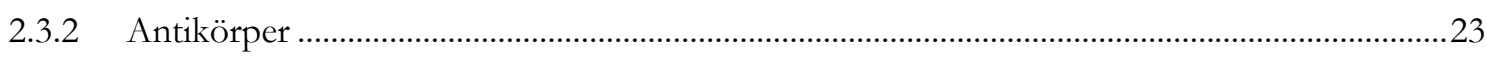

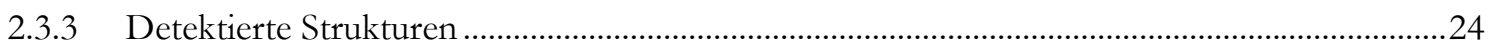




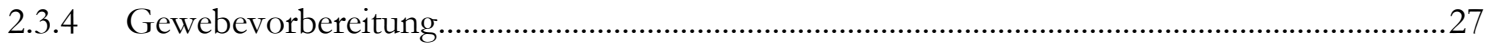

2.3.5 Allgemeine Durchführung der Immunofluoreszenz-Färbung (indirekte Methode) .............27

2.3.6 Durchführung der Immunofluoreszenz-Färbung von Olig2 2................................................28

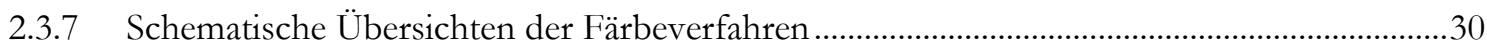

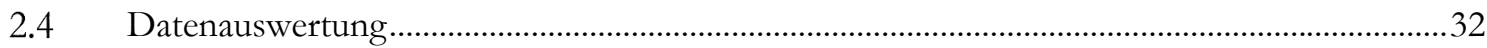

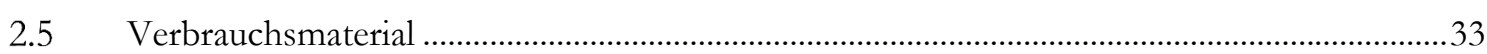

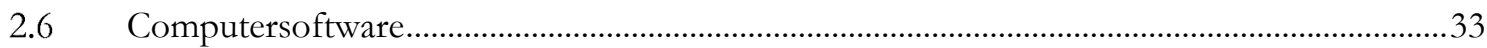

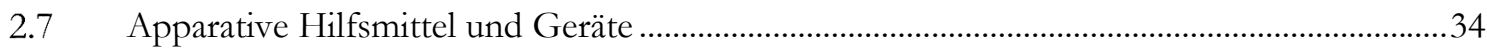

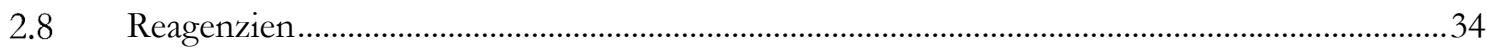

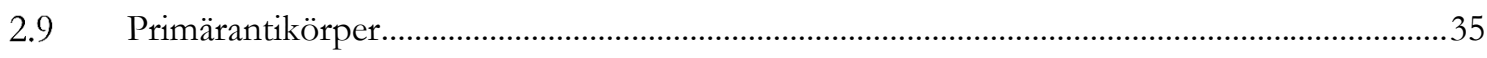

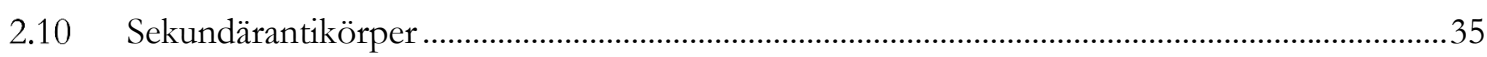

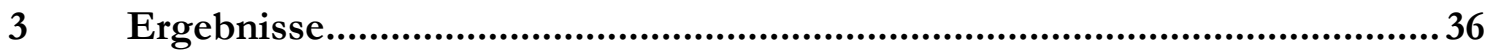

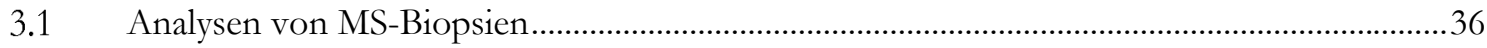

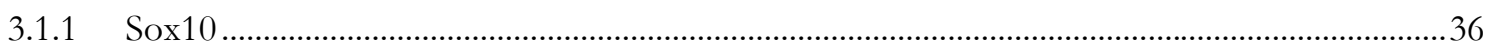

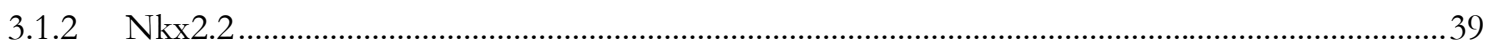

3.2 Analysen tierexperimentell erzeugter Gewebeproben ................................................................4 41

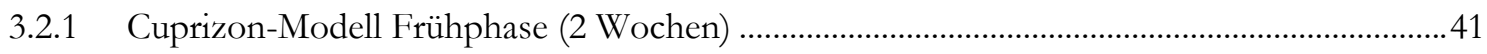

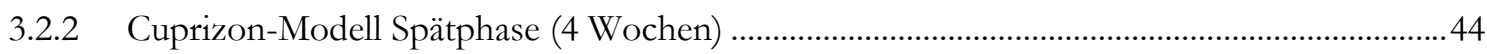

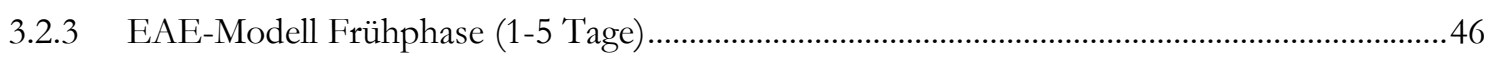

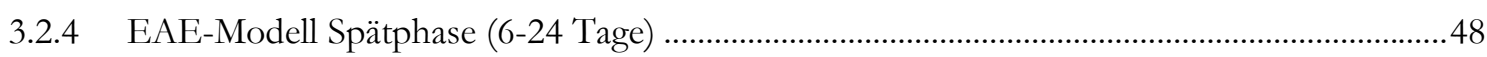

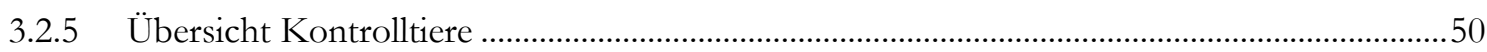

$4 \quad$ Diskussion..........................................................................................52

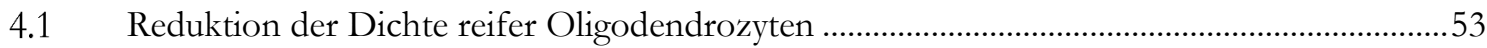

4.2 Mögliche Gründe für die Abnahme der Dichte reifer Oligodendrozyten .............................53

4.3 Erst kürzlich differenzierte reife Oligodendrozyten ...............................................................5 54

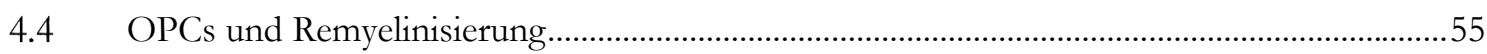

4.5 Einflussfaktoren auf OPCs: Zytotoxizität vs. Differenzierungsblock .....................................56

4.6 Einflussfaktoren auf OPCs: Astrozyten und Mikromilieu ..................................................57

4.7 Die Rolle entzündlicher Prozesse bei Differenzierung und Remyelinisierung........................58

4.8 Die mögliche Rolle molekularer Signalwege in der Beeinflussung von

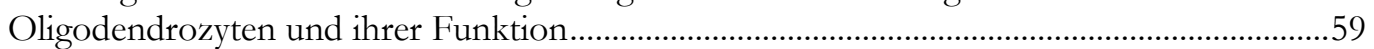

4.9 Herunterregulation der Transkriptionsfaktoren Olig2 und Sox10 in MS-Läsionen..............60

4.10 Vorkommen und mögliche Bedeutung von Olig2-/p25+-Zellen .........................................61

4.11 Epigenetische Regulationsmechanismen als möglicher Erklärungsansatz für

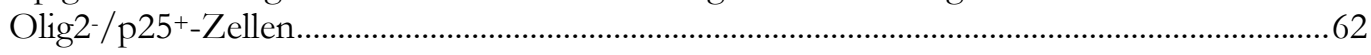

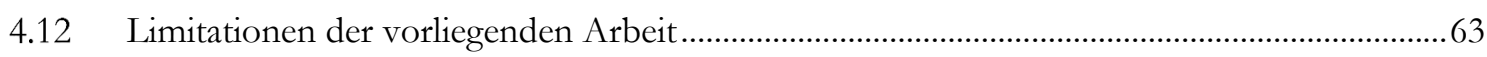

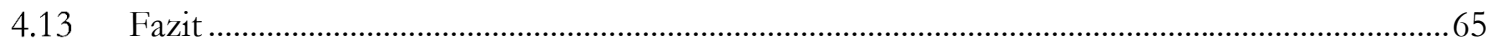

$5 \quad$ Zusammenfassung..............................................................................6 67

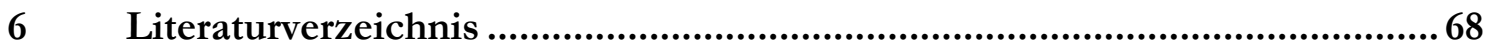




\section{Abbildungsverzeichnis}

Abbildung 1: Schematische Darstellung IgG

Abbildung 2: Übersicht indirektes Färbeverfahren

Abbildung 3: Schematische Übersicht Olig2-Färbung mit TSA-Kit..................................................... 31

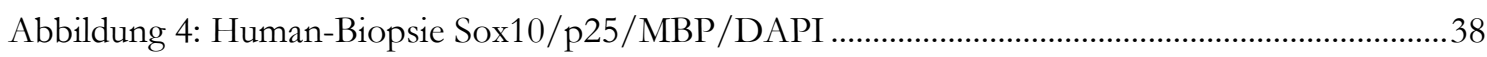

Abbildung 5: Human-Biopsie Nkx2.2/p25/MBP/DAPI .....................................................................40

Abbildung 6: Cuprizon-Modell Woche 2 Olig2/p25/MBP/DAPI......................................................43

Abbildung 7: Cuprizon-Modell Woche 4 Olig2/p25/MBP/DAPI.......................................................45

Abbildung 8: EAE-Modell Frühphase (Tag1-5) Olig2/p25/MBP/DAPI .........................................47

Abbildung 9: EAE-Modell Spätphase (Tag6-24) Olig2/p25/MBP/DAPI........................................49

Abbildung 10: Kontrollgewebe gesunde Maus Olig2/p25/MBP/DAPI ..........................................51

\section{Tabellenverzeichnis}

Tabelle 1: Patientendaten Humanbiopsien .........................................................................................19

Tabelle 2 Verwendete Lösungen zur Entparaffinierung und Rehydrierung......................................22

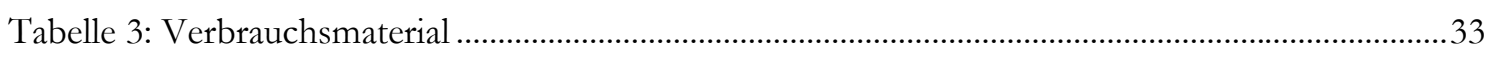

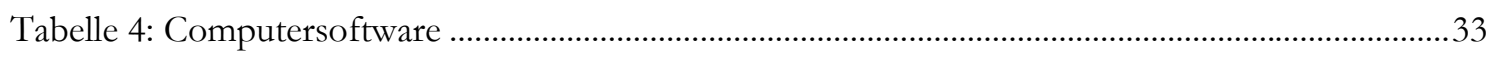

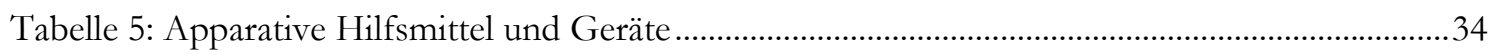

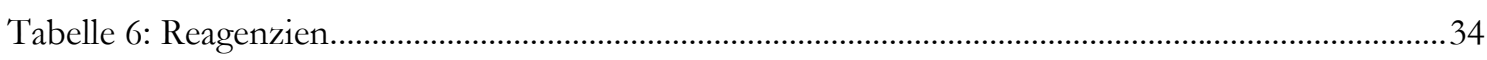

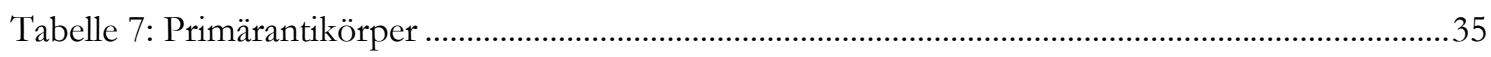

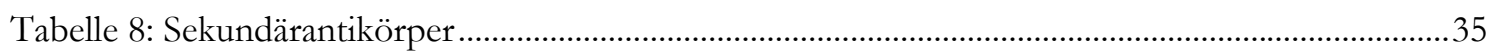




\section{Abkürzungsverzeichnis}

Ag

$\mathrm{Ak}$

bHLH

BHS

CD

CIS

CMV

CNP

CT

DAPI

DNA

DOD

DPZ

EAE

EBV

EDTA

$\mathrm{Fab}$

Fc

FFPE

FGF

$\mathrm{H}_{2} \mathrm{O}_{2}$

HAT

$\mathrm{HCl}$

HDAC

HIER

HLA

HRP

IFN- $\gamma$
Antigen

Antikörper

basic helix-loop-belix

Blut-Hirn-Schranke

cluster of differentiation

clinically isolated syndrome

Cytomegalovirus

cyclic nucleotide phosphodiesterase, zyklische Nukleotidphosphodiesterase

Computertomographie

4',6-Diamidin-2-phenylindol

Desoxyribonukleinsäure

Distale Oligodendropathie

Deutsches Primatenzentrum

Experimentelle autoimmune Enzephalomyelitis

Epstein-Barr Virus

Ethylendiamintetraessigsäure

fragment antigen-binding

fragment crystallisable

formalin fixed paraffin embedded

fibroblast growth factor

Wasserstoffperoxid

Histonacetyltransferase

Salzsäure

Histondeacetylase

beat-induced epitope retrieval

buman leukocyte antigen

horseradish peroxidase, Meerrettichperoxidase

Interferon- $\gamma$ 
IgG Immunglobulin-G

IL Interleukin

KFA komplettes Freund-Adjuvans

LT Lymphotoxin

MAG myelinassoziiertes Glykoprotein

MBP myelin basic protein, basisches Myelinprotein

MOG Myelin-Oligodendrozyten-Glykoprotein

MRT Magnetresonanztomographie

MS Multiple Sklerose

MyRF Myelin-Regulationsfaktor

NA not available

NAWM normal appearing white matter

NGS normal goat serum

Olig2 oligodendrocyte transcription factor 2

OPC oligodendrocyte precursor cell

OR Odds-Ratio

PBS phosphat-gepufferte Salzlösung

PDGF platelet-derived growth factor

PFA Paraformaldehyd

PIER protease-induced epitope retrieval

PLP Proteolipidprotein

PNS peripheres Nervensystem

RIS radiologisch isoliertes Syndrom

SEMA Semaphorin

TNF- $\alpha \quad$ Tumornekrosefaktor- $\alpha$

TPPP/p25 tubulin polymerization promoting protein

TSA-Kit Tyramid-Signal-Amplifikations-Kit

NF-xB nuclear factor 'kappa-light-chain-enhancer' of activated B-cells 


\section{Einleitung}

\subsection{Multiple Sklerose}

\subsubsection{Multiple Sklerose (MS) - Allgemeines}

Multiple Sklerose (MS), auch als Enzephalomyelitis disseminata bezeichnet, ist eine chronisch entzündliche Erkrankung des zentralen Nervensystems (ZNS) und die häufigste nichttraumatische Ursache für eine Behinderung im jungen Erwachsenenalter (Marrie 2004). Sie ist im Wesentlichen gekennzeichnet durch Entmarkungsherde (Läsionen, Plaques), die sowohl in der weißen als auch grauen Substanz des gesamten ZNS auftreten können. Weltweit sind etwa 2,5 Millionen Menschen betroffen, wobei Frauen mehr als doppelt so häufig erkranken wie Männer (Kuhlmann et al. 2009; Petersen et al. 2014; Holstiege et al. 2017).

Die Ätiologie der MS ist nicht eindeutig geklärt (Ascherio und Munger 2007). Diskutiert wird im Wesentlichen eine autoimmune Genese, bei welcher es im Rahmen einer fehlgeleiteten Immunantwort zu einer Zerstörung von Oligodendrozyten, Myelin und Axonen kommt. Ebenfalls diskutiert wird die Möglichkeit, dass der Autoimmunprozess nur sekundär als Folge eines primären Oligodendrozytenuntergangs geschieht und die zugrundeliegende primäre Pathologie eine andere ist. Diese Pathologien könnten mit dem Einfluss verschiedenster biologischer und chemischer Noxen sowie generellen Umwelteinflüssen zusammenhängen.

\subsubsection{Epidemiologie und Ätiologie}

Bezogen auf epidemiologische Daten für Deutschland ging man noch im Jahr 2000 von einer Prävalenzrate von 149,1 Erkrankungen pro 100.000 Einwohnern und somit ca. 122.000 an MS erkrankten Menschen in Deutschland aus (Hein und Hopfenmüller 2000). Nach einer neueren Auswertung von Daten des Bundesversicherungsamtes und Daten der gesetzlichen Krankenversicherungen für die Jahre 2009 bis 2015 jedoch ergibt sich eine Zahl von mindestens 200.000 - 220.000 Erkrankungen und eine Prävalenzrate von ca. 268 pro 100.000 Einwohnern (mit steigender Tendenz). Das Prävalenzmaximum findet sich in der Altersgruppe der 45- bis 54-Jährigen, wobei Frauen rund 2,5-mal so häufig wie Männer betroffen sind (Petersen et al. 2014; Holstiege et al. 2017).

Auch wenn bis zum heutigen Tag nicht ganz geklärt ist, wie es zur MS kommt (Ascherio und Munger 2007), ist stark anzunehmen, dass es sich um ein multifaktorielles Geschehen mit einem Zusammenspiel aus genetischen und Umweltfaktoren handelt (Ramagopalan et al. 2008). 
Solche Umweltfaktoren können beispielsweise eine bakterielle (chlamydia pneumoniae (Giovannoni et al. 2006)) oder virale Infektion ((Epstein-Barr Virus (EBV) (Moreno et al. 2018)) sein. Vermutet wird, dass eine molekulare Mimikry viraler Antigene zu einer fehlgeleiteten Immunantwort gegen körpereigene Strukturen führt (Lindsey 2017).

Ebenso besteht anscheinend ein Zusammenhang zwischen der Exposition zu inhalativen Noxen (insbesondere Rauchen), häufigem Kontakt mit Lösungsmitteln sowie Schichtarbeit und der Zunahme des Erkrankungsrisikos. Gar konnte eine Assoziation zwischen Adipositas im Jugendalter und der MS beschrieben werden (Olsson et al. 2017).

Weiterhin wird der Einfluss des Klimas am Wohnort des Erkrankten als weiterer Umweltfaktor diskutiert. So ist die erhöhte Prävalenz in Gebieten mit mangelnder Sonneneinstrahlung durch den mutmaßlich fehlenden Effekt von UV-Licht auf immunregulatorische Zellen (Aubin 2003; Sospedra und Martin 2005) und die erniedrigte endogene Produktion von aktiviertem Vitamin-D bzw. dessen immunmodulatorische Wirkung (Döring et al. 2013) kompatibel mit epidemiologischen Beobachtungen bezüglich der geografischen Häufigkeitsverteilung der MS. So spielt die Entfernung zum Äquator bzw. der geodätische Breitengrad anscheinend eine Rolle bei der Prävalenz der MS innerhalb einer geografischen Population. Mit vereinzelten Ausnahmen nimmt die Krankheitshäufigkeit proportional zur Entfernung vom Äquator sowohl nach Süden als auch nach Norden zu (Simpson et al. 2011).

Erkenntnisse aus Migrationsstudien lassen den Schluss zu, dass das Risiko zu erkranken besonders vom geografischen Lebensmittelpunkt vor der Pubertät geprägt wird. Zieht ein Kind vor seinem 15. Lebensjahr von einem Ort mit statistisch hohem Risiko zu erkranken an einen Ort mit niedrigem Erkrankungsrisiko, so passt sich die Erkrankungswahrscheinlichkeit des Kindes an den neuen Lebensort an. Geschieht der Umzug jedoch nach der Pubertät, behält ein Mensch das Risiko seines ehemaligen Lebensmittelpunktes (Dean und Elian 1997). Ebenso variiert das Erkrankungsrisiko zwischen ethnischen Gruppen. Asiaten und Subsahara-Afrikaner erkranken beispielsweise seltener als Kaukasier, welche im Vergleich am häufigsten an MS erkranken (Stangel et al. 2018).

Doch neben den mannigfachen Umwelteinflüssen, welche eine Rolle bei der Entstehung der MS spielen mögen, spricht auch vieles für eine genetische Komponente in der Entstehung der MS.

Unser Verständnis für die MS-Genetik hat sich im letzten Jahrzehnt deutlich weiterentwickelt (Hoffmann et al. 2009). Das Risiko an MS zu erkranken steigt von typischerweise 1:1.000 in der Normalbevölkerung auf etwa 1:4 bei eineiigen Zwillingen, bei denen ein Zwilling betroffen ist (Parnell und Booth 2017). Ein großer Teil dieser Erblichkeit ist jetzt besser verstanden und größtenteils auf Gene zurückzuführen, die die Immunantwort beeinflussen. Dabei gelten die Gene innerhalb des HLA-Komplexes als die stärksten genetischen Einflussfaktoren für die Entwicklung einer MS. 
Die HLA-Klasse-II und -I-Gene gelten dabei als besonders relevante Modifikatoren des Krankheitsrisikos: Varianten von Genen der Klasse II kodieren Produkte, welche Antigene für $\mathrm{CD} 4^{+}-\mathrm{T}-L y m p h o z y t e n$ präsentieren und Klasse-I-Produkte, die Antigene für $\mathrm{CD} 8^{+}-$ Lymphozyten präsentieren. Bei Vorhandensein der Klasse-II-Variante HLA-DRB1*15:01 besteht ein signifikant höheres Risiko an MS zu erkranken (Odds Ratio (OR) 3), während die Klasse-I-Variante HLA-A*02 mit dem Schutz vor einer Erkrankung an MS assoziiert ist (OR 0,6). Das Fehlen von HLA-A*02 und das Vorhandensein von DRB1*15:01 hat eine kombinierte OR von 5 (Sawcer et al. 2011; Beecham et al. 2013; Olsson et al. 2017).

Interessanterweise konnten neben potenziell protektiven Genvarianten (wie HLA-A*02), ebenfalls Umweltfaktoren identifiziert werden, welche anscheinend einen protektiven Faktor im Hinblick auf MS darstellen. So scheint oraler Tabakkonsum in Form von zum Beispiel Kautabak, wie er in skandinavischen Ländern oft zu sich genommen wird, oder erhöhter Kaffeekonsum statistisch das Risiko der Ausbildung einer MS zu senken. Ebenfalls protektiv auszuwirken scheint sich beispielsweise eine Infektion mit dem humanen Cytomegalovirus (CMV), welches wie das Epstein-Barr Virus ebenfalls zu der Familie der humanen HerpesViren gezählt wird (Olsson et al. 2017).

Obgleich einige der genannten genetischen und Umweltfaktoren mittlerweile als sehr wahrscheinliche Faktoren für die Entwicklung der MS gelten (Olsson et al. 2017), konnte bislang für keinen von ihnen eine Schlüsselrolle in der Pathogenese der MS nachgewiesen und so die Pathogenese in Gänze verstanden werden.

\subsubsection{Klinik der MS}

Da sich die MS mit ihren Läsionen im gesamten ZNS manifestieren kann, gibt es keine prototypische Klinik. Auch wenn die Optikusneuritis die häufigste Hirnnervenstörung im Rahmen einer MS ist und eine Abnahme des Sehvermögens oft als typisches Initialsymptom gesehen wird, so ist sie jedoch mit nur 20\% Vorkommen als Initialsymptom seltener als in Lehrbüchern häufig vermittelt (Stangel et al. 2018). Analog zur betroffenen Region präsentiert sich auch das Beschwerdebild der Patienten. Die Symptomatik kann von Beschwerdefreiheit bei „stummen Läsionen“ in nicht eloquenten Arealen des ZNS bzw. als radiologisch isoliertes Syndrom (RIS) bis hin zu schweren Störungen der Motorik, Sensibilität und Kognition reichen (Chiaravalloti und DeLuca 2008).

Die mitunter häufigste motorische Erstmanifestation der MS ist eine Schwäche der Extremitäten, welche sich als eine anfänglich schnelle Ermüdbarkeit von Armen und Beinen äuBern kann, sich aber im Verlauf meist zu manifesten Paresen und schmerzhaften Spastiken entwickeln kann (Compston et al. 2006). 
Rasche Ermüdbarkeit des Bewegungsapparates sowie ein globales Gefühl der Kraftlosigkeit werden unter dem Symptomkomplex „Fatigue“ zusammengefasst und ebenfalls häufig von Erkrankten angegeben.

Läsionen auf Rückenmarksebene können bei Fortschreiten der Erkrankung mit erektiler Dysfunktion und Miktionsstörungen einhergehen. Blasenstörungen sind mit bis zu 75\% betroffener Patienten ein sehr häufiges und belastendes Symptom. Weiterhin können bei Läsionen im parietalen Kortex oder auf spinaler Ebene sensible Störungen aller Qualitäten auftreten. So weist beispielsweise das Lhermitte-Zeichen, repräsentiert durch Kribbelparästhesien entlang des Rückens bei Beugung des Nackens, auf einen möglichen spinalen Demyelinisierungsprozess hin, ist jedoch nicht spezifisch für diesen.

Generell werden von MS-Patienten Schmerzen angegeben, welchen viele Ursachen zugrunde liegen können. So können Schmerzen direkt durch Demylinisierungszonen per se verursacht werden und sich im Sinne von neuropathischen Schmerzen äußern oder aber sekundär, zum Beispiel durch Fehlhaltungen oder spastische Muskelkontraktionen, entstehen.

Läsionen im Hirnstamm oder im Bereich der Hirnnerven können Schluckbeschwerden, Nystagmus oder Doppelbilder verursachen. Sind die Sehnerven (Nervus opticus) betroffen, kann es basierend auf einer Optikusneuritis bzw. Retrobulbärneuritis zu einer Visusverschlechterung bis hin zum kompletten Visusverlust kommen.

Auch wenn zerebellär lokalisierte Symptome in der Initialphase der MS selten sind, so sind sie im weiteren Krankheitsverlauf doch häufig anzutreffen. Diese können sich dann zum Beispiel durch Tremor, Gangstörung oder Dysarthrie äußern.

Bei kortikalen Läsionen können unabhängig von der Verlaufsform epileptische Anfälle, kognitive Einschränkungen sowie neuropsychologische Veränderungen auftreten. Rund die Hälfte aller MS-Patienten leidet an einer Depression, wobei nicht nur hirnorganische Ursachen, sondern insbesondere auch der hohe Leidensdruck und der Krankheitsbewältigungsprozess hier eine maßgebliche Rolle spielen können (Chwastiak et al. 2002; Compston und Coles 2002; Stangel et al. 2018).

\subsubsection{Verlaufsformen der MS}

Wie eingangs erwähnt, präsentiert sich die MS sehr heterogen, nicht nur was die klinische Symptomatik angeht, sondern auch was den Verlauf der Erkrankung betrifft.

Bereits 1996 definierte die „National Multiple Sclerosis Society USA“ (Lublin und Reingold 1996) vier Verlaufsformen der Erkrankung, welche bis heute Anwendung bei der Unterteilung und Therapieentscheidung finden. 
Wesentliche Merkmale zur Beurteilung des Verlaufes sind zum einen das Muster der Schübe und zum anderen die chronische Progredienz. Definiert wird ein Schub dabei als das Auftreten neuer neurologischer Symptome in einem Zeitraum von 30 Tagen, wobei die Symptome länger als 24 Stunden bestehen bleiben müssen. Nach In-Erscheinung-Treten eines Schubes kommt es in der Regel zur Teil- oder Vollremission. Zeitlich begrenzte Verschlechterungen der Symptomatik können sich in Form des sogenannten Uhthoff-Phänomens äuBern, bei welchem durch einen Anstieg der Körpertemperatur (beispielsweise durch warmes Duschen) eine zeitlich begrenzte Verschlechterung der Symptomatik auftritt (auch Pseudoexazerbation genannt).

Die (mit rund 80\%) häufigste Verlaufsform der MS ist die schubförmige MS (relapsing remitting, RRMS), welche durch das Auftreten von symptomatischen Schüben mit oder ohne Residuen und beschwerdefreien Phasen gekennzeichnet ist. Im Intervall zwischen den einzelnen Schüben, welches Monate oder gar Jahre andauern kann, darf dabei keine Progression vorhanden sein (Lublin und Reingold 1996; Limmroth und Sindern 2004).

Die primär chronisch-progrediente MS (primary progressive, PPMS) zeichnet sich durch eine von Krankheitsbeginn an relativ kontinuierlich verlaufende Progression mit möglichen Phasen des Krankheitsstillstands oder gar der Verbesserung aus. Schübe kommen bei dieser Verlaufsform definitionsgemäß nicht vor (Lublin und Reingold 1996; Stangel et al. 2018).

Von einem sekundär chronisch-progredienten Verlauf (secondary progressive, SPMS) spricht man, wenn sich in der Initialphase ein schubförmiger Verlauf findet, welcher im weiteren Verlauf in eine stetige Progression übergeht. Diese Verlaufsform tritt im späteren Krankheitsverlauf sowohl mit als auch ohne Schübe auf (Stangel et al. 2018).

Der progredient-schubförmige Verlauf (progressive relapsing, PRMS) ist durch einen kontinuierlichen Krankheitsprogress mit zusätzlich zum Progress auftretenden Exazerbationen (welche wieder abklingen können) gekennzeichnet (Lublin und Reingold 1996).

Im Jahr 2013 ergänzten Lublin et al. zwei weitere Begriffe im Kontext der MS und ihrer klinischen Präsentation. So wird die Erstmanifestation klinischer Symptome, welche zwar mit einer entzündlich-demyelinisierenden Schädigung vereinbar sind, jedoch die Diagnosekriterien für eine MS noch nicht erfüllen, als klinisch isoliertes Syndrom (clinically isolated syndrome, CIS) bezeichnet.

Als radiologisch isoliertes Syndrom (RIS) bezeichnet man einen inzidentellen Befund in der Bildgebung, welcher bildmorphologisch mit einem entzündlich-demyelinisierenden Prozess vereinbar ist, zu dem jedoch kein klinisches Korrelat besteht (Lublin et al. 2014)

\subsubsection{Allgemeine Pathologie der MS}

Die Pathologie der MS wird durch einen chronischen Entzündungsprozess des zentralen Nervensystems definiert, welcher zur Bildung von demyelinisierten Plaques führt (Lassmann 
1983). Die pathologischen Merkmale dieser Plaques sind die Zerstörung der Myelinscheiden, gliale Narbenbildung sowie eine Entzündung mit zellulärem Infiltrat, welches hauptsächlich aus Lymphozyten und mononukleären Phagozyten besteht (Brück et al. 1996).

Typische Prädilektionsstellen für das Auftreten von MS-Läsionen sind unter anderem die periventrikulär angrenzende weiße Substanz, der Nervus opticus, der Hirnstamm sowie das Rückenmark (Lucchinetti et al. 2000).

Läsionen lassen sich durch den Nachweis von Myelinabbauprodukten in Makrophagen sowie über den Nachweis der Expression von makrophagenspezifischen Markern (wie MRP14 und 27E10) in unterschiedliche Aktivitätsstadien einteilen. Beispiele für solche Myelinabbauprodukte sind PLP (Proteolipidprotein), MOG (Myelin-Oligodendrozyten-Glykoprotein), MAG (myelinassoziiertes Glykoprotein) sowie CNP (zyklische Nukleotidphosphodiesterase). So lassen sich die Läsionen unter Berücksichtigung der Morphologie, der nachweisbaren Myelinabbauprodukte und von Makrophagenmarkern in früh-aktiv, spät-aktiv, inaktiv sowie früh- und spät-remyelinisierend einteilen (Brück et al. 1995; Brück et al. 1996; Lucchinetti et al. 1996).

\subsubsection{Diagnose der MS}

Aufgrund der heterogenen klinischen Präsentation der MS und der bis heute nicht eindeutig geklärten Mechanismen der Krankheitsentstehung kann sich die Diagnostik der MS in Einzelfällen noch heute als schwieriges Unterfangen erweisen.

Die Diagnose der MS wird im Allgemeinen unter Berücksichtigung klinischer und apparativer Kriterien gestellt, wobei durch Verbesserung technischer Hilfsmittel und stetige Weiterentwicklung diagnostischer Leitlinien zum heutigen Zeitpunkt eine immer frühere Diagnosestellung möglich ist. Aktueller Schwerpunkt in der Diagnosefindung liegt im Gegensatz zu den 1965 (Schumacher et al. 1965) und 1976 (Rose et al. 1976) vorgeschlagenen Kriterien nicht mehr hauptsächlich auf der Klinik. Klassische klinische Symptome werden durch liquorchemische (Poser et al. 1983), elektrophysiologische und bildgebende Verfahren ergänzt (McDonald et al. 2001).

Die seit dem Jahr 2001 mehrfach revidierten McDonald-Kriterien (McDonald et al. 2001; Polman et al. 2005; Polman et al. 2011; Thompson et al. 2018) legen hierbei besonderen Fokus auf die Bildgebung mittels Magnetresonanztomographie (MRT), welche im Hinblick auf die Darstellung von MS-Läsionen anderen Modalitäten wie der Computertomographie (CT) überlegen ist (Noseworthy et al. 2000). Sie stellen sich in T1-gewichteten Aufnahmen hypointens und in T2-gewichteten Aufnahmen hyperintens dar, wobei der radiologische Befund nicht unbedingt mit dem Ausmaß der klinischen Symptomatik übereinstimmen muss (Bakshi et al. 2004). Frühe MS-Läsionen können in der MRT aufgrund der Störung der BHS (Blut-Hirn-Schranke) und dadurch kräftigen Kontrastmittelaufnahme gut dargestellt werden. 
Prinzipiell ist die räumliche und zeitliche Dissemination von klinischer Symptomatik und Läsionen nach wie vor ein wichtiger Hinweis für das Vorliegen einer MS, wobei nach den neuesten McDonald-Kriterien eine zeitliche Dissemination bei einem MS-typischen Liquorbefund nicht mehr zwingend nachgewiesen werden muss, um die Diagnose stellen zu können. Auch werden Sonderfälle wie das klinisch isolierte Syndrom (CIS = erstes Auftreten typischer neurologischer Symptome mit einer Dauer von mindestens 24 Stunden) mit in die Diagnosekriterien integriert, welches eine zumeist bessere Abgrenzung von anderen in Klinik und Bildgebung überlappenden Krankheitsbildern ermöglicht.

Da die Diagnose der MS prinzipiell in Zusammenschau der gebotenen Symptomatik sowie der Befunde bildgebender Verfahren nach den McDonald-Kriterien gestellt wird (Thompson et al. 2018), ist eine Biopsie bei Verdacht auf eine MS-Erkrankung eher eine Ausnahme und Gewebeproben früh-aktiver Läsionen somit selten. Dies ist erwähnenswert, da MS eigentlich nach den gängigen Diagnosekriterien gut identifizierbar ist und die hier untersuchten Fälle daher als initial eher atypisch bezeichnet werden könnten, was auch den Umstand der Probenentnahme erklärt.

Es ist dennoch davon auszugehen, dass die im Rahmen dieser Studie gewonnenen Erkenntnisse über entmarkende Läsionen in menschlichen Gewebeproben auch auf Patienten mit typischen Krankheitsverlauf der MS angewendet werden können. Bei einem Großteil von Patienten mit initial atypischem Krankheitsverlauf und durchgeführter Biopsie entwickelt sich im weiteren Verlauf eine MS (Pittock et al. 2005; Lucchinetti et al. 2008; Lucchinetti et al. 2011).

\subsubsection{Therapie der MS}

Bis heute gilt die MS als nicht heilbar; eine kausale Therapie existiert nicht.

Die Zielsetzung der vorhandenen Therapieansätze besteht in der Schubprophylaxe, der schnellen Remission akuter Schübe sowie der Verlaufsmodifikation im Sinne einer Stabilisierung des Krankheitsprozesses bzw. dessen Verzögerung.

Aufgrund der immunologischen Komponente der MS ist die Beeinflussung des Immunsystems Hauptangriffspunkt der Therapien, sowohl für die akute Schubtherapie als auch in der Verlaufsmodifikation.

Im akuten Schub sind hochdosierte Glukokortikoide (Methylprednisolon) ein etabliertes Mittel zur Linderung der Symptome und Verkürzung der Symptomdauer. Durch die antiinflammatorische Wirkung von Glukokortikoiden werden immunologische, Prozesse wie beispielsweise die Migration von Immunzellen, herunterreguliert und die BHS stabilisiert. Sollte die Schubtherapie trotz Eskalation der Glukokortikoidtherapie ohne gewünschten Erfolg 
verlaufen, besteht als Mittel der zweiten Wahl die Plasmaseparation mittels Plasmapherese oder Immunadsorption (Brandt et al. 2012; Montalban et al. 2018).

Der Verlaufsmodifikation liegt eine Stufentherapie zugrunde, welche sich vornehmlich auf den Einsatz von Immunmodulatoren und Immunsuppressiva stützt und sich an der Verlaufsform und Krankheitsaktivität orientiert. Eingesetzte Wirkstoffe können bei leichten bis mittelschweren Verläufen zum Beispiel Fumarsäure (Fumarsäuredimethylester) oder BetaInterferone sein. Bei schwereren Verläufen können unter anderem sog. Biologicals, also gentechnisch hergestellte Antikörper gegen Effektorzellen des Immunsystems wie z. B. B-Lymphozyten, eingesetzt werden (Montalban et al. 2018).

Ein weiterer Schwerpunkt im Therapiekonzept der MS liegt neben Immunmodulation und Immunsuppression in der symptomatischen Therapie. Symptome, die von Spastiken und Schmerzen über vegetative Funktionsstörungen bis hin zu Depressionen reichen, können je nach Ausmaß für einen enormen Leidensdruck bei den Erkrankten sorgen und bedürfen ebenfalls einer adäquaten Therapiestrategie. So spielt die Physiotherapie insbesondere für Patienten mit Koordinationsstörungen und Gehbehinderungen eine integrale Rolle in der Therapie (Henze et al. 2004). Auch eine psychologische Anbindung im Rahmen eines ganzheitlichen Therapiekonzeptes sollte in Erwägung gezogen werden (Crawford und McIvor 1985).

\subsection{Oligodendrozyten - Aufgaben und assoziierte Strukturen}

\subsubsection{Oligodendrozyten - Allgemeines}

Oligodendrozyten wurden erstmals von J.D. Robertson im Jahre 1899 beschrieben und 1921 von del Rio Hortega näher klassifiziert und benannt. Ihr Name leitet sich aus dem Griechischen ab und beschreibt dabei eine Zelle mit baumartig verzweigten Zellausläufern (oligos $=$ wenig, dendron $=$ Baum und zytos $=$ Zelle) (Jakovcevski et al. 2009).

Oligodendrozyten zählen zusammen mit Astrozyten und Ependymzellen zur zentralen Glia, genauer zur sogenannten Makroglia (Lüllmann-Rauch und Asan 2015). Sie entstehen während ihrer Entwicklung aus ektodermalen Oligodendrozyten-Vorläuferzellen (OPC = oligodendrocyte precursor cell), welche vornehmlich in der subventrikulären Zone (Kettenmann und Verkhratsky 2011) bzw. bei spinalen Oligodendrozyten aus der ventralen Region des Neuralrohrs stammen (Zhou et al. 2001). Die OPCs migrieren an ihren Bestimmungsort und differenzieren dort über zelluläre Zwischenstufen zu reifen Oligodendrozyten. Diese Differenzierung wird durch unterschiedliche Wachstumsfaktoren wie zum Beispiel PDGF (plateletderived growth factor) oder FGF (fibroblast growth factor), welche hauptsächlich von Neuronen, aber auch von Typ-1-Astrozyten ausgeschüttet werden, gesteuert (Emery 2010). Eine Frak- 
tion (ca. 5-8\% der gesamten Zellpopulation) der OPCs bleibt jedoch undifferenziert im adulten ZNS erhalten und behält die Fähigkeit zur Proliferation und Differenzierung zu reifen Oligodendrozyten bei (Levine et al. 2001).

Die Hauptfunktion von Oligodendrozyten im ZNS ist nach heutigem Kenntnisstand die Bildung und Unterhaltung der Myelinscheiden, welche Axone hauptsächlich in der weißen Substanz des ZNS als Ausläufer der Oligodendrozyten mehrschichtig und segmentweise ummanteln. Ein Oligodendrozyt kann mit seinen Zellausläufern 40-50 solcher Segmente bei unterschiedlichen Axonen ausbilden, wobei jeder Oligodendrozyt für ein jedes gegebene Axon jeweils nur ein Segment stellt (Miron et al. 2011; Lüllmann-Rauch und Asan 2015).

Die so von den Myelinscheiden umwickelten Segmente werden Internodien genannt und sind mehrere $100 \mu \mathrm{m}$ lang. Die nicht von Myelin bedeckten Bereiche werden Ranviersche Schnürringe genannt und sind etwa $1 \mu \mathrm{m}$ lang.

Im Gegensatz zum peripheren Nervensystem, wo Schwann-Zellen und auswachsende Axone direkt assoziiert sind, erfolgt die Myelinisierung durch Oligodendrozyten erst, nachdem die Axone im ZNS ihre Zielzellen erreicht haben. Die Myelinisierung im ZNS beginnt in der Fetalzeit und reicht bis in die zweite Lebensdekade hinein. In den ersten zwei Lebensjahren verläuft die Markscheidenbildung rapide, später jedoch zunehmend langsamer (Lüllmann-Rauch und Asan 2015). Auch wenn die Myelinisierung im Erwachsenenalter weitgehend abgeschlossen ist, kann die Neubildung von Myelin, sowohl durch funktionelle Reize (wie Lesen, Jonglieren oder Klavierübungen (Sampaio-Baptista und Johansen-Berg 2017)), als auch durch traumatischen oder autoimmun-entzündlich bedingten Myelinverlust stimuliert werden (Scholz et al. 2009; Liu et al. 2012; Nave und Werner 2014).

\subsubsection{Myelin}

Myelin wurde erstmals 1854 durch Rudolf Virchow beschrieben und benannt. Durch die chemische Zusammensetzung des Myelins wird eine elektrochemische Isolation des Axons vom umliegenden Gewebe erreicht (Stegemeyer und Stegemeyer 2004). Die multilamelläre Myelinschicht zeichnet sich durch einen hohen elektrischen Widerstand und geringe Membrankapazität aus, wodurch physikalisch eine rasche Reizweiterleitung ermöglicht wird. Die isolierenden Eigenschaften der Myelinscheide sind vor allem auf ihre Struktur, ihre Dicke, ihren geringen Wasser- und hohen Lipidgehalt zurückzuführen. Myelin enthält im Gegensatz zu grauer Substanz, welche 80\% Wasser enthält, nur 40\% Wasser. Dabei besteht das Trockengewicht von Myelin zu 70\% aus Lipiden und zu 30\% aus Proteinen. Dieses Lipid-Protein-Verhältnis ist sehr charakteristisch für Myelin und bei anderen Zellmembranen meist umgekehrt. Die Lipidkomponente setzt sich zum Großteil aus Cholesterin, Galactocerebrosid und weiteren Phospholipiden zusammen. Die Proteinkomponente des Myelins besteht zu großen Teilen aus PLP (Proteolipid-Protein) und MBP (basisches Myelinprotein) (Baumann und Pham-Dinh 2001). 


\subsubsection{Aufgaben der Oligodendrozyten}

Aktuelle Erkenntnisse deuten darauf hin, dass Oligodendrozyten weitere Funktionen über die Bildung und Erhaltung der Myelinscheide hinaus haben (Nave und Werner 2014) und dass die Myelinscheide mehr ist als nur eine isolierende Membranstruktur.

Oligodendrozyten sind metabolisch aktiv und funktionell mit dem darunter liegenden Axon über zytoplasmatische Kanäle verbunden (Simons und Nave 2016). Zwar wird benötigte Energie in Form von ATP für die $\mathrm{Na}^{+} / \mathrm{K}^{+}$-ATPasen und die sonstige metabolische Versorgung des Axons über Glukosetransporter auf neuronalen Zellkörpern gewonnen, doch erscheint es plausibel, dass der lokale Energiebedarf der langen Axone auch über die Oligodendrozyten geschehen muss. Dies ist darin begründet, dass Axone aufgrund der Barrierefunktion des sie umgebenden Myelins nur eingeschränkten Zugang zu extrazellulärer Glukose und anderen energiereichen Metaboliten haben (Morrison et al. 2013). So werden die Axone wahrscheinlich metabolisch durch den Austausch energiereicher Stoffwechselprodukte durch die Oligodendrozyten unterstützt und so die Integrität des Axons, auch über längere Strecken, bewahrt (Fünfschilling et al. 2012; Lee et al. 2012).

Ebenfalls hat es den Anschein, als hätten Oligodendrozyten eine immunmodulatorische Funktion, indem sie selbst Immunrezeptoren exprimieren, ferner Chemo- sowie Zytokine produzieren und auch auf diese reagieren (Peferoen et al. 2014).

Oligodendrozyten spielen also, so hat es den Anschein, in vielerlei Hinsicht eine wichtige Rolle für das ZNS und die Aufrechterhaltung der axonalen Integrität.

Viele Aspekte bezüglich der Rolle von Oligodendrozyten in Krankheitsentstehung und Krankheitsgeschehen der MS sind noch Gegenstand aktueller Forschung, insbesondere die Frage, ob etwa Schädigungen von Oligodendrozyten möglicherweise primär ein Auslöser und nicht zwingend nur die Folge der MS sind und welche Mechanismen und Prozesse dabei im Detail eine Rolle spielen.

\subsubsection{Oligodendrogliale Schädigung}

\subsubsection{Hypothese der primären Schädigung von Oligodendrozyten}

Nach Bradl und Lassmann (2010) gibt es eine Vielzahl verschiedener Schädigungsmechanismen, welche als Auslöser dieses primären Oligodendrozyten-Schadens fungieren könnten: Ein Beispiel hierfür ist oxidativer Stress, denn durch die Kombination einer hohen Stoffwechselrate und der damit einhergehenden Bildung von toxischen Nebenprodukten, hohem intrazellulären Eisen und niedrigen Konzentrationen des antioxidativ wirkenden Glutathions, sind Oligodendrozyten besonders anfällig für oxidative Schäden (Thorburne und 
Juurlink 1996; Juurlink 1997). In der Folge ist oxidativer Schaden ein häufiger Faktor für den Verlust von Oligodendrozyten unter pathologischen Bedingungen wie z. B. Entzündung oder Ischämie.

Denkbar ist ebenfalls, dass der Sphingomyelinase-Ceramid-Pfad als weiterer Schädigungsmechanismus für Zellen der oligodendroglialen Reihe eine Rolle spielt. Ceramid ist ein Kernbestandteil der Sphingolipide, welche als wichtige Lipidkomponenten der Myelinscheiden fungieren (Baumann und Pham-Dinh 2001). Es wird durch die Aktivität des Enzyms Sphingomyelinase freigesetzt, welches normalerweise inaktiv ist, aber als Reaktion auf oxidativen Stress (Singh et al. 1998; Jana und Pahan 2007), entzündliche Mediatoren (Brogi et al. 1997; Singh et al. 1998; Testai et al. 2004), Schädigung oder Infektion aktiviert wird (Schenck et al. 2007). Einmal freigesetzt, kann Ceramid pro-apoptotische Signalkaskaden aktivieren, die schließlich zum Untergang der Oligodendrozyten führen (Brogi et al. 1997; McTigue und Tripathi 2008).

Oligodendrozyten exprimieren darüber hinaus eine ganze Reihe von Rezeptoren, welche sie anfällig für einen exzitotoxischen Zelltod machen (Mcdonald et al. 1998; Domercq et al. 2007). So tragen sie AMPA- (Tanaka et al. 2000), Kainat- bzw. Kainsäure- (ein pflanzliches Strukturanalogon von Glutamat) (Sánchez-Gómez und Matute 1999) sowie NMDA-Rezeptoren, welche sie anfällig für die toxische Wirkung hoher Konzentrationen von Glutamat machen (Káradóttir et al. 2005; Micu et al. 2006). Ebenfalls exprimieren Oligodendrozyten den ATP-Rezeptor P2X7, welcher für die schädliche Wirkung anhaltend erhöhter Konzentrationen von extrazellulärem ATP prädisponiert (Matute et al. 2007).

Darüber hinaus kann der zelluläre Untergang von Oligodendrozyten auch durch den direkten Einfluss von entzündlichen Zytokinen verursacht werden. TNF- $\alpha$ (Tumornekrosefaktor- $\alpha$ ) kann beispielsweise die Apoptose von Oligodendrozyten induzieren, indem er an ihren p55TNF-Rezeptor bindet (Jurewicz et al. 2005). Komplexer ist die Situation beispielsweise beim Zytokin IFN- $\gamma$ (Interferon-gamma), welches in hohem Maße toxisch für aktiv proliferierende OPCs, weniger jedoch für unreife Oligodendrozyten und praktisch nicht toxisch für reife Oligodendrozyten ist (Horiuchi et al. 2006).

Entzündungsmediatoren können die Oligodendrozyten weiterhin auch durch die Stimulation der Radikalproduktion durch Mikroglia schädigen. Sauerstoff- und Stickoxid-Radikale sind besonders toxisch für Mitochondrien, da diese mit verschiedenen Proteinen der Atmungskette interagieren und diese blockieren können (Smith und Lassmann 2002; Mahad et al. 2008). Des Weiteren können verschiedene proinflammatorische Zytokine, auch ohne direkte Anwesenheit von Immunzellen, eine Schädigung durch Veränderungen der Genexpression in den betroffenen Zellen mit Wirkungen auf Zell-Metabolismus und mitochondriale Funktion verursachen (Bradl und Lassmann 2010; Lisak et al. 2009).

Genauer betrachtet beginnt nach Barnett und Prineas (2004) die Ausbildung von MS-Läsionen, wenn Oligodendrozyten apoptotisch werden und durch primäre Schädigung zugrunde 
gehen. Durch den oligodendroglialen Zelltod kommt es zur Degeneration von Myelin, worauf folgend Makrophagen rekrutiert werden, um das degenerierte Myelin zu phagozytieren und abzubauen. Im Anschluss beginnen Immunreaktionen unter Beteiligung von T- und BZellen zeitgleich mit oligodendroglialer Regeneration und Remyelinisierung. Diese Hypothese steht auch im Einklang mit der Erkenntnis, dass residuales Myelin die Remyelinisierung negativ beeinflussen kann (Kotter et al. 2006) und dass eine Aktivierung des Toll-Like Rezeptors im Rahmen der sekundären Entzündungsreaktion zur Verbesserung der Remyelinisierung führt (Barnett und Prineas 2004; Setzu et al. 2006).

Daraus könnte man folgern, dass die entzündlichen Myelin-Abbauprozesse (welche allgemein als "autoimmune Demyelinisierung" eingestuft werden) tatsächlich hilfreiche Prozesse für die Wiederherstellung neuronaler Funktionen durch Remyelinisierung nach oligodendroglialem Untergang darstellen könnten (Nakahara et al. 2010). Gar wird ein positiver Effekt vereinzelter Autoantikörper auf die Remyelinisierung vermutet, welches für einen positiven Effekt einer Entzündung auf die Remyelinisierung sprechen würde (Rodriguez et al. 2009).

\subsubsection{Autoimmun-Hypothese der Oligodendrozytenschädigung}

Neben der Theorie einer primären Oligodendrozytenschädigung ist die Theorie der autoimmunvermittelten Immunopathogenese der MS die derzeit am weitesten anerkannte und diskutierte Hypothese. Es werden viele mögliche Faktoren und Zusammenhänge in Erwägung gezogen, welche letztendlich alle in der Auslösung einer fehlgeleiteten Immunantwort und dem konsekutiven Untergang von Myelin münden.

Nakahara und Kollegen (2010) schildern einen möglichen Pathomechanismus, in dem der Autoimmunprozess möglicherweise dadurch angestoßen wird, dass im ersten Schritt myelinspezifische CD4-T-Zellen in wahrscheinlich zervikalen Lymphknoten (welche für den Lymphabfluss des Gehirns zuständig sind) (Furtado et al. 2008) durch dendritische Zellen, die entweder Myelin oder kreuzreaktive Myelin-Epitope präsentieren, aktiviert werden. Th17-Helferzellen, die sich von diesen aktivierten T-Zellen durch Interleukin (IL)-23 induziert differenzieren, spielen vermutlich eine wesentliche Rolle im Verlauf der Entwicklung der Autoimmunität (Cua et al. 2003; Tzartos et al. 2008). Im Rahmen der Immunüberwachung gelangen die autoreaktiven Th17-Zellen mittels Chemokinrezeptoren über den Plexus choroideus in den Liquor cerebrospinalis (Reboldi et al. 2009). Im Liquor werden die nun patrouillierenden T-Zellen durch MHC-Klasse-ll-exprimierende Makrophagen oder dendritische Zellen (welche Myelin-Epitope präsentieren) reaktiviert, was wiederum zu einer Migration der T-Zellen in das ZNS-Parenchym und zu einer Entzündungsreaktion und konsekutiven Permeabilitätserhöhung der BHS führt (Bartholomäus et al. 2009). Wenn nun weitere T-Zellen in das Parenchym gelangen, scheiden sie zusammen mit aktivierten Makrophagen und Gliazellen (Mikroglia und Astrozyten) proinflammatorische Faktoren wie TNF- $\alpha$, 
LT (Lymphotoxin), IL-12 (Interleukin-12) sowie freie Radikale wie Stickstoffmonoxid aus, welche eine Demyelinisierung bewirken können.

Weiterhin erfolgt über eine T-Zell-vermittelte Aktivierung der B-Zellen die Bildung von Autoantikörpern gegen Proteine wie MBP oder MOG, welche dann über Aktivierung des Komplementsystems oder direkte Opsonisierung und konsekutive Phagozytose des Myelins ebenfalls zur Zerstörung der Myelinscheiden führen (Nakahara et al. 2010).

\subsection{Remyelinisierung}

\subsubsection{Der Prozess der Remyelinisierung}

Als Remyelinisierung bezeichnet man den Prozess der Bildung neuer Myelinscheiden um demyelinisierte Axone nach primärer Demyelinisierung (Franklin und ffrench-Constant 2008).

Dabei ist der Verlust von Myelin bei sonst intaktem Axon, beispielsweise bei Schädigung und Untergang von Oligodendrozyten, als primäre Demyelinisierung definiert. Kommt es zum Untergang von Axonen und daran anschließend zu einer Demyelinisierung, so wird dieses als sekundäre Demyelinisierung definiert.

Die Neubildung der Myelinscheiden ähnelt dabei in vielerlei Hinsicht den regenerativen Prozessen, welche auch in anderen Geweben des Körpers als Antwort auf Schädigung stattfinden, und stellt somit die physiologische Antwort auf Demyelinisierung dar (Franklin und ffrench-Constant 2008; Franklin und Goldman 2015).

Im Rahmen von demyelinisierenden Erkrankungen, insbesondere der MS, kann sich jedoch ein variables Bild im Ausmaß der Remyelinisierung zeigen. Dieses kann von vollständiger bis hin zu im Verlauf nur insuffizienter Remyelinisierung reichen und sich so auch in der Symptomatik der Patienten zum Ausdruck bringen (Franklin 2002).

Regelrecht konfigurierte weiße Substanz enthält beim erwachsenen Menschen neben myelinisierenden Oligodendrozyten auch Astrozyten, Mikroglia und OPCs (Lüllmann-Rauch und Asan 2015). Letztgenannte OPCs spielen eine wesentliche Schlüsselrolle beim Wiederaufbau der Myelinscheiden (Wolswijk 1998).

In der Konsequenz ist der erste Schritt im Remyelinisierungsprozess in der Regel die Aktivierung von ortsständigen sowie regional angrenzenden OPCs.

Die Aktivierung von OPCs ist dabei vermutlich eine Reaktion auf die durch akute Schädigung induzierten Veränderungen der Mikroglia und Astrozyten, welche äußerst empfindlich auf Störungen der Gewebehomöostase reagieren (Glezer et al. 2006; Rhodes et al. 2006; Franklin und Goldman 2015). 
Während Makrophagen Myelinreste beseitigen, kommt es unter dem Einfluss von Mitogenen und pro-migratorischen Faktoren, die überwiegend von reaktiven Astrozyten und Entzündungszellen gebildet werden, zur Proliferation und Besiedelung des demyelinisierten Areals durch eine große Zahl OPCs (Franklin und ffrench-Constant 2008).

In der Endphase der Remyelinisierung differenzieren sich rekrutierte OPCs in remyelinisierende Oligodendrozyten und beginnen konsekutiv mit der Neubildung der Myelinscheiden.

So können im Ergebnis, dem Grad und der Qualität der Remyelinisierung entsprechend, die saltatorische Reizweiterleitung teilweise wiederhergestellt und funktionelle Defizite behoben werden (Smith et al. 1979; Liebetanz und Merkler 2006).

Die Differenzierung der OPCs in myelinisierende Oligodendrozyten umfasst nicht nur Veränderungen in der Zellmorphologie, sondern auch in der Regulation verschiedener Transkriptionsfaktoren und Genprodukte, welche in der weiteren Entwicklung und Differenzierung der Oligodendrozyten eine wichtige Rolle spielen.

Insbesondere Transkriptionsfaktoren wie Olig2, Nkx2.2 sowie Sox10 werden dabei Schlüsselrollen zugeschrieben (Fancy et al. 2004; Watanabe et al. 2004; Liu et al. 2007; Franklin und Goldman 2015). Sie können außerdem zusammen mit weiteren Proteinen wie p25 zur Einteilung der Oligodendrozyten in verschiedene Differenzierungsstadien herangezogen werden. Dies liegt darin begründet, dass sie im Laufe der Ausreifung oft nur während einer begrenzten Zeitspanne bzw. in einem bestimmten Stadium nachweisbar sind. Im Rahmen dieser Arbeit wurden ebenfalls o. g. Markerproteine herangezogen, um eine Einteilung in reife und unreife Oligodendrozyten zu treffen. Näher besprochen werden die verwendeten Marker im Methodikteil (2.3.3).

\subsubsection{Fehlgeschlagene Remyelinisierung}

Die genauen Hintergründe für die unterschiedliche Ausprägung oder gar das gänzliche Fehlschlagen einer Remyelinisierung sind, ähnlich der überhaupt zugrundeliegenden Pathologien der Demyelinisierung, nicht gänzlich geklärt und wahrscheinlich nicht monokausal zu begründen. Es ist wie bereits angeklungen ein komplexes Zusammenspiel von Aktivierung, Proliferation, Migration und Differenzierung unter dem Einfluss verschiedenster löslicher und zellulärer Faktoren notwendig, um eine erfolgreiche Remyelinisierung zu gewährleisten. Dementsprechend gibt es auch viele mögliche Ansatzpunkte für ein Scheitern der Remyelinisierung.

Läsionen können sich zudem in ihrem oligodendroglialen Zellgehalt unterscheiden. So sind einige demyelinisierte Läsionen durch einen oligodendroglialen Verlust gekennzeichnet und andere wiederum durch die Persistenz einer großen Zahl von Zellen der oligodendroglialen Reihe, einschließlich OPCs (Piaton et al. 2009). 
Mechanismen, die entweder zum Erfolg oder zum Scheitern der Remyelinisierung führen, können also vermutlich zwischen verschiedenen Läsionen unterschiedlich sein.

Beispielsweise gibt es bei Läsionen mit oligodendroglialem Verlust eine Hypothese, welche besagt, dass ein Defekt in der Rekrutierung von adulten OPCs in Richtung des demyelinisierten Bereichs durch Dysregulation von pro-migratorischen Faktoren wie z.B. Chemokinen (Dziembowska et al. 2005) oder Neurotransmittern (Gudz et al. 2006) existieren muss. Dies würde ein Scheitern der Migration von OPCs in betroffene Areale und, damit verbunden, ein Scheitern der Remyelinisierung dieser Läsionen erklären.

Zum anderen gibt es Läsionen, in denen nach wie vor eine hohe Zahl von Zellen der oligodendroglialen Reihe (einschließlich OPCs) anzutreffen ist (Wolswijk 1998; Chang et al. 2000), in denen es also wahrscheinlich zu einer Migration von Vorläuferzellen kommt, aber dennoch keine suffiziente Remyelinisierung stattfindet. Hier wird eine Störung in der Differenzierung der OPCs angenommen (hervorgerufen beispielsweise durch eine Dysregulation inhibitorischer Faktoren). Ein Beispiel hierfür wäre ein Differenzierungsarrest, etwa hervorgerufen durch eine Interaktion des Jagged1-Liganden (auf Seiten des Axons) und des Notch1-Rezeptors (auf Seiten der OPCs) (Wang et al. 1998; Piaton et al. 2009).

Diskutiert werden jedoch auch eine Vielzahl an weiteren möglichen Faktoren, welche einen Einfluss auf Rekrutierung oder Differenzierung der Oligodendrozyten ausüben können. Diese können von fehlerhaften zellulären Interaktionen zwischen Oligodendrozyten und Axonen (Nave und Trapp 2008) über den Einfluss von Wachstumsfaktoren (wie FGF-2 oder PDGF) (Redwine und Armstrong 1998; Maeda et al. 2001), Klasse-3-Semaphorinen (membranständige Moleküle, die an der Wegfindung von Axonen beteiligt sind z. B. SEMA3s) (Mecollari et al. 2014) bis hin zu nicht direkt krankheitsbezogenen Faktoren wie Alter und Geschlecht der Betroffenen reichen (Shen et al. 2008).

Experimentelle und klinische Daten deuten jedoch generell darauf hin, dass die Differenzierungsphase der OPCs als verwundbarster Abschnitt auf dem Weg zur Remyelinisierung angesehen werden kann und es in dieser Phase anscheinend gehäuft zum Versagen der Remyelinisierungsbestrebungen kommt (Franklin und ffrench-Constant 2008; Kuhlmann et al. 2008; Fancy et al. 2010).

Zusammenfassend lässt sich also ein komplexes Bild aus möglichen Störungen in der sensiblen Phase der Differenzierung von OPCs unter dem lokalen Einfluss negativer bzw. dem Fehlen positiver Faktoren zeichnen. So könnte es letztlich zum Ausbleiben einer regelrechten Differenzierung von OPCs zu myelinisierenden Oligodendrozyten und daher auch zu einem Fehlschlagen der lokalen Remyelinisierungsbestrebungen kommen. 


\section{$1.4 \quad$ Experimentelle Modelle der MS}

\subsubsection{Experimentelle autoimmune Enzephalomyelitits (EAE)}

Die experimentelle autoimmune Enzephalomyelitis (EAE) ist eines der am besten erforschten Tiermodelle zu Autoimmunerkrankungen (Denic et al. 2011) und stellt ein ausgezeichnetes Modell in Bezug auf die entzündlichen Aspekte der MS dar (Baxter 2007).

Die Grundlage für das Modell der EAE wurde 1930 von dem Virologen Thomas M. Rivers und seinen Kollegen beschrieben, während sie versuchten, die Ursachen seltener, jedoch schwerwiegender neurologischer Komplikationen nach Tollwutimpfungen aufzuklären (Rivers et al. 1933). Dabei untersuchten sie, weswegen es bei Betroffenen in manchen Fällen zu schmerzhaften motorischen Störungen kam, welche teilweise reversibel waren und in anderen Fällen einen tödlichen Ausgang fanden.

Rivers Untersuchungen stützten sich auf die Injektion von Extrakten aus zerkleinertem Kaninchenhirn in Rhesusaffen und der daraus resultierenden entzündlichen Entmarkung im ZNS. Das daraus entwickelte Tiermodel der EAE wurde in den darauffolgenden Jahrzehnten bis zum heutigen Tag weiterentwickelt.

Durch den kombinierten Einsatz verschiedener Hilfsstoffe (zusammengefasst im FreundAdjuvans) stellt die EAE heute ein relativ einfach auszulösendes und auf verschiedene Spezies (in dieser Studie Mäuse) anwendbares Modell für immunpathologische Aspekte der MS dar und wird darüber hinaus zur Erprobung verschiedener Therapieansätze herangezogen (Baxter 2007).

Im Laufe der Identifizierung zunehmend spezifischerer Proteine als Auslöser der EAE wurde die einfache Emulsion aus Hirngewebe über die Zeit durch immer genauer definierte Autoantigene ersetzt. Prinzipiell beruht die EAE auf einer Immunreaktion auf Myelin bzw. Myelinbestandteile. Die dabei am häufigsten verwendeten Antigene sind MBP (basisches Myelinprotein) (Einstein et al. 1962; Laatsch et al. 1962), MOG (Myelin-OligodendrozytenGlykoprotein) (Lebar et al. 1986) und PLP (Proteolipid-Protein) (Tuohy et al. 1988).

Zur Provokation einer raschen und ausgeprägten Immunantwort besteht das Injektionsmaterial neben dem eigentlichen Antigen aus einer Emulsion aus Mineralöl, hitzedeaktivierten Mykobakterien und einem Emulgator - welches auch als komplettes Freund-Adjuvans (KFA) bezeichnet wird (Freund und McDermott 1942). Zeitgleich zu dieser Injektion erfolgt in der Regel eine begleitende Injektion von Pertussis-Toxin, welche meist in einem Zeitraum von ca. 48 Stunden wiederholt wird und ebenfalls zur Intensivierung der Immunantwort führen soll (Munoz et al. 1984).

Die EAE ist bei vielen verschiedenen Spezies auslösbar, hierzu zählen Ratten, Mäuse, Meerschweinchen, Kaninchen sowie Primaten. Die Histopathologie und der klinische Verlauf können sich hierbei bei den einzelnen Tierarten unterscheiden und sind hauptsächlich abhängig von dem verwendeten Antigen sowie der genetischen Veranlagung der Tierart. Die 
Tiere können, entsprechend des verwendeten Antigens und des artspezifischen Genotyps, einen monophasischen Verlauf, eine schubförmig remittierende Form oder eine chronische EAE ausbilden (Olsson et al. 2000; Hartung et al. 2005; Mix et al. 2010).

Beispielsweise induziert PLP (PLP139-151) bei SJL-Mäusen eine schubförmig remittierende EAE, während MOG (MOG35-55) bei C57BL-Mäusen eine chronisch-progressive EAE auslöst (Gold et al. 2006). Zur Induktion werden hierbei nicht die vollständigen Proteine verwendet, sondern ausgewählte Peptidfragmente. Die genaue Sequenzfolge der Aminosäuren wird dabei durch die Ziffern hinter der jeweiligen Abkürzung angezeigt (z.B. Aminosäuren 35 bis 55 innerhalb der Gesamtsequenz des MOG-Proteins bei MOG35-55).

Die EAE hat sich im Laufe der Jahre als ein wesentliches experimentelles Modell der MS herauskristallisiert, da sie wichtige Merkmale aufweist, welche beide Erkrankungen gemein haben. Vereinbar mit der Hypothese einer Autoimmun-Genese der MS fußt die Demyelinisierung bei der EAE ebenfalls auf immunologischen Vorgängen, welche im Verlauf zu einer Zerstörung der Myelinscheiden führen. Hinzu kommt, dass es bei der EAE ähnlich wie bei der MS zu multiplen Läsionen mit räumlicher und z.T. auch zeitlicher Dissemination kommt. Ferner kommt es bei der EAE ähnlich wie bei der MS zu zeitlichen Veränderungen der Läsionen welche beginnend mit Inflammation über Demyelinisierung und Gliose hin zu partieller Remyelinisierung reichen können. Weiterhin finden sich im Liquor von Tieren mit EAE Immunglobuline, welches auch bei MS-Betroffenen der Fall ist und regelmäßig zur Diagnostik der MS herangezogen wird (Baxter 2007).

\subsubsection{Cuprizoninduzierte Demyelinisierung}

Die Substanz Bis-Cyclohexanon-Oxaldihydrazon oder Cuprizon ist ein Kupferchelator, welcher seit seiner Synthese in den 1950er Jahren hauptsächlich zum quantitativen Nachweis von Kupfer in nichtmedizinischen Proben verwendet wird (Messori et al. 2007). Erst in den frühen 1970er Jahren wurde Cuprizon aufgrund seiner neurotoxischen Wirkung in experimentellen Versuchen zur Demyelinisierung des ZNS zum Einsatz gebracht (Carlton 1966; Ludwin 1978; Kipp et al. 2009).

Cuprizon führt bei oraler Aufnahme durch Ratten oder Mäusen zu einer reversiblen Demyelinisierung vornehmlich im Corpus callosum. Dies ist vermutlich darin begründet, dass durch die Komplexbildung von Cuprizon mit Kupfer die Verfügbarkeit von Kupfer für mitochondriale und andere kupferabhängige Enzyme abnimmt und es so zu einer Störung ihrer Funktion kommt. Dies führt zu einer Schädigung und zum Zelltod insbesondere der reifen Oligodendrozyten im ZNS (Copray et al. 2005). So unterscheidet sich das Cuprizon-Modell der Demyelinisierung von der EAE, wo die Demyelinisierung maßgeblich immunologischer Natur ist. 
Die zugrundeliegenden Pathomechanismen des cuprizoninduzierten Untergangs von Oligodendrozyten sind nicht vollständig geklärt.

Man vermutet, dass es, bedingt durch den Kupfermangel, insbesondere zu einer Dysfunktion der Enzyme Monoaminooxidase und Cytochrom-C-Oxidase (Komplex IV der Atmungskette) kommt (Venturini 1973). Einerseits mündet dies in Verschiebungen des pH-Wertes in den Zellen (durch die Abnahme der Aktivität der Cytochrom-C-Oxidase), andererseits in einem vermehrten Anfall von zytotoxischen Metaboliten (durch die Dysfunktion der Monoaminooxidase) (Kipp et al. 2009). Beides führt zu einer Schädigung und Störung im Energiehaushalt der Oligodendrozyten (Kipp et al. 2009), in dessen Folge es letztlich zur Apoptose der Oligodendrozyten und konsekutiver Demyelinisierung der Axone kommt (Blakemore 1972; Matsushima und Morell 2001; Copray et al. 2005).

Das Cuprizon-Modell eignet sich so, um Fragestellungen zu begegnen, welche sich im Hinblick auf die Theorie einer primären Oligodendrozytenschädigung als Auslöser für eine Entmarkung im Rahmen der MS ergeben. Bei der cuprizoninduzierten Demyelinisierung lässt sich ein Untergang von Oligodendrozyten noch vor der eigentlichen Demyelinisierung oder einer Immunreaktion beobachten (Torkildsen et al. 2008; Acs und Kalman 2012).

Insbesondere da die Demyelinisieurng rasch reversibel ist (Irvine und Blakemore 2006), stellt das Cuprizon-Modell nicht nur ein gutes Instrument für Beobachtungen zu Prozessen der Demyelinisierung dar, sondern eignet sich ebenfalls, um Prozesse der Remyelinisierung zu untersuchen (Torkildsen et al. 2008).

\subsection{Fragestellung}

Zum besseren Verständnis der oligodendroglialen Pathogenese der MS wurden in der vorliegenden Arbeit immunhistologische Untersuchungen an MS-Biopsien sowie an Tiermodellen der MS durchgeführt. Es wurde insbesondere untersucht, wie sich die Zelldichte verschiedener Oligodendrozyten-Subpopulationen in der frühen Läsionsentwicklung der MS beim Menschen, in verschiedenen Stadien der Läsionsentwicklung im Rahmen des Cuprizon-Modells (toxische Demyelinisierung) sowie im Rahmen des EAE-Modells (autoimmun-induzierte Demyelinisierung) im ZNS der Maus verhält.

Hierzu wurden durch Immunfluoreszenz-Mehrfachmarkierungen zell- und phasenspezifischer Zellmarker reife Oligodendrozyten, Oligodendrozyten-Vorläuferzellen (OPCs) sowie mutmaßlich geschädigte Oligodendrozyten identifiziert und deren Dichte in demyelinisierten Läsionen, angrenzenden Periläsionsarealen sowie gesundem Gewebe (NAWM) ermittelt. 


\section{$2 \quad$ Material und Methoden}

\subsection{Untersuchtes Gewebe}

Das untersuchte Gewebe setzte sich aus humanen Biopsien sowie tierexperimentell gewonnenen Gewebeproben zusammen, welche in beiden Fällen fluoreszenzoptisch gefärbt wurden.

Proben der Demyelinisierung im Nagetiermodell wurden entsprechend der im Folgenden unter 2.1.2 für das jeweilige Tiermodell dargestellten Verfahrensweisen erzeugt und gewonnen.

\subsubsection{MS-Biopsien}

Die hier verwendeten MS-Biopsien wurden aus differentialdiagnostischen Gründen entnommen und entstammten dem Archiv des Instituts für Neuropathologie der Universitätsmedizin Göttingen.

Das formalinfixierte und in Paraffin eingebettete Gewebe (FFPE-Gewebe = formalin fixed paraffin embedded) von insgesamt 9 Patienten (2 männlich, 7 weiblich, Alter: 4-72 Jahre, Altersmedian: 35 Jahre), wurde im Rahmen weiterführender Diagnostik bei zum Zeitpunkt der Probeentnahme unklaren neurologischen Grunderkrankungen durch Biopsie gewonnen. Bei der pathologischen Befundung stellte sich eine entzündliche Entmarkung, vereinbar mit einer Erkrankung aus dem Formenkreis der MS, dar.

Die hier untersuchten Läsionen entsprachen nach durchgeführter Stadienanalyse mittels Myelinproteinen und Makrophagenmarkern (1.1.5) früh aktiven Läsionen (Brück et al. 1995).

Tabelle 1 gibt einen zusammenfassenden Überblick über klinische und pathologische Daten der untersuchten Patienten.

Tabelle 1: Patientendaten Humanbiopsien

\begin{tabular}{|l|l|l|l|l|}
\hline $\begin{array}{l}\text { Patient } \\
\text { Nr. }\end{array}$ & Alter & Geschlecht & Grund der Biopsie & Diagnose \\
\hline 1 & 38 & w & V. a. Malignom & $\begin{array}{l}\text { Entzündlich entmarkender } \\
\text { ZNS-Prozess }\end{array}$ \\
\hline 2 & 29 & w & $\begin{array}{l}\text { V. a. Malignom oder In- } \\
\text { fektion }\end{array}$ & $\begin{array}{l}\text { Entzündlich entmarkender } \\
\text { ZNS-Prozess }\end{array}$ \\
\hline 3 & 35 & w & V. a. Malignom & $\begin{array}{l}\text { Entzündlich entmarkender } \\
\text { ZNS-Prozess }\end{array}$ \\
\hline 4 & 72 & $\mathrm{~m}$ & V.a. Malignom & $\begin{array}{l}\text { Entzündlich entmarkender } \\
\text { ZNS-Prozess }\end{array}$ \\
\hline
\end{tabular}




\begin{tabular}{|l|l|l|l|l|}
\hline $\begin{array}{l}\text { Patient } \\
\text { Nr. }\end{array}$ & Alter & Geschlecht & Grund der Biopsie & Diagnose \\
\hline 5 & 46 & w & $\begin{array}{l}\text { V. a. Malignom oder Va- } \\
\text { skulitis }\end{array}$ & $\begin{array}{l}\text { Entzündlich entmarkender } \\
\text { ZNS-Prozess }\end{array}$ \\
\hline 6 & 34 & w & V. a. Malignom & $\begin{array}{l}\text { Entzündlich entmarkender } \\
\text { ZNS-Prozess }\end{array}$ \\
\hline 7 & 29 & w & NA & $\begin{array}{l}\text { Entzündlich entmarkender } \\
\text { ZNS-Prozess }\end{array}$ \\
\hline 8 & 4 & m & V. a. Vaskulitis & $\begin{array}{l}\text { Entzündlich entmarkender } \\
\text { ZNS-Prozess }\end{array}$ \\
\hline 9 & 43 & w & NA & $\begin{array}{l}\text { Entzündlich entmarkender } \\
\text { ZNS-Prozess }\end{array}$ \\
\hline
\end{tabular}

\subsubsection{Experimentell erzeugte Proben in Tiermodellen der MS}

Es gibt kein Tiermodell, das für sich alleine genommen in der Lage ist, der MS in ihrer Vielfalt der klinischen, pathologischen und radiologischen Präsentation gerecht zu werden. Nichtsdestotrotz sind über die letzten Jahrzehnte nützliche und relevante Tiermodelle entwickelt worden, welche ausgewählte Teilaspekte der Erkrankung widerspiegeln können. Abhängig von der genauen Fragestellung ist es durch gezielte Auswahl des geeigneten Tiermodells möglich, Ergebnisse zu liefern, welche mit hoher Wahrscheinlichkeit auch auf die MS beim Menschen anwendbar sind (Denic et al. 2011).

Um diesem Umstand Rechnung zu tragen, fußen die Ergebnisse dieser Untersuchung neben humanen Proben auf zwei etablierten und häufig untersuchten Tiermodellen, welche unterschiedliche Teilaspekte der MS darstellen.

Diese sind die experimentelle autoimmune Enzephalomyelitis (EAE) (siehe 1.4.1) und das Cuprizon-Modell der toxisch induzierten Demyelinisierung (siehe 1.4.2).

\subsection{Durchführung der Tierexperimente}

\subsubsection{Versuchstiere}

Mäuse des Stammes C57Bl/6J der Firma Charles River Laboratories (Charles River Laboratories, Sulzfeld, Deutschland) wurden käuflich erworben und nach initialer Grunduntersuchung und Erfassung für mindestens sechs Tage an die neue Unterbringung, das Futter und die Umgebung der Tierexperimentellen Einrichtung der Universitätsmedizin Göttingen gewöhnt. Die Haltung der Tiere (zwei bis fünf Tiere pro Käfig) fand unter licht- und temperaturkontrollierten Bedingungen mit Ad-libitum-Zugang zu Wasser und Futter statt. 


\subsubsection{Experimentelle autoimmune Enzephalomyelitis (EAE)}

Die Induktion der EAE erfolgte an 6-12 Wochen alten C57BL/6J Mäusen durch subkutane Injektion von rekombinantem Myelin-Oligodendrozyten-Glykoprotein (rMOG1-125). Die Immunisierung erfolgte durch Injektion einer Emulsion bestehend aus $100 \mu \mathrm{g}$ in KFA (siehe 1.4.1) emulgiertem MOG zusammen mit $5 \mathrm{mg} / \mathrm{ml}$ Mycobacterium tuberculosis (Stamm H37Ra) in inguinale und axilläre Regionen. Zeitgleich erfolgte eine intraperitoneale Injektion von 300 ng Pertussis-Toxin, welche nach Ablauf von 48 Stunden wiederholt wurde.

Das klinische Ausmaß der EAE wurde anhand eines Scoring-Systems beurteilt, wobei ein klinischer Score $\geq 3,5$ oder ein Gewichtsverlust von $\geq 25 \%$ als Abbruchkriterium definiert wurde und die betroffenen Tiere frühzeitig euthanasiert und aus der Studie genommen wurden.

\subsubsection{Cuprizon-Modell}

Für die cuprizoninduzierte Demyelinisierung wurde 6-12 Wochen alten Mäusen (Stamm C57BL/6J) 0,25\% (2,5 g/kg) Cuprizon (Sigma-Aldrich Chemie GmbH) in das Futterpulver (SSNIFF Spezialitäten GmbH, Soest, Deutschland) gemischt. Nach einer Versuchsdauer von zwei oder vier Wochen wurden die Tiere schmerzlos getötet und das Gewebe für nachfolgende histopathologische Untersuchungen asserviert (siehe 2.2.4).

\subsubsection{Gewebeasservation und Fixierung}

\subsubsection{Transkardiale Perfusion}

Die Versuchstiere wurden nach zwei oder vier Wochen durch eine letale Dosis Xylazin/Ketamin schmerzlos getötet. Nach dem Ausfall aller Reflexe wurden das Herz frei präpariert, der rechte Herzvorhof inzidiert und der linke Ventrikel punktiert. Es erfolgte zunächst eine langsame Perfusion der Tiere mit etwa 10-15 ml PBS, um das Gefässsystem blutfrei zu bekommen. Anschließend wurden die Tiere mit PBS/4\% PFA zur Gewebeasservierung perfundiert. Nach Entnahme von Gehirn und Rückenmark erfolgte eine zusätzliche Nachfixierung in PBS/4\% PFA für weitere 48 Stunden.

\subsubsection{Gewebepräparation}

Das fixierte Gewebe wurde nach erfolgter Spülung mit PBS in ca. $3 \mathrm{~mm}$ dicke koronare Scheiben geschnitten. Nach einer weiteren Waschung in destilliertem Wasser erfolgte die Dehydrierung in einer aufsteigenden Alkoholreihe (jeweils eine Stunde in einer Lösung aus 
$50 \%, 70 \%, 90 \%, 95 \%, 96 \%, 100 \%$ Ethanol in destilliertem Wasser bei einer Temperatur von $37^{\circ} \mathrm{C}$ ) und Xylol als Intermedium.

Die Einbettung in Paraffin erfolgte maschinell unter Zuhilfenahme eines Gewebeinfiltrationsautomaten (TP 1020 Automatic Tissue Processor, Leica ${ }^{\circledR}$ Microsystems Deutschland).

Die dabei erzeugten Paraffinblöcke wurden im Anschluss mit einem Mikrotom (Leica Biosystems Deutschland) in Schnitte von einer Dicke von 1-2 $\mu \mathrm{m}$ geschnitten und auf einen Objektträger (Menzel-Gläser,Braunschweig, Deutschland) aufgebracht.

\subsubsection{Entparaffinierung und Rehydrierung}

Um eine histologische Färbung durchzuführen, ist eine Entparaffinierung und anschließende Rehydrierung der Einzelpäparate notwendig. Dies geschieht durch Erhitzung auf $55^{\circ}-60^{\circ} \mathrm{C}$ für ca. 100 Minuten und aufeinanderfolgendem Tauchbad in den in Tabelle 2 aufgeführten Lösungen.

Tabelle 2 Verwendete Lösungen zur Entparaffinierung und Rehydrierung

\begin{tabular}{||l|l|l|}
\hline Verwendete Lösung & Dauer in Minuten & Wiederholungen \\
\hline Xylol & 10 & 4 \\
\hline $1: 1$ Gemisch aus Isopropanol und Xylol & 5 & 1 \\
\hline $100 \%$ Isopropanol & 5 & 2 \\
\hline $90 \%$ Isopropanol und destilliertes Wasser & 5 & 1 \\
\hline $70 \%$ Isopropanol und destilliertes Wasser & 5 & 1 \\
\hline $50 \%$ Isopropanol und destilliertes Wasser & 5 & 1 \\
\hline \multirow{2}{*}{} & 5 \\
\hline
\end{tabular}

\subsection{Immunhistochemische Untersuchungen}

\subsubsection{Grundlegendes}

Immunhistochemische Färbemethoden ermöglichen den gezielten Nachweis von Strukturen in Geweben und stellen eine etablierte Methode in histopathologischer Diagnostik und Forschung dar. Sie sind anwendbar auf eine Vielzahl von Probetypen wie Gefrier-, Kunststoffund Paraffinschnitten, Vibratomschnitten sowie frei flottierenden Schnitten oder Zellkulturen (Lang 2013).

Das Grundprinzip immunhistochemischer Nachweis- bzw. Färbe-Verfahren, wie der hier verwendeten Immunofluoreszenz-Markierung, beruht auf der Affinität von Antikörpern gegen definierte Zielstrukturen. Diese Zielstrukturen, auch Antigene genannt, können verschieden geartet sein und mehrere Epitope (Bindungsstellen für Antikörper) vorweisen. Epitope können beispielsweise Aminosäuregruppen oder Oligosaccharidketten sein, und nachzuweisende Antigene können sich auf der Oberfläche von Zellen, im Zytoplasma oder Zellkern befinden. 


\subsubsection{Antikörper}

Antikörper, welche in immunhistochemischen Färbeverfahren zum Einsatz kommen, gehören hauptsächlich der Gruppe der Gamma-Immunglobuline $(\operatorname{Ig} G)$ an, welche sich durch ihre vergleichsweise geringe Größe und Masse ( $150 \mathrm{kDa})$ auszeichnen und daher besonders gut in Gewebe eindringen können, sich dabei aber gegenseitig nur wenig sterisch behindern. Sie sind meist tierischen Ursprungs und werden durch gezielte Immunisierung von Tieren (zumeist Ziege, Maus, Kaninchen oder Meerschweinchen) gegen entsprechende Antigene gewonnen. Durch Präsentation des Antigens gegenüber dem Immunsystem des Tieres kommt es zu einer Immunantwort mit der Produktion von Antikörpern. Durch Isolierung, Kultivierung und Vermehrung entsprechender Plasmazellen erhält man schließlich die gewünschten Antikörper in großen Mengen.

Der Länge nach geteilt, besteht ein IgG-Antikörper aus einer kurzen, leichten Kette und einer langen, schweren Kette. Die einzelnen Anteile des Antikörpers werden durch Disulfidbrücken miteinander verbunden (siehe Abbildung 1).

Die für eine jeweilige Herkunftsspezies gleichbleibende $\mathrm{Fc}$-Komponente $(\mathrm{Fc}=$ fragment crystallisable) und die zwei modifizierbaren Fab-Fragmente (Fab = fragment antigen binding), geben den Antikörpern ihre für IgG charakteristische Y-Form. Die Fab-Domänen weisen dabei eine Affinität zu einem spezifischen Epitop eines Antigens auf und funktionieren nach dem Schlüssel-Schloss-Prinzip.

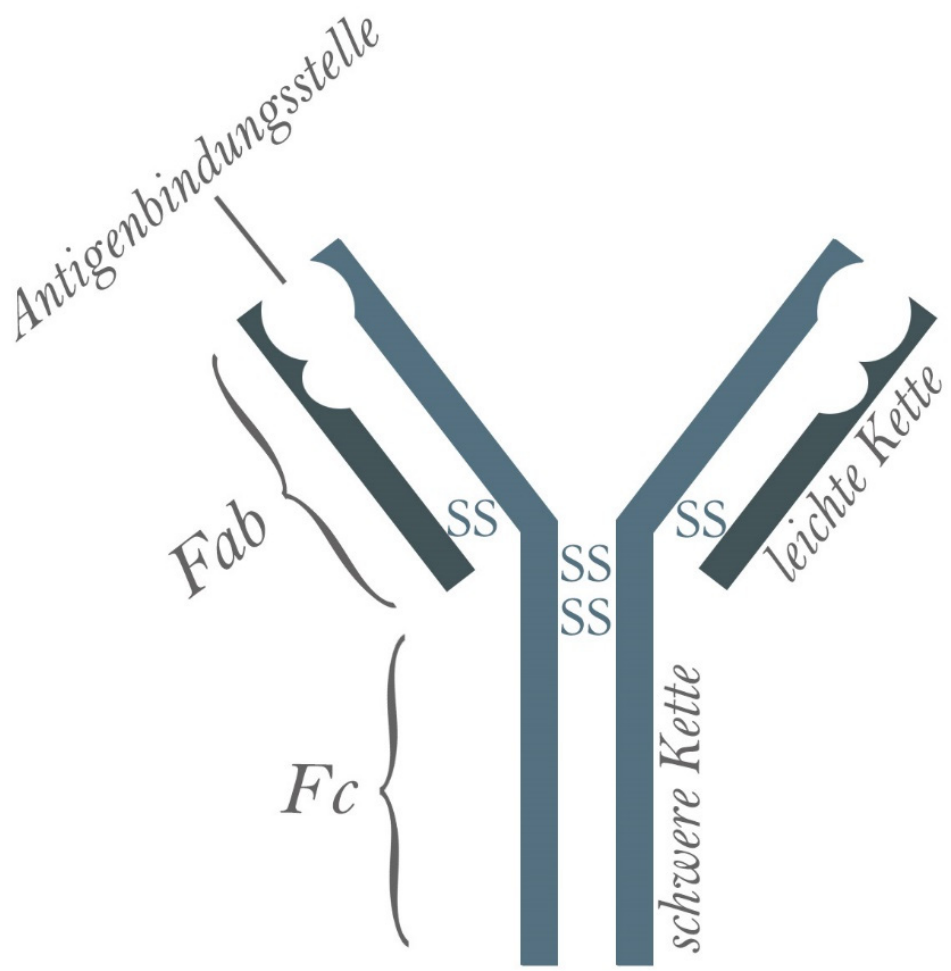

Abbildung 1: Schematische Darstellung IgG 
Immunglobuline haben durch ihre makromolekulare Struktur selbst antigene Eigenschaften. Durch Verabreichung artfremder Antikörper können Tiere Antikörper bilden (beispielsweise durch Immunisierung einer Ziege mit Antikörpern eines Kaninchens), welche wiederum selbst gegen die verabreichten Antikörper gerichtet sind. Auf diesem Weg können sogenannte polyklonale Sekundärantikörper generiert werden, welche zwar alle gegen das gleiche Zielantigen gerichtet sind (in der Regel das Fc-Fragment des eingebrachten Antikörpers), sich jedoch in ihrer Epitopspezifität unterscheiden. Polyklonale Antikörper unterscheiden sich von monoklonalen Antikörpern dadurch, dass sie ihren Ursprung in unterschiedlichen Plasmazellen haben und gegen verschiedene Epitope des gleichen Antigens gerichtet sein können, wohingegen monoklonale Antikörper von dem Zellklon einer einzelnen Plasmazelle stammen (Hauk 2014). So können mehrere polyklonale Sekundärantikörper an einem Primärantikörper binden und so zu einer Verstärkung des Färbesignals beitragen (Lang 2013; Luttmann et al. 2014).

Im Fall der Antikörper, welche wiederum selbst gegen andere Antikörper gerichtet sind, stellt das Fc-Fragment, welches sich am Ende der schweren Ketten befindet, das Antigen dar.

Sollen wie bei der hier vorliegenden Arbeit mehrere Strukturen innerhalb einer Gewebeprobe sichtbar gemacht werden, sind Mehrfachfärbungen mit Antikörpern gegen unterschiedliche Zielstrukturen notwendig. Hierzu eignen sich Fluorochrom-konjugierte-Sekundärantikörper, an welche Fluoreszenzfarbstoffe gebunden sind. Fluorochrome sind Moleküle, welche die Eigenschaft besitzen, bei Anregung durch Licht einer bestimmten Wellenlänge selbst Licht in einer anderen Wellenlänge zu emittieren (siehe Abbildung 2 Kasten A5 und A6). Es ist zu bedenken, dass die verschiedenen Fluorochrome, die in einer Mehrfachfärbung zum Einsatz kommen, untereinander möglichst weit auseinanderliegende Anregungs- und Emissionswellenlängen besitzen müssen, um Störungen durch Überlagerung der einzelnen Signale zu vermeiden.

\subsubsection{Detektierte Strukturen}

Die Unterscheidung der unterschiedlichen Reifestufen und funktionellen Stadien der Oligodendrozyten nur anhand ihrer Morphologie ist sehr schwierig. Da für die Fragestellung dieser Arbeit jedoch eine Unterteilung in zum Beispiel reife Oligodendrozyten und Oligodendrozyten-Vorläuferzellen (OPC) ausschlaggebend ist, fand die Identifikation mittels immunhistochemischer Markierung exprimierter Trankriptionsfaktoren und biochemischer Marker statt.

Durch immunhistochemische Färbemethoden wurden einerseits die im Nucleus befindlichen Marker Olig2, Nkx2.2 sowie Sox10 sichtbar gemacht und andererseits der zytosolische Marker p25 angefärbt. 
Die Darstellung struktureller Veränderungen des Myelins im Sinne einer Demyelinisierung wurde durch die Färbung von MBP (basisches Myelinprotein) realisiert. Dabei wurden Zellen, welche einfach positiv für die Transkriptionsfaktoren Olig2, Nkx2.2 oder Sox10 angefärbt wurden, als Oligodendrozyten-Vorläuferzellen identifiziert und Zellen, welche zusätzlich dazu positiv für p25 waren (also doppelt positiv), als reife Oligodendrozyten eingeordnet.

Eine grundsätzliche und unspezifische Identifizierung von Zellen im Allgemeinen fand durch Färbung ihrer Zellkerne mittels DAPI statt und diente der Reduzierung von Fehlzählungen, verursacht durch unspezifische Färbeartefakte.

Im Folgenden werden die einzelnen Zielstrukturen der immunhistochemischen Färbungen kurz vorgestellt.

\subsubsection{Olig2}

Der Transkriptionsfaktor Olig2 (oligodendrocyte transcription factor 2) gehört zur Familie der bHLH-Proteine (basic helix-loop-helix) (Takebayashi et al. 2002) und stellt einen spezifischen Marker für Oligodendrozyten dar, ist jedoch relativ phasenunspezifisch, da er sowohl in OPCs als auch in reifen Oligodendrozyten exprimiert wird (Ligon et al. 2004; Liu et al. 2007). Die Aussagekraft von Olig2 als Marker zur Bestimmung der Entwicklungsstufe von Oligodendrozyten ist darum abhängig von der Abwesenheit oder Anwesenheit von weiteren Markern wie beispielsweise p25.

Olig2 wird eine Rolle in der Antwort auf Schäden an Oligodendrozyten und Verletzungen des Gehirns zugeschrieben, da eine Erhöhung von Olig2 beispielsweise nach Stichverletzungen im Gehirn nachweisbar ist (Buffo et al. 2005; Ou et al. 2016).

Darüber hinaus wird Olig2 jedoch eine Hauptrolle bei der Reifung und Differenzierung von Zellen der oligodendroglialen Reihe zugeschrieben (Zhou et al. 2001; Jakovcevski und Zecevic 2005), auch wenn davon ausgegangen wird, dass ein Zusammenspiel mit weiteren Transkriptionsfaktoren wie Sox10 und Nkx2.2 existiert, ist die Expression von Olig2 alleine in der Lage, Reifung und Differenzierung von Oligodendrozyten zu initiieren (Liu et al. 2007). Somit stellt Olig2 einen hervorragenden Basalmarker für Zellen der oligodendroglialen Reihe dar.

\subsubsection{Sox10}

Der Transkriptionsfaktor Sox10 ist ein früher Marker für Zellen der oligodendroglialen Reihe und gehört zu der Gruppe der High-Mobility-Group-Proteine (Liu et al. 2007). Zusammen 
mit Olig2 und Nkx2.2 spielt er eine Rolle bei der oligodendroglialen Reifung und Differenzierung und wird darüber hinaus auch im reifen Oligodendrozyten weiter exprimiert (Stolt et al. 2002).

\subsubsection{Nkx2.2}

Ebenso kann Nkx2.2/(Nk2.2), welches zu den Home-domain-Proteinen zählt, als Marker für Oligodendrozyten verwendet werden. Es spielt ähnlich wie Sox10 in Kombination mit Olig2 eine synergistische Rolle bei der Differenzierung und Reifung von Oligodendrozyten (Liu et al. 2007). Insbesondere Untersuchungen zur Entwicklung von Oligodendrozyten in Mäusen deuten darauf hin, dass der Transkriptionsfaktor Nkx2.2 nicht nur die Entwicklung bzw. Differenzierung mit steuert, sondern in besonderem Maß einen begrenzenden Einfluss auf die Anzahl der gebildeten OPCs ausübt (Kucenas et al. 2008). Ähnlich wie Sox10 ist es im ZNS im Nucleus von OPCs nachweisbar, wird aber nach Differenzierung zu reifen Oligodendrozyten herunterreguliert (Xu et al. 2000; Watanabe et al. 2004; Kuhlmann et al. 2008) und kann somit insbesondere in Koexpression mit p25 als Marker für frühe bzw. erst kürzlich differenzierte, reife Oligodendrozyten verwendet werden.

\subsubsection{4 p25/TPPP}

Im Gegensatz zu den nukleären Markern Olig2, Sox10 und Nkx2.2 ist der Marker p25 (TPPP/p25 = tubulin polymerization promoting protein) ein zytoplasmatisches (Phospho)-Protein, welches sehr spezifisch in reifen, myelinisierenden Oligodendrozyten exprimiert wird (Lehotzky et al. 2008). Man geht davon aus, dass das Markerprotein eine Rolle bei der Strukturierung der Mikrotubuli innehat (Takahashi et al. 1993; Song et al. 2007).

\subsubsection{MBP}

MBP ist eine Hauptkomponente im Proteinanteil von Myelin und spielt anscheinend eine Rolle in diversen Struktur- und Signalnetzwerken, welche in unterschiedlichen Mikrodomänen des Myelins in unterschiedlichen Stadien der zellulären Differenzierung auftreten (Harauz und Boggs 2013). MBP verankert die zytosolischen Oberflächen der das Axon umwickelnden Oligodendrozytenmembranen, wodurch es zur Ausbildung der multilamellären Barriere für Proteindiffusion und Ionenaustausch durch das kompakte Myelin kommt (Trapp und Kidd 2004). Weiterhin spielt MBP eine Rolle beim Aufbau des Zytoskeletts sowie im Rahmen der Membranerweiterung und Ausdehnung (Harauz und Boggs 2013; Vassall et al. 2015). Als Hauptbestandteil im Proteinanteil von Myelin im ZNS (Zhou et al. 2017) und aufgrund seiner relativ homogenen Verteilung im Myelin (Brunner et al. 1989) eignet es sich besonders gut für den Nachweis von Myelin in histologischen Präparaten. So können mit 
MBP als Zielantigen immunhistochemischer Färbeverfahren Areale mit normaler Myelinisierung gut von strukturellen Veränderungen im Sinne einer Demyelinisierung unterschieden werden.

\subsubsection{Gewebevorbereitung}

Im Zuge der Fixierung und Einbettung von Geweben kann es zu Einbußen in der Morphologie und strukturellen Veränderungen kommen. So kann beispielsweise die häufig verwendete Formalinfixierung durch Bildung von Methylgruppen Proteinstrukturen verändern und so Epitope maskieren. Formalininduzierte Veränderungen an Epitopen sind dabei oft reversibel und können beispielsweise durch proteolytische Enzyme im Rahmen der PIER (proteaseinduced epitope retrieval), oder der weitaus häufiger verwendeten feuchtigkeits- und hitzevermittelten HIER (beat-induced epitope retrieval) wiederhergestellt und der Erkennung durch Antikörper zugänglich gemacht werden. Diesen Prozess bezeichnet man daher auch als Demaskierung oder epitope retrieval (Hantschke und Palmedo 2015). Dazu wurden die Präparate in Puffer (Citratpuffer (pH6) oder Tris/EDTA (pH9)) in einem Dampfgarer (Braun, FS 3000, De'Longhi Deutschland GmbH) für 35 Minuten erhitzt. Nachfolgend wurden die Proben wieder mit destilliertem Wasser und PBS gespült.

Bei der Färbung gegen Olig2 mittels Tyramid-Kit (TSA ${ }^{\text {TM}}-$ Kit, Invitrogen/Fisher Scientfic, Waltham, USA) wurde im nächsten Schritt die Aktivität der endogenen Peroxidase unterbunden, um unerwünschte Hintergrundfärbungen zu vermeiden. Hierzu wurden die Proben 10 Minuten in 3\%iger Wasserstoffperoxid/PBS-Lösung inkubiert und anschließend mehrfach mit PBS gespült.

\subsubsection{Allgemeine Durchführung der Immunofluoreszenz-Färbung (indirekte Methode)}

Bei der hier verwendeten, auch als „Indirekte Methode“ bezeichneten Färbemethode, kommt es im ersten Inkubationsschritt zur Bindung eines unkonjugierten Primärantikörpers (siehe Tabelle 7) an das zu detektierende Epitop. Im nächsten Inkubationsschritt wird dann ein Fluorochrom-konjugierter Sekundärantikörper eingesetzt (siehe Tabelle 8), welcher spezifisch für die Herkunftsspezies des Primärantikörpers ist und an diesen bindet. Da mehrere Sekundärantikörper an einen einzelnen Primärantikörper binden können, kommt es zu einer Signalamplifikation, welche das Färbeergebnis im Vergleich zu direkten Färbungen (nur mit Primärantikörpern) verbessert (Lang 2013). Im Folgenden ist das Färbeprotokoll exemplarisch dargestellt. 
Im ersten Schritt erfolgte die Inkubation mit dem jeweiligen Primärantikörper in Blockpuffer (10\% NGS/PBS). Dies geschah bei $4^{\circ} \mathrm{C}$ über Nacht und in Dunkelheit. Anschließend erfolgte die Spülung mit PBS-Puffer (Schritt zwei) und die Inkubation mit dem (fluorochromkonjugierten) Sekundärantikörper (1:100) in Blockpuffer ((10\% NGS/PBS) (Schritt drei)). Dies geschah über zwei Stunden bei Raumtemperatur und in Dunkelheit. Auch nach diesem Schritt erfolgte eine Spülung mit PBS-Puffer (Schritt vier).

Für Mehrfachmarkierungen wurden ggf. Schritte eins bis vier mit abweichenden Primär- Sekundärantikörpern wiederholt.

Weiter schloss sich die Inkubation mit DAPI ((1:1000) (Sigma-Aldrich Chemie GmbH)) in PBS-Puffer für fünf bis zehn Minuten an. Dies wurde in einer feuchten Kammer bei Raumtemperatur und ebenfalls in Dunkelheit durchgeführt (Schritt fünf).

Letztlich erfolgte eine weitere Spülung mit PBS-Puffer und $\mathrm{H}_{2} \mathrm{O}$ (Schritt sechs) wonach die Präparate mit Fluoromount (Fluorescence Mounting Medium, Dako) eingedeckelt wurden (Schritt sieben) und dann bis zur weiteren Verwendung bei $4^{\circ} \mathrm{C}$ aufbewahrt wurden.

\subsubsection{Durchführung der Immunofluoreszenz-Färbung von Olig2}

Zur Färbung des Transkriptionsfaktors Olig2 wurde ein durch Tyramid-Signalverstärkung ergänztes Färbeverfahren angewandt. Ähnlich wie bei dem LSAB-Verfahren (labelled streptavidin-biotin) oder dem ABC-Verfahren (avidin-biotin complex), wird sich auch hier die intermolekulare Affinität des Avidin- bzw. hier Streptavidin-Moleküls zu Biotin (Vitamin H) zunutze gemacht.

Streptavidin ist ein Protein, welches dem in Hühnereiweiß enthaltenen Avidin sehr ähnelt und genau wie dieses vier Bindungsstellen für eine nichtkovalente Bindung zu Biotin besitzt. Die Bindung zwischen Streptavidin und Biotin zählt dabei zu einer der stärksten nichtkovalenten Bindungen in der Natur. Streptavidin wird von Bakterien der Gattung Streptomyces avidinii hergestellt und hat im Vergleich zu Avidin den Vorteil, dass es nicht dazu neigt, bei physiologischem $\mathrm{pH}$ an negative Gewebebestandteile zu binden.

Im Detail kommt es analog zur indirekten Methode auch hier zur Bindung eines unkonjugierten, monoklonalen Primärantikörpers am Zielantigen, an welchem dann im weiteren Verlauf ein (mehrfach) biotinylierter Sekundärantikörper bindet. Folgend wird mit Meerrettichperoxidase konjugiertes Streptavidin hinzugegeben, welches seinerseits über Biotin an den Sekundärantikörper bindet. Nun hinzugegebenes Tyramid, welches mit einem Fluoreszenzfarbstoff markiert wurde, wird (in Anwesenheit von Wasserstoffperoxid) zu einem hochreaktiven Derivat umgesetzt, welches an Proteinstrukturen in unmittelbarer Nähe der Reaktion bindet. So kommt es nicht nur durch die Polyklonalität des Sekundärantikörpers, sondern auch durch die Verwendung der Tyramidreaktion zu einer vielfachen Verstärkung des Färbesignals. Dieses modifizierte Verfahren wurde bei der Färbung von Olig2 angewandt, um 
auch bei Mehrfachfärbungen mit Primärantikörpern der gleichen Herkunftsspezies eine optimale Färbung der Zielstrukturen zu gewährleisten, und wird im Folgenden dargestellt.

Die Färbung gegen Olig2 wurde mit dem Tyramide Signal Amplification-Kit Invitrogen/Fisher Scientfic, Waltham, USA) durchgeführt, wobei die beiliegenden Protokolle des Herstellers beachtet wurden:

Im ersten Schritt erfolgte die Inkubation mit einer 1 \%igen Lösung „TSA ${ }^{\text {TM}}$-Blocking-Reagenz" in PBS für eine Stunde bei Raumtemperatur.

Anschließend erfolgte eine Spülung mit PBS-Puffer (Schritt zwei) und die Inkubation mit dem Primärantikörper rabbit-anti-Olig2 (IBL) in 1 \%iger „TSA TM-Blocking-Reagenz“ (1:300) über Nacht bei $4^{\circ} \mathrm{C}$ und in Dunkelheit (Schritt drei).

Nach dreimaliger Spülung mit PBS-Puffer (Schritt vier) erfolgte die Inkubation mit dem biotinylierten Sekundärantikörper goat-anti-rabbit (Dianova, 1:250) in „TSA TM-Blocking-Reagenz" für 2 Stunden bei Raumtemperatur und Dunkelheit (Schritt fünf). Hieran schloss sich eine erneute Spülung mit PBS-Puffer (Schritt sechs) und die Inkubation mit StreptavidinHRP-Konjugat (1:100) in 1\%iger „TSA TM-Blocking-Reagenz“ für 30 Minuten an (Schritt sieben). Darauffolgend wurden die Proben erneut mit PBS-Puffer gespült (Schritt acht) und für zehn Minuten in Verstärkungspuffer mit 0,0015\% $\mathrm{H}_{2} \mathrm{O}_{2}$ mit Alexa555-Fluorochrom gekoppeltem Tyramid (1:100) inkubiert (Schritt neun). Abschließend erfolgte eine weitere Spülung mit PBS-Puffer (Schritt zehn). 


\subsubsection{Schematische Übersichten der Färbeverfahren}

\subsubsection{Schematische Übersicht: indirektes Färbeverfahren}
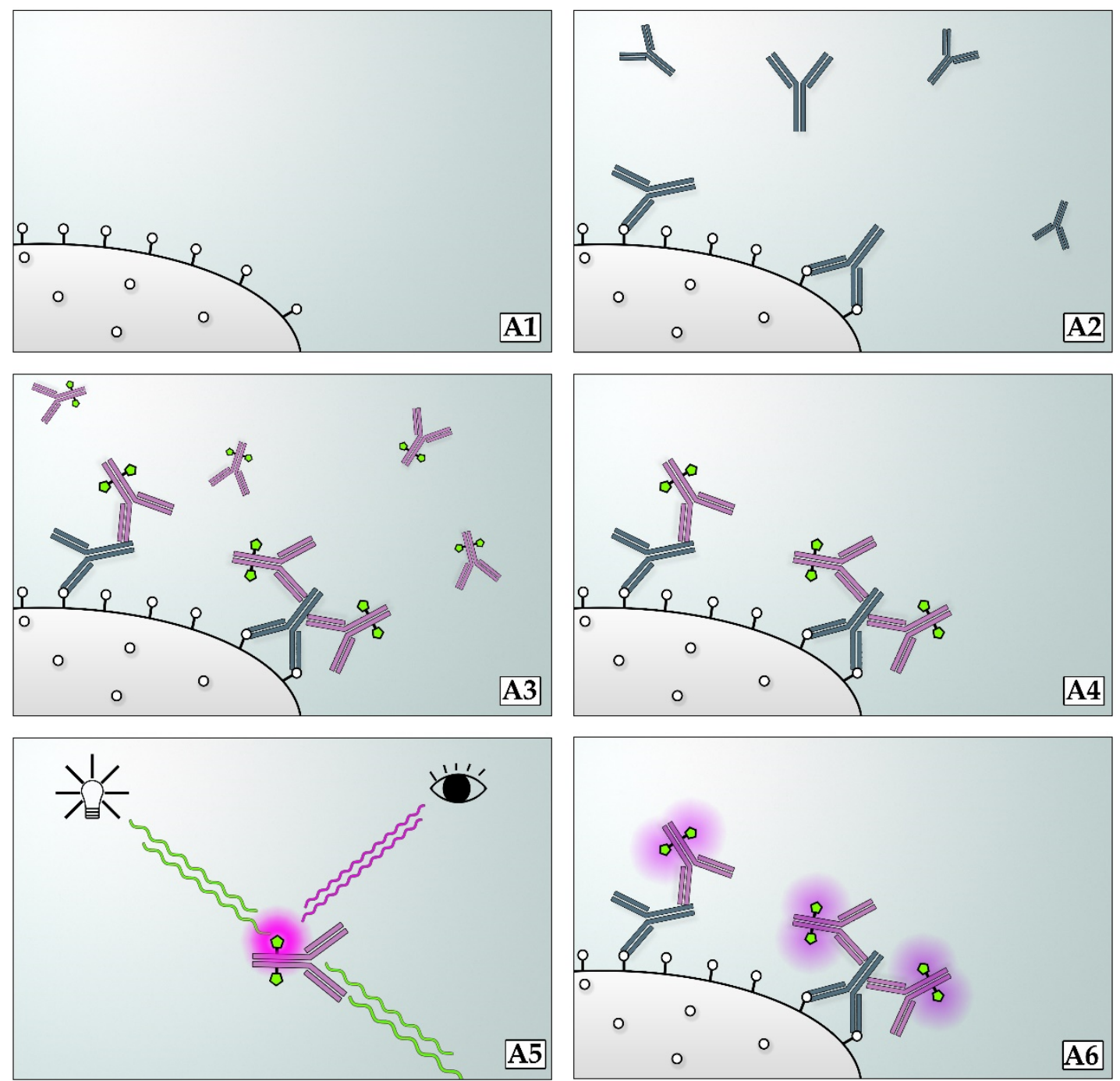

Abbildung 2: Übersicht indirektes Färbeverfahren (Legende siehe Abbildung 3)

A1: Demaskierte Antigene nach erfolgter HIER, A2: Inkubation mit Primärantikörper, A3: Inkubation mit farbstoffmarkiertem Sekundärantikörper, A4: Zustand nach erfolgter Spülung - Primärantikörper gebunden an Antigen und Sekundärantikörper gebunden an Primärantikörper, A5: Schematische Darstellung von Fluoreszenzinduktion durch Licht mit farbstoffspezifischer Wellenlänge, A6: Fluoreszierender Farbstoff in unmittelbarer Nähe des Zielantigens. 
2.3.7.2 Schematische Übersicht: Färbung Olig2 unter Verwendung des TSATM-Kits
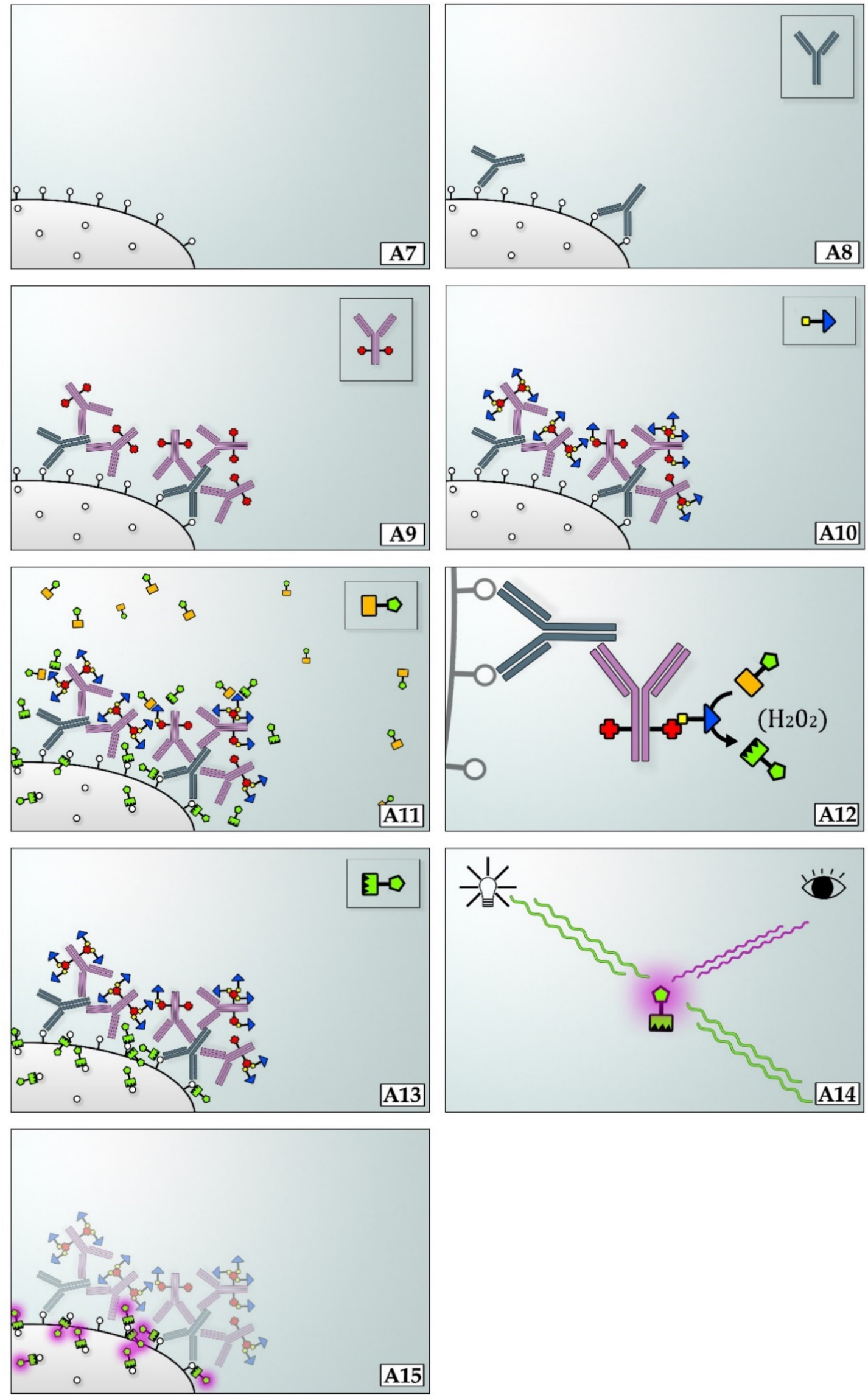

Abbildung 3: Schematische Übersicht Olig2-Färbung mit TSA-Kit 


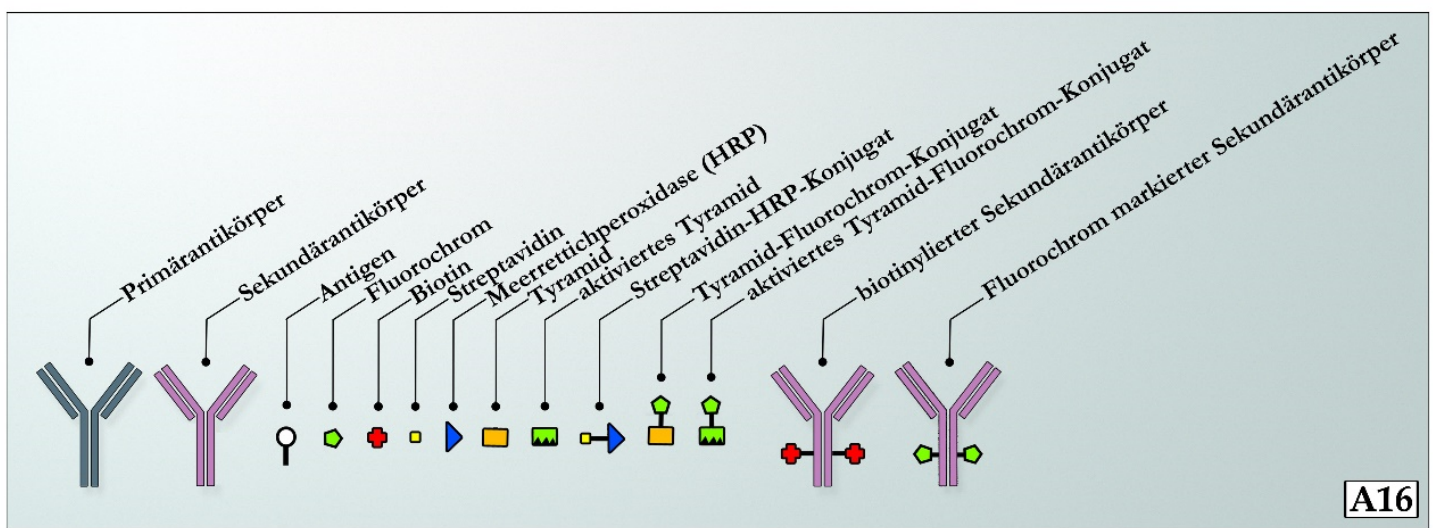

Abbildung 3 (fortges.): Schematische Übersicht Olig2-Färbung mit TSA-Kit (Legende)

Erläuterung zu Abbildung 3: (Zustand nach erfolgter Spülung - Kasten rechts oben, jeweils neu hinzugekommene bzw. aktivierte Komponente) A7: (demaskiertes) Antigen nach erfolgter HIER, A8: Zustand nach Inkubation mit Primärantikörper, A9: Zustand nach Inkubation mit biotinyliertem Sekundärantikörper, A10: Zustand nach Inkubation mit Streptavidin-HRP-Konjugat, A11: Inkubation mit Fluorochrom-markiertem Tyramid und geringer Menge $\mathrm{H}_{2} \mathrm{O}_{2}$, A12: HRP-vermittelte Aktivierung des Tyramids unter Anwesenheit von $\mathrm{H}_{2} \mathrm{O}_{2}$, A13: unspezifische Bindung von aktiviertem Tyramid in unmittelbarer Nähe der enzymvermittelten Aktivierung, A14: Schematische Darstellung von Fluoreszenzinduktion durch Licht mit farbstoffspezifischer Wellenlänge, A15: Fluoreszierender Farbstoff in unmittelbarer Nähe des Zielantigens, A16: Legende

\subsection{Datenauswertung}

Die gefärbten Schnittpräparate wurden mit einem automatisierten Scanner für Objektträger (VS-120, Olympus Deutschland GmbH, Hamburg, Deutschland) digitalisiert. Die Auswertung der digitalisierten Aufnahmen erfolgte unter Zuhilfenahme der Bildanalysesoftware cellSens $^{\text {TM }}$ (Olympus Europa SE \& CO. KG, Hamburg, Deutschland) sowie ImageJ-win64 (National Institutes of Health, Bethesda, USA).

Erhobene Daten wurden in Microsoft-Excel ${ }^{\mathrm{TM}}$ (Microsoft Corporation, Redmont, USA) tabellarisch zusammengeführt und für die statistische Analyse aufbereitet.

Statistische Analyse und grafische Visualisierung der Ergebnisse erfolgte über GraphPad Prism $5^{\mathrm{TM}}$ (GraphPad software Inc., La Jolla, USA). 


\subsection{Verbrauchsmaterial}

Tabelle 3: Verbrauchsmaterial

\begin{tabular}{|l|l|}
\hline \multicolumn{1}{|c|}{ Verbrauchsmaterial } & \multicolumn{1}{|c|}{ Hersteller } \\
\hline Futtermittel (Pressfutter R/M,10 mm) & $\begin{array}{l}\text { Ssniff Spezialdiäten GmbH, Soest, } \\
\text { Deutschland }\end{array}$ \\
\hline Eppendorfgefäße $1.5 \mathrm{ml}$ & Eppendorf AG, Hamburg, Deutschland \\
\hline Objektträger & $\begin{array}{l}\text { Menzel-Gläser, Braunschweig, } \\
\text { Deutschland }\end{array}$ \\
\hline Einweghandschuhe & $\begin{array}{l}\text { MaiMed GmbH, Neuenkirchen, Deutsch- } \\
\text { land }\end{array}$ \\
\hline Injektionsspritzen & BD Biosciences, Franklin Lakes, USA \\
\hline Präparationsbesteck & $\begin{array}{l}\text { Fine Science Tools, Heidelberg, } \\
\text { Deutschland }\end{array}$ \\
\hline
\end{tabular}

\subsection{Computersoftware}

Tabelle 4: Computersoftware

\begin{tabular}{|c|c|c|}
\hline Software & Verwendungszaweck & Hersteller \\
\hline $\begin{array}{l}\text { cellSens dimension 1.15- } \\
1.16\end{array}$ & $\begin{array}{l}\text { Erstellung und Konvertie- } \\
\text { rung von Bilddateien }\end{array}$ & $\begin{array}{l}\text { Olympus Deutschland } \\
\text { GmbH, Hamburg, } \\
\text { Deutschland }\end{array}$ \\
\hline ImageJ-(64bit)/Fiji & $\begin{array}{l}\text { Messung des Läsionsareals } \\
\text { und Quantifizierung der } \\
\text { Zellen }\end{array}$ & $\begin{array}{l}\text { National Institutes of } \\
\text { Health, Bethesda, USA }\end{array}$ \\
\hline Microsoft Office Excel & $\begin{array}{l}\text { Tabellarische Erfassung der } \\
\text { Quantifizierungen }\end{array}$ & $\begin{array}{l}\text { Microsoft Corporation, } \\
\text { Redmond, USA }\end{array}$ \\
\hline GraphPad Prism 5 & $\begin{array}{l}\text { Statistische Analyse und } \\
\text { Erstellung von Diagrammen } \\
\text { und Graphen }\end{array}$ & $\begin{array}{l}\text { GraphPad software Inc., } \\
\text { La Jolla, USA }\end{array}$ \\
\hline Corel Draw X3 & $\begin{array}{l}\text { Erstellung und Bearbeitung } \\
\text { von Grafiken und } \\
\text { Abbildungen }\end{array}$ & $\begin{array}{l}\text { Corel GmbH, München, } \\
\text { Deutschland }\end{array}$ \\
\hline
\end{tabular}




\subsection{Apparative Hilfsmittel und Geräte}

Tabelle 5: Apparative Hilfsmittel und Geräte

\begin{tabular}{|l|l|}
\hline Bezeichnung & Hersteller \\
\hline Dampfgarer FS 3000 & Braun, FS 3000, De'Longhi Deutschland GmbH \\
\hline Färbekammer & Sonderanfertigung für die Neuropathologie an der UMG \\
\hline $\begin{array}{l}\text { Gewebeinfiltrationsautomat } \\
\text { Automatic Tissue Processor } \\
\text { TP 1020 }\end{array}$ & Leica® Microsystems, Wetzlar, Deutschland \\
\hline Mikrotom & Leica® Microsystems, Wetzlar, Deutschland \\
\hline $\begin{array}{l}\text { Fluoreszenz-Mikroskop BX- } \\
41\end{array}$ & Olympus Deutschland GmbH, Hamburg, Deutschland \\
\hline $\begin{array}{l}\text { Scanner für Mikroskop-Ob- } \\
\text { jektträger VS120 }\end{array}$ & Olympus Deutschland GmbH, Hamburg, Deutschland \\
\hline
\end{tabular}

\subsection{Reagenzien}

Tabelle 6: Reagenzien

\begin{tabular}{|c|c|}
\hline Reagenz & Hersteller \\
\hline Citronensäure-Monohydrat & Merck Millipore, Darmstadt, Deutschland \\
\hline $\begin{array}{l}4^{\prime}, 6 \text {-diamidino-2‘-phenylindole dihydro- } \\
\text { chlorid (DAPI) }\end{array}$ & $\begin{array}{l}\text { Sigma-Aldrich Chemie GmbH, Steinheim, } \\
\text { Deutschland }\end{array}$ \\
\hline Ethylendiamintetraessigsäure (EDTA) & $\begin{array}{l}\text { Carl Roth GmbH \& Co. KG, Karlsruhe, } \\
\text { Deutschland }\end{array}$ \\
\hline Ethanol absolute & Merck Millipore, Darmstadt, Deutschland \\
\hline ExtrAvidin $\AA$-Peroxidase & $\begin{array}{l}\text { Sigma-Aldrich Chemie GmbH, Steinheim, } \\
\text { Deutschland }\end{array}$ \\
\hline Fluoromount-G $G^{\text {TM }}$ Mounting medium & $\begin{array}{l}\text { Sigma-Aldrich Chemie GmbH, } \\
\text { Steinheim Deutschland }\end{array}$ \\
\hline Formaldehyd (Formalin) $(37 \%)$ & Merck Millipore, Darmstadt, Deutschland \\
\hline Isopropanol (Chemsolute $\left.{ }^{\circledR}\right)(99,5 \%)$ & $\begin{array}{l}\text { Th. Geyer GmbH \& Co. KG, Renningen, } \\
\text { Deutschland }\end{array}$ \\
\hline Isoxylol (Xylol 1:1 Isopronalol) & $\begin{array}{l}\text { Th. Geyer GmbH \& Co. KG, Renningen, } \\
\text { Deutschland }\end{array}$ \\
\hline Ketamin 10\%, (Medistar $\left.{ }^{\circledR}\right)$ & $\begin{array}{l}\text { Arzneimittel-Vertrieb GmbH, Ascheberg, } \\
\text { Deutschland }\end{array}$ \\
\hline $\mathrm{NaOH}$ (Natriumhydroxid) (1M) & Merck Millipore, Darmstadt, Deutschland \\
\hline Normal goat serum (NGS) & $\begin{array}{l}\text { Sigma-Aldrich Chemie GmbH, Steinheim, } \\
\text { Deutschland }\end{array}$ \\
\hline Paraffin (Paraplast Plus $®)$ & Tyco Healthcare, Neustadt, Deutschland \\
\hline Paraformaldehyd (PFA) & Merck Millipore, Darmstadt, Deutschland \\
\hline Phosphat-gepufferte Salzlösung (PBS) & Biochrom AG, Berlin, Deutschland \\
\hline Tris-(hydroxymethyl)-aminomethan (Tris) & $\begin{array}{l}\text { Carl Roth GmbH \& Co. KG, Karlsruhe, } \\
\text { Deutschland }\end{array}$ \\
\hline Triton $\mathbb{R}$ X-100 & MP Biomedicals, LLC, Santa Ana, USA \\
\hline
\end{tabular}




\begin{tabular}{|c|c|}
\hline Reagenz & Hersteller \\
\hline $\mathrm{H}_{2} \mathrm{O}_{2}$, (Wasserstoffperoxid) (30\%) & $\begin{array}{l}\text { Merck Millipore, Darmstadt, } \\
\text { Deutschland }\end{array}$ \\
\hline Xylazin $(20 \mathrm{mg} / \mathrm{ml})$ & Ecuphar Nv, Oostkamp, Belgien \\
\hline Xylol (Chemsolute $($ ) $)(99,5 \%)$ & $\begin{array}{l}\text { Th. Geyer GmbH \& Co. KG, Renningen, } \\
\text { Deutschland }\end{array}$ \\
\hline
\end{tabular}

\subsection{Primärantikörper}

Tabelle 7: Primärantikörper

\begin{tabular}{|l|c|c|l|l|}
\hline Antigen & $\begin{array}{l}\text { Herkunfts- } \\
\text { spezies }\end{array}$ & Verdünnung & Hersteller & Vorbehandlung \\
\hline Olig2 & Kaninchen & $1: 300$ & $\begin{array}{l}\text { IBL International } \\
\text { GmbH, Hamburg, } \\
\text { Deutschland }\end{array}$ & $\begin{array}{l}\text { Tris/EDTA - } \\
\text { Puffer pH9 }\end{array}$ \\
\hline p25 & Kaninchen & $1: 250$ & $\begin{array}{l}\text { Abcam, Cambridge, } \\
\text { Vereinigtes Königreich }\end{array}$ & $\begin{array}{l}\text { Tris/EDTA- } \\
\text { Puffer pH9 }\end{array}$ \\
\hline Nkx2.2 & Maus & $1: 50$ & $\begin{array}{l}\text { University of Iowa, } \\
\text { Iowa city, USA }\end{array}$ & $\begin{array}{l}\text { Tris/EDTA- } \\
\text { Puffer pH9 }\end{array}$ \\
\hline Sox10 & Maus & $1: 50$ & $\begin{array}{l}\text { Novus Biologicals, } \\
\text { Centennial, USA }\end{array}$ & Citrat-Puffer pH6 \\
\hline MBP & Ratte & $1: 200$ & $\begin{array}{l}\text { Abcam, Cambridge, } \\
\text { Vereinigtes Königreich }\end{array}$ & Citrat-Puffer pH6 \\
\hline
\end{tabular}

\subsection{Sekundärantikörper}

Tabelle 8: Sekundärantikörper

\begin{tabular}{|c|c|c|c|}
\hline Bezeichnung & $\begin{array}{l}\text { Herkunfts- } \\
\text { spezies }\end{array}$ & Verdünnung & Hersteller \\
\hline $\begin{array}{l}\text { (biotinyliert)-anti-Kanin- } \\
\text { chen-Ak }\end{array}$ & Ziege & $1: 250$ & $\begin{array}{l}\text { DIANOVA GmbH, } \\
\text { Hamburg, Deutschland }\end{array}$ \\
\hline $\begin{array}{l}\text { Alexa Fluor }{ }^{\circledR-488-a n t i-} \\
\text { Kaninchen-Ak }\end{array}$ & Ziege & $1: 100$ & $\begin{array}{l}\text { Invitrogen/Fisher } \\
\text { Scientfic, Waltham, USA }\end{array}$ \\
\hline $\mathrm{Cy}^{\mathrm{TM}} 3$-anti-Maus-Ak & Ziege & 1:100 & $\begin{array}{l}\text { Jackson Immuno Research } \\
\text { Laboratories, } \\
\text { Inc., West Grove, USA }\end{array}$ \\
\hline $\mathrm{Cy}^{\mathrm{TM}} 3$-anti-Maus- $\mathrm{Ak}$ & Ziege & $1: 100$ & $\begin{array}{l}\text { Jackson Immuno Research } \\
\text { Laboratories, } \\
\text { Inc., West Grove, USA }\end{array}$ \\
\hline $\begin{array}{l}\text { Alexa Fluor }{ }^{\circledR-647-a n t i-} \\
\text { Ratte-Ak }\end{array}$ & Ziege & 1:100 & $\begin{array}{l}\text { Abcam, Cambridge, Verei- } \\
\text { nigtes Königreich }\end{array}$ \\
\hline
\end{tabular}

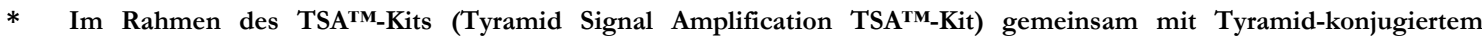
Fluoreszenzfarbstoff Alexa Fluor ${ }^{\circledR}$ - 555 (1:100), Invitrogen/Fisher Scientfic, Waltham, USA) verwendet 


\section{Ergebnisse}

\subsection{Analysen von MS-Biopsien}

Wie unter 2.1.1 bereits näher beschrieben, wurde hier Biopsiegewebe von Patienten mit einer entzündlichen Demyelinisierung, welche mit einer MS im Frühstadium vereinbar ist, untersucht. Zur Detektion und Unterscheidung von Zellen der oligodendroglialen Reihe und deren Subpopulationen wurden die oligodendrozytenspezifischen Marker Sox10, Nkx2.2 und p25 genutzt (siehe 2.3.3).

Durch die Färbung des myelinspezifischen Markers MBP (basisches Myelinprotein) wurde die Myelinisierung des untersuchten Biopsates beurteilt. Anhand der MBP-Färbung wurde das Gewebe dann in Demyelinisierungszonen (bzw. Läsionen), periläsionale Areale sowie normal myelinisiertes Gewebe (normal appearing white matter, NAWM) unterteilt. Es wurden in allen drei Arealen Zellen mit den möglichen Markerkonstellationen Sox $10^{+} / \mathrm{p} 25^{+}$, Sox $10^{+} / \mathrm{p} 25^{-}$und Sox $10^{-} / \mathrm{p} 25^{+}$bzw. Nkx2.2 $/ \mathrm{p} 25^{+}, \mathrm{Nkx} 2.2^{+} / \mathrm{p} 25^{-}$und $\mathrm{Nkx} 2.2^{-} / \mathrm{p} 25^{+}$quantifiziert. Die Markerkombination lässt dabei Rückschlüsse auf das Entwicklungsstadium der Oligodendrozyten zu.

Zur Beurteilung, ob die beobachteten Unterschiede statistisch signifikant sind, wurde eine zwei-faktorielle Varianzanalyse (2-way-ANOVA) mit Hilfe der Software GraphPad Prism durchgeführt. Die errechneten Signifikanzniveaus bzw. P-Werte werden in den Abbildungen durch die Anzahl der Sternchen $\left(^{*}\right)$ ausgedrückt ( $(*=\mathrm{P} \leq 0,05),(* *=\mathrm{P} \leq 0,01),(* * *=\mathrm{P} \leq$ $0,001),(* * * *=\mathrm{P} \leq 0,0001))$.

\subsubsection{Sox10}

Es wurden Biopsate von n=9 Patienten ausgewertet (7 Frauen / 2 Männer; Altersmedian 35 $\pm 17,8$ Jahre). Die Resultate sind in Abbildung 4 dargestellt.

Die Gesamtdichte von Zellen der oligodendroglialen Reihe (Sox $10^{+} / \mathrm{p} 25^{+}$, Sox $10^{+/} \mathrm{p} 25^{-}$oder Sox $10^{-} / \mathrm{p} 25^{+}$) betrug im Läsionsareal 315,5 $\pm 229,3$ Zellen $/ \mathrm{mm}^{2}$, im Periläsionsareal 261,8 $\pm 240,8$ Zellen $/ \mathrm{mm}^{2}$ und in der NAWM 365,9 $\pm 410,2$ Zellen $/ \mathrm{mm}^{2}$.

Wie in Abbildung 4g abgebildet, war ein signifikanter Unterschied in der Dichte von Sox $10^{+/}$p $25^{+}$doppelpositiven Zellen im Vergleich von NAWM zur Läsion $(\mathrm{P} \leq 0,001)$ bzw. Periläsion ( $\mathrm{P} \leq 0,001)$ erkennbar (zwei-faktorielle Varianzanalyse (2-way-ANOVA)). Die Dichte von Sox $10^{+} / \mathrm{p} 25^{+}$-Zellen betrug 621,2 $\pm 59,3$ Zellen $/ \mathrm{mm}^{2}(\mathrm{n}=6)$ im Läsionsareal, 596,6 $\pm 43,3$ Zellen $/ \mathrm{mm}^{2}(\mathrm{n}=8)$ im Periläsionsareal und 944,8 $\pm 128,3$ Zellen $/ \mathrm{mm}^{2}(\mathrm{n}=9)$ in der NAWM. Somit zeigte sich eine signifikante Abnahme p25-positiver Oligodendrozyten, welche gleichzeitig Sox10 exprimieren $\left(\operatorname{Sox} 10^{+} / \mathrm{p} 25^{+}\right)$von der NAWM über die Periläsion zu Läsion. 
Die Dichte von Sox10 $/$ p25 einfach positiven Zellen betrug im Läsionsareal 256,4 $\pm 24,9$ Zellen $/ \mathrm{mm}^{2}(\mathrm{n}=8)$, im Periläsionsareal 148,5 $\pm 19,4$ Zellen $/ \mathrm{mm}^{2}(\mathrm{n}=6)$ und in der NAWM 108,5 $\pm 15,5$ Zellen $/ \mathrm{mm}^{2}(\mathrm{n}=9)$. Es bestand somit visuell eine Tendenz zu einer erhöhten zellulären Dichte von Sox $10^{+} / \mathrm{p} 25^{-}$oligodendroglialen Vorläuferzellen im Läsionsareal, welche jedoch keine statistische Signifikanz erreichte (Abbildung 4g).

Die Dichte von Sox $10^{-} / \mathrm{p} 25^{+}$einfach positiven Oligodendrozyten betrug im Läsionsareal 68,9 $\pm 15,1$ Zellen $/ \mathrm{mm}^{2}(\mathrm{n}=8)$, im Periläsionsareal 40,4 $\pm 17,9$ Zellen $/ \mathrm{mm}^{2}(\mathrm{n}=6)$ und in der NAWM 44,3 $\pm 12,7$ Zellen $/ \mathrm{mm}^{2}$ ( $\mathrm{n}=9$ ). Für diese Zellpopulation konnte kein signifikanter Unterschied zwischen den untersuchten Arealen festgestellt werden (Abbildung 4g).

Der prozentuale Gesamtanteil für Sox $10^{+} / \mathrm{p} 25^{+}$-Zellen betrug $84,9 \%$ in der NAWM, 76,2\% in Periläsionsareal und 65,5\% im Läsionsareal. Einfach positive Sox $10^{+} / \mathrm{p} 25-$ Zellen machten einen prozentualen Gesamtanteil von 11,0\% in der NAWM, 18,8\% im Periläsionsareal und $5,0 \%$ im Läsionsareal aus. Für einfach positive Sox $10^{-} / \mathrm{p} 25^{+}$-Zellen konnte ein prozentualer Gesamtanteil von 4,1\% in NAWM, 5,0\% in der Periläsion und 7,2\% im Läsionsareal ermittelt werden. Somit nahm der Anteil von Sox $10^{+} / \mathrm{p} 25^{+}$doppelpositiven Zellen von der Läsion über die Periläsion zur NAWM zu (Abbildung 4h). 


\section{HUMAN Sox10 / p25 / MBP / DAPI}
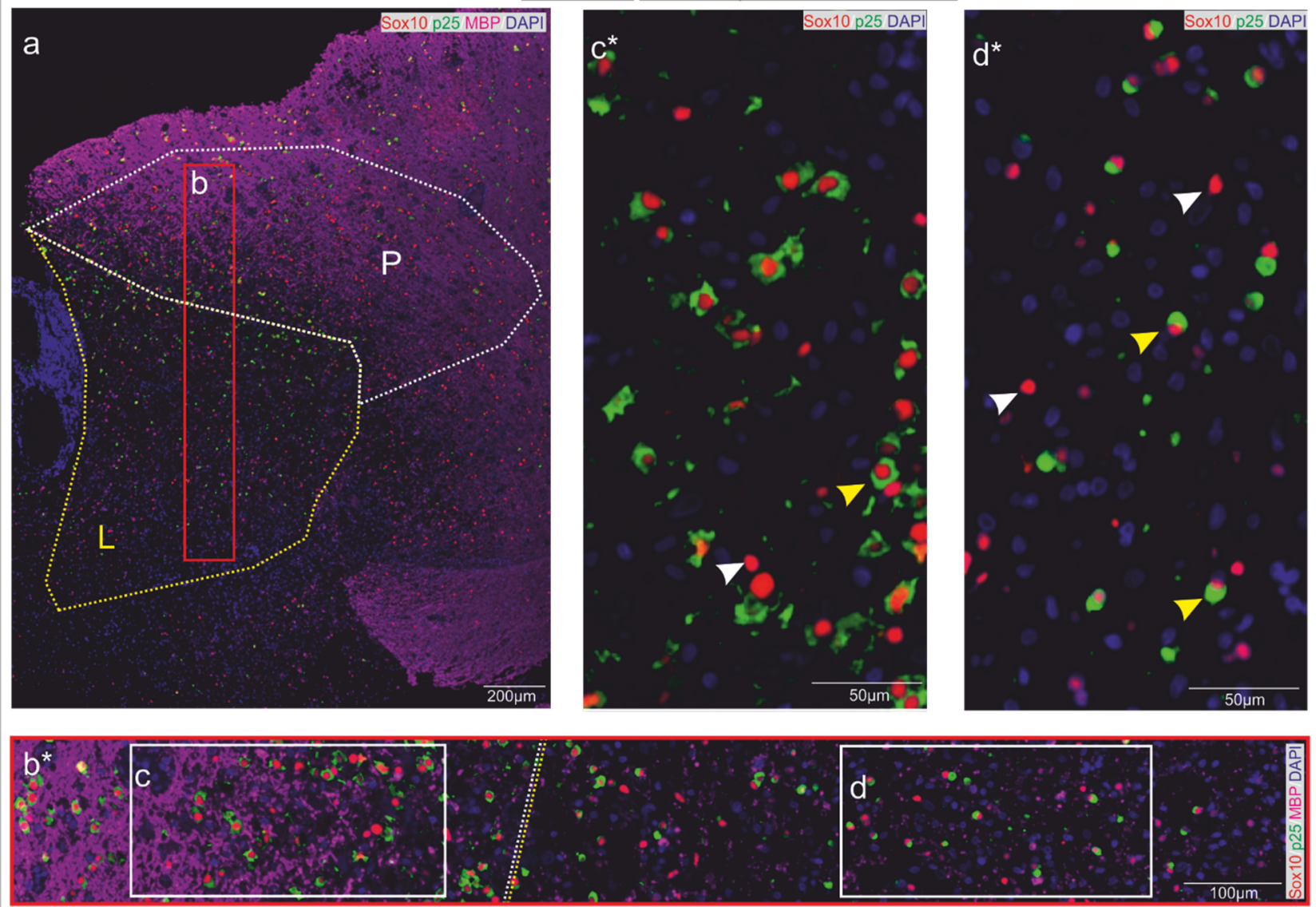

Periläsion

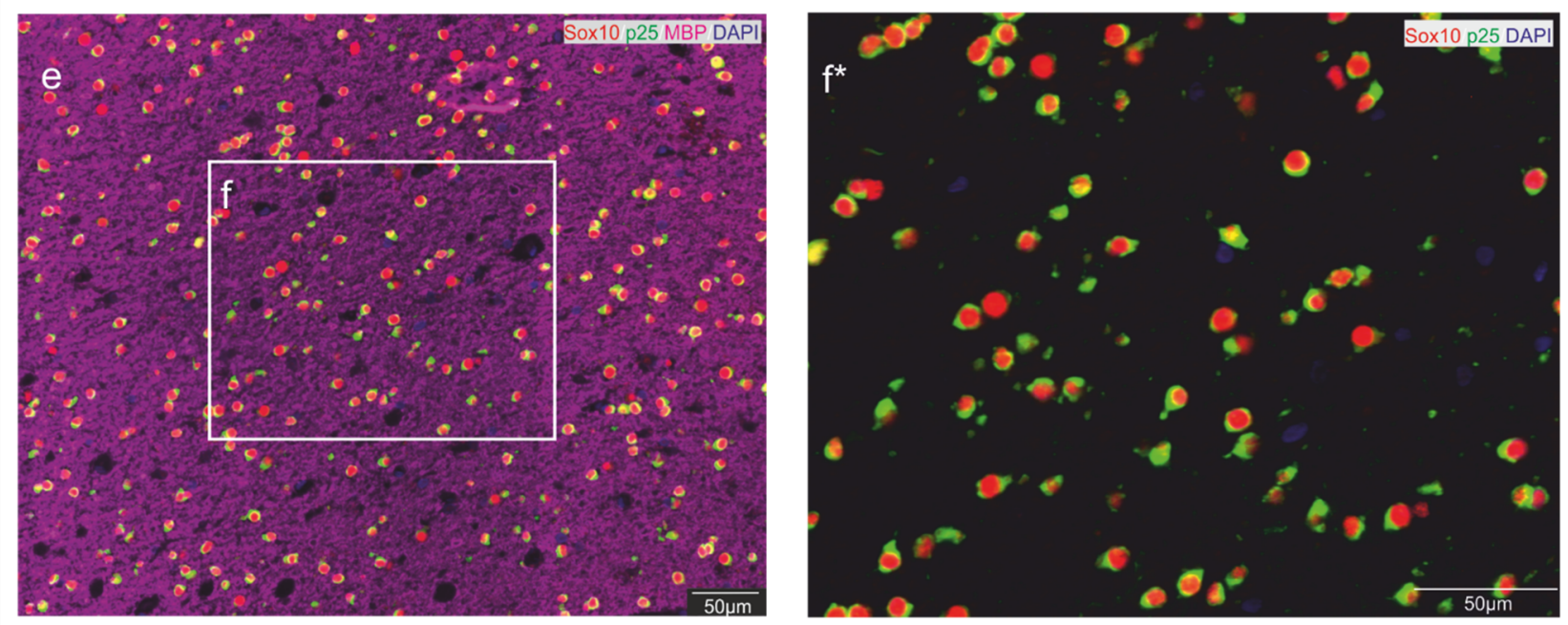

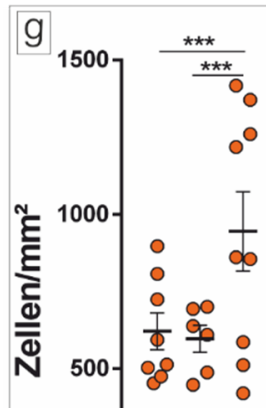

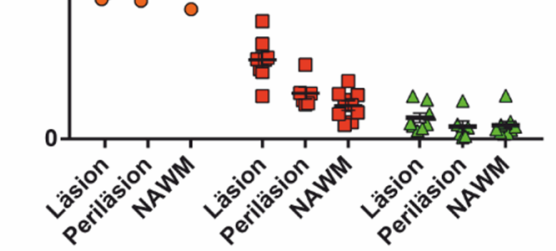

- Sox10+p25+ $\square$ Sox10+p25- $\Delta$ Sox10-p25+
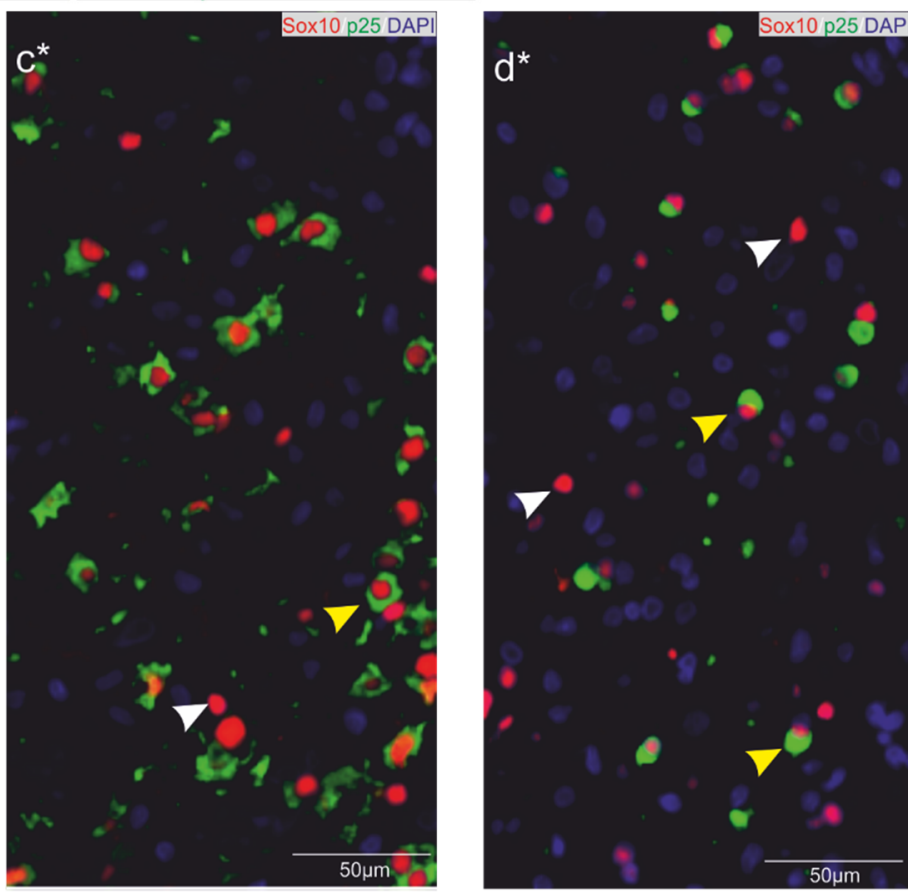

Läsion h NAWM

Periläsion

Läsion

0,0

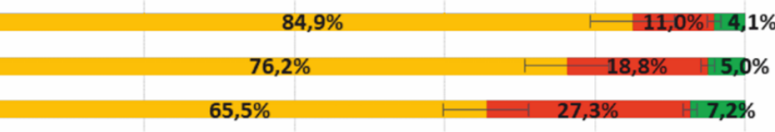

40,0

60,0

80,0

100,0 Gesamtverteilung in Prozent

a Sox10+p25+ $\square$ Sox10+p25- $=$ Sox10-p25+

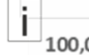

50,0

Läsion Periläsion NAWM

- $[$ Sox 10$]$ p25+ E[Sox10] p25-
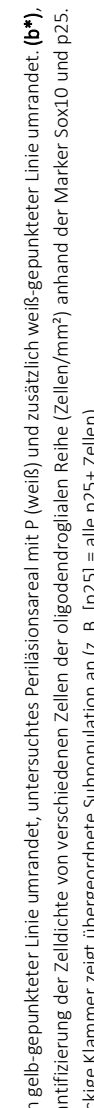

穿 可

空

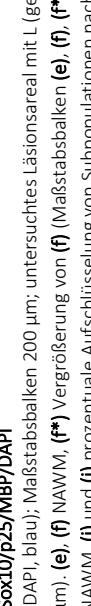

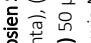

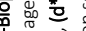

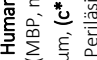

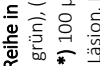

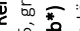

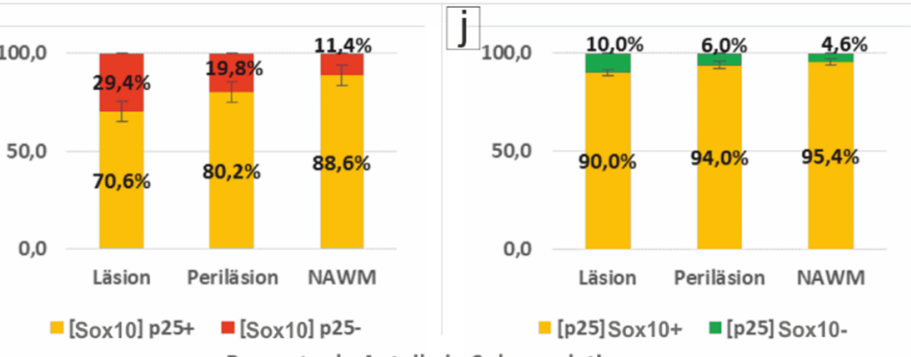




\subsubsection{Nkx2.2}

Es wurden Biopsate von $n=7$ Patienten ausgewertet (6 Frauen / 1 Mann; Altersmedian 38 $\pm 14,9$ Jahre).

Die Gesamtdichte von Zellen der oligodendroglialen Reihe $\left(\mathrm{Nkx} 2.2^{+/} \mathrm{p} 25^{+}\right.$, Nkx2.2 $22^{+/} 25^{-}$ und $\mathrm{Nkx} 2.2^{-} / \mathrm{p} 25^{+}$) betrug im Läsionsareal 217,2 $\pm 14,7$ Zellen $/ \mathrm{mm}^{2}$, im Periläsionsareal $311,6 \pm 153,1$ Zellen $/ \mathrm{mm}^{2}$ und in NAWM 305,1 $\pm 257,8$ Zellen $/ \mathrm{mm}^{2}$.

Hier war ein Gradient für doppelt positive Nkx2.2 $/ \mathrm{p} 25^{+}$-Zellen angedeutet, in welchem die Dichte vom Läsionsareal über Periläsionsareal zu NAWM zunahm (Abbildung 5f). Statistische Signifikanz $(\mathrm{P} \leq 0,01)$ wurde jedoch lediglich für den Unterschied zwischen der Dichte im Läsionsareal 198,3 $\pm 73.4(\mathrm{n}=7)$ und NAWM 665,2 $\pm 67,2$ Zellen $/ \mathrm{mm}^{2}(\mathrm{n}=3)$ erreicht (zwei-faktorielle Varianzanalyse (2-way-ANOVA)). Im Periläsionsareal bestand für Nkx2.2 $/$ p25-Oligodendrozyten eine Dichte von 523,2 $\pm 32,9$ Zellen $/ \mathrm{mm}^{2}(\mathrm{n}=3)$.

Die Dichte von einfach positiven Nkx2.2 / p25-Zellen betrug im Läsionsareal 234,1 \pm 106,9 Zellen $/ \mathrm{mm}^{2}(\mathrm{n}=7)$, im Periläsionsareal 245,7 $\pm 66,9$ Zellen $/ \mathrm{mm}^{2}(\mathrm{n}=3)$ und in der NAWM 174,6 $\pm 58,0$ Zellen $/ \mathrm{mm}^{2}(\mathrm{n}=3)$. Somit bestand zwischen den Arealen kein signifikanter Unterschied.

Die Dichte von einfach positiven Nkx2.2/ $25^{+}$-Zellen betrug im Läsionsareal 219,2 $\pm 91,4$ Zellen $/ \mathrm{mm}^{2}(\mathrm{n}=7)$, im Periläsionsareal 166,0 $\pm 56,3$ Zellen $/ \mathrm{mm}^{2}(\mathrm{n}=3)$ und in der NAWM 75,6 $\pm 1,0$ Zellen $/ \mathrm{mm}^{2}(\mathrm{n}=3)$. Hier bestand eine visuelle Tendenz zu erhöhter zellulärer Dichte von Nkx2.2/p25 -Oligodendrozyten im Läsionsareal, welche jedoch keine statistische Signifikanz aufwies.

Der prozentuale Gesamtanteil von Nkx2.2 $/ \mathrm{p} 25^{+}$-Zellen betrug 72,6\% in NAWM, 56,6\% im Periläsionsareal und nur 28,1\% im Läsionsareal. Einfach positive Nkx2.2 /p25-Oligodendrozyten machten einen prozentualen Gesamtanteil von 19,1\% in NAWM, 25,8\% im Periläsionsareal und 31,3\% im Läsionsareal aus. Für einfach positive Nkx2.2 /p25 -Zellen konnte ein prozentualer Gesamtanteil von 8,3\% in NAWM, 17,6\% im Periläsionsareal und 40,5\% im Läsionsareal ermittelt werden. 


\section{HUMAN Nkx2.2 / p25 / MBP / DAPI}
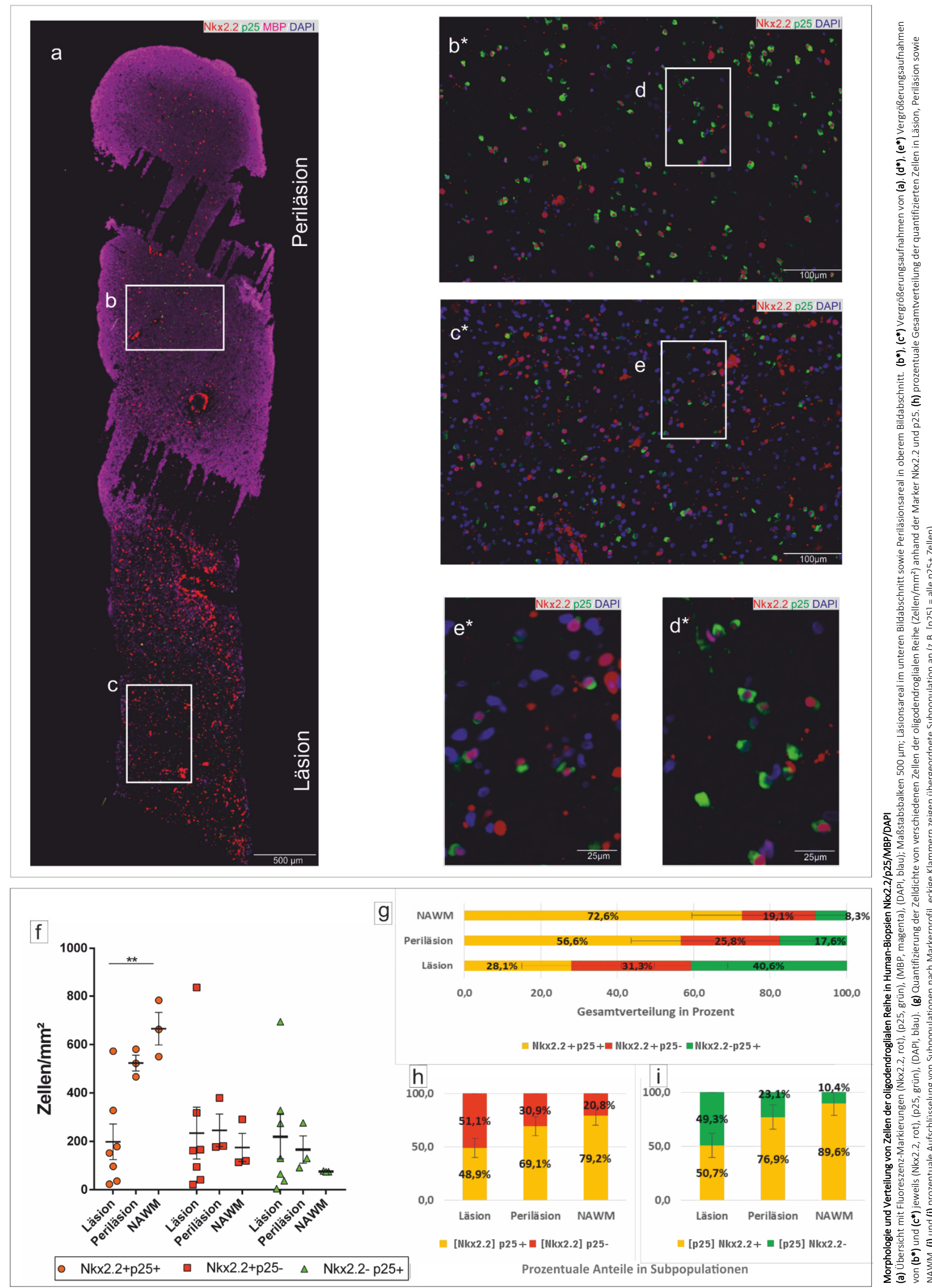

Abbildung 5: Human-Biopsie Nkx2.2/p25/MBP/DAPI 


\subsection{Analysen tierexperimentell erzeugter Gewebeproben}

Im Folgenden werden Zellen der oligodendroglialen Reihe durch die Färbung der oligodendrozytenspezifischen Marker Olig2 und p25 in verschiedenen Mausmodellen untersucht. Der myelinspezifische Marker MBP wurde auch hier zur Einteilung des Gewebes in Läsion, Periläsion und NAWM genutzt.

Gewebeproben der Mäuse, welche im Rahmen der toxischen Induktion einer Demyelinisierung mittels Cuprizon untersucht wurden, stammten aus den Corpora callosa der Tiere. Es erfolgte eine Gruppierung in Tiere nach zwei- und vierwöchiger Cuprizon-Aufnahme. Mikroskopisch optisch intaktes Gewebe im Sinne von NAWM wurde ebenfalls analysiert.

Gewebeproben der Mäuse, welche im Rahmen der autoimmunvermittelten Demyelinisierung (EAE-Modell) gewonnen wurden, entstammten aus dem Rückenmark der Tiere und wurden ebenfalls in zwei Gruppen entsprechend einer Früh- (Erkrankungsdauer 1-5 Tage) und einer Spätphase (Erkrankungsdauer 6-24 Tage) unterteilt. Optisch unbeschädigtes Rückenmarksgewebe wurde als NAWM mit in die Analyse einbezogen.

Weiterhin wurden Corpora callosa und das Rückenmark von gesunden Kontrolltieren untersucht.

\subsubsection{Cuprizon-Modell Frühphase (2 Wochen)}

Die Dichte von Zellen der oligodendroglialen Reihe (Olig2 ${ }^{+} / \mathrm{p}^{2} 5^{+}$, Olig2 ${ }^{+} / \mathrm{p} 25^{-}$, Olig2 $/ \mathrm{p} 25^{+}$) betrug in gesundem Kontrollgewebe $792,1 \pm 732,5$ Zellen $/ \mathrm{mm}^{2}$, in der Läsion 553,3 $\pm 506,2$ Zellen $/ \mathrm{mm}^{2}$, in der Periläsion 586,6 $\pm 538,4$ Zellen/ $\mathrm{mm}^{2}$ und in der NAWM 465,1 $\pm 336,6$ Zellen $/ \mathrm{mm}^{2}$.

Wie in Abbildung 6c abgebildet, bestand ein signifikanter Unterschied in der Dichte von Olig2 $2^{+} / \mathrm{p} 25^{+}$-Zellen $(\mathrm{P} \leq 0,0001)$ und einfach positiven Olig2 $/ \mathrm{p} 25^{+}$-Oligodendrozyten $(\mathrm{P} \leq$ 0,0001) nur im direkten Vergleich zu gesundem Kontrollgewebe (zwei-faktorielle Varianzanalyse (2-way-ANOVA)). Dabei waren es mehr Olig2 $2^{+} / \mathrm{p} 25^{+}$-Zellen und weniger einfach positive Olig2 $/ \mathrm{p} 25^{+}$-Zellen im gesunden Tier als in der erkrankten Maus, nach zwei Wochen Cuprizon-Aufnahme.

Die Dichte von Olig2 ${ }^{+} / \mathrm{p}^{2} 5^{+}$-Zellen in der Kontrolle lag bei 1820,8 \pm 59.5 Zellen $/ \mathrm{mm}^{2}$ ( $\mathrm{n}=13) \mathrm{im}$ Gegensatz zu 280,2 $\pm 126,7$ Zellen $/ \mathrm{mm}^{2}$ (n=3) im Läsionsareal, 256,9 $\pm 101,5$ Zellen $/ \mathrm{mm}^{2}(\mathrm{n}=3)$ im Periläsionsareal und 310,8 $\pm 59,0$ Zellen $/ \mathrm{mm}^{2}(\mathrm{n}=7)$ in der NAWM.

Die Dichte einfach positiver Olig2 $/ \mathrm{p} 25$-Zellen wies keinen signifikanten Unterschied auf und betrug in der Kontrolle 171,2 $\pm 16,63$ Zellen $/ \mathrm{mm}^{2}$ ( $\left.\mathrm{n}=13\right), 116,2 \pm 19,8$ Zellen $/ \mathrm{mm}^{2}$ $(\mathrm{n}=3)$ im Läsionsareal, 157,2 $\pm 29,2$ Zellen $/ \mathrm{mm}^{2}(\mathrm{n}=3)$ im Periläsionsareal und 152,3 $\pm 27,0$ Zellen $/ \mathrm{mm}^{2}(\mathrm{n}=7)$ in der NAWM. 
Die Dichte einfach positiver Olig2 / p25 -Zellen im Kontrollgewebe lag bei 383,4 \pm 38 , 2 Zellen $/ \mathrm{mm}^{2}(\mathrm{n}=13) \mathrm{im}$ Gegensatz zu 1262,9 $\pm 336,2$ Zellen $/ \mathrm{mm}^{2}(\mathrm{n}=3)$ im Läsionsareal, 1245,9 $\pm 271,7$ Zellen $/ \mathrm{mm}^{2}(\mathrm{n}=3)$ im Periläsionsareal und 932,2 $\pm 123,3$ Zellen $/ \mathrm{mm}^{2}(\mathrm{n}=7)$ in der NAWM.

Der prozentuale Gesamtanteil von Olig2 $2^{+} / \mathrm{p} 25^{+}$-Zellen betrug $76,7 \%$ in der Kontrolle, 21,6\% in der NAWM, 16,0\% im Periläsionsareal und 19,6\% im Läsionsareal. Einfach positive Olig2 $2^{+} / \mathrm{p} 25$-Oligodendrozyten machten einen prozentualen Gesamtanteil von 7,3\% in der Kontrolle, 10,8\% in der NAWM, 9,0\% im Periläsionsareal und 7,3\% im Läsionsareal aus. Für einfach positive Olig2 / $25^{+}$-Zellen konnte ein prozentualer Gesamtanteil von 16,0\% in der Kontrolle, 67,7\% in der NAWM, 75,0\% im Periläsionsareal und 73,1\% im Läsionsareal ermittelt werden. 


\section{Cuprizon Woche 2 Olig2/ p25/MBP/DAP}
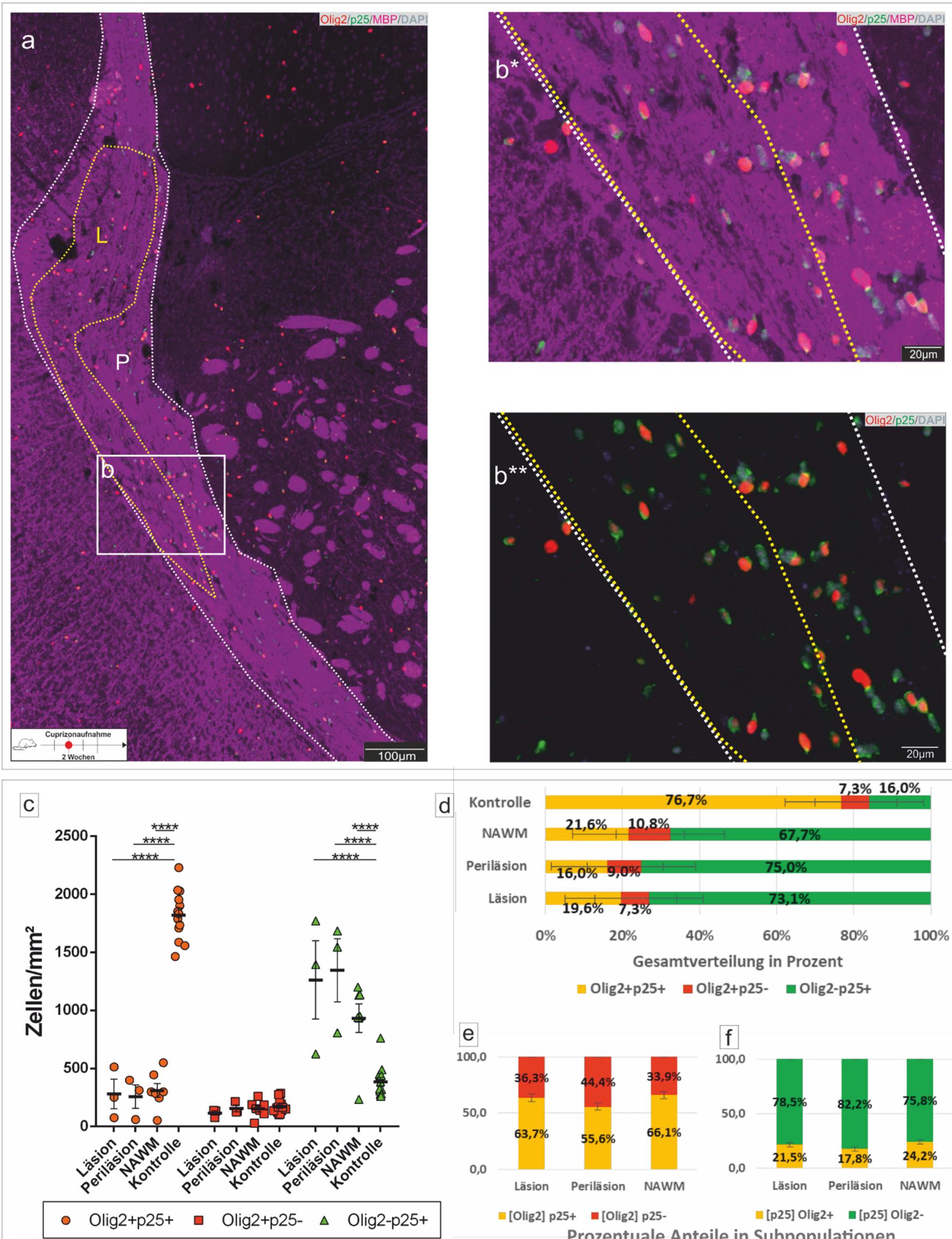

口 Olig2+p25+ =Olig2+p25- a Olig2-p25+

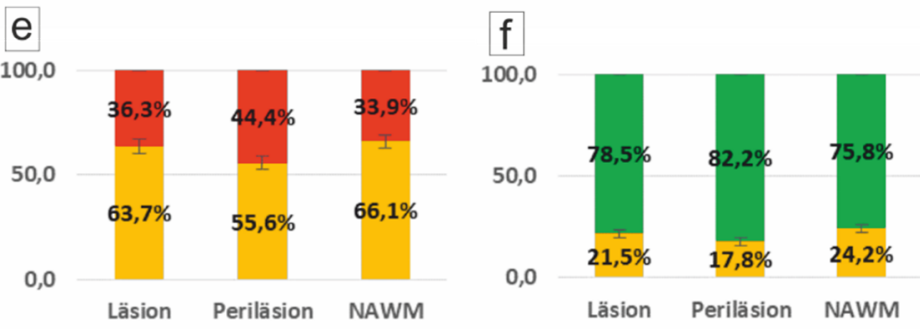

- [Olig2] p25+ $\quad$ [Olig2] p25-

[p25] Olig2+ $\quad$ [p25] Olig2-

Prozentuale Anteile in Subpopulationen

\section{Abbildung 6: Cuprizon-Modell Woche 2 Olig2/p25/MBP/DAPI}

Morphologie und Verteilung von Zellen der oligodendroglialen Reihe im Corpus callosum von C57BL/6 - Mäusen nach 2 Wochen Cuprizon-Aufnahme über die Nahrung

(a) Übersicht mit Fluoreszenz-Markierungen (Olig2, rot), (p25, grün), (MBP, magenta), (DAPI, hellblau); Maßstabsbalken 100 m; untersuchtes Läsionsareal mit L (gelb) und zusätzlich gelb-gepunkteter Linie umrandet, untersuchtes Periläsionsareal (bzw. Begrenzung Corpus callosum) mit P (weiß) und zusätzlich weiß-gepunkteter Linie umrandet. (b*), (b**) Vergrößerungen von (b). (c) Quantifizierung der Zelldichte von verschiedenen Zellen der oligodendroglialen Reihe (Zellen/ $\mathrm{mm}^{2}$ ) anhand der Marker Olig2 und p25. (d) prozentuale Gesamtverteilung der quantifizierten Zellen in Läsion, Periläsion sowie NAWM. (e) und (f) prozentuale Aufschlüsselung von Subpopulationen nach Markerprofil, eckige Klammern zeigt übergeordnete Subpopulation an (z.B. [p25] = alle p25+ Zellen). 


\subsubsection{Cuprizon-Modell Spätphase (4 Wochen)}

Die Gesamtdichte von Zellen der oligodendroglialen Reihe $\left(\mathrm{Olig}^{+} / \mathrm{p} 25^{+}\right.$, Olig2 $/ \mathrm{p} 25^{-}$, Olig2 $/ \mathrm{p}^{+} 5^{+}$) betrug in gesundem Kontrollgewebe 792,1 $\pm 732,5$ Zellen $/ \mathrm{mm}^{2}$, im Läsionsareal 376,3 $\pm 81,8$ Zellen $/ \mathrm{mm}^{2}$, im Periläsionsareal 429,0 $\pm 123,1$ Zellen $/ \mathrm{mm}^{2}$ und in der NAWM 465,1 $\pm 336,6$ Zellen $/ \mathrm{mm}^{2}$.

Die Dichte von Olig2 ${ }^{+} / \mathrm{p} 25^{+}$-Oligodendrozyten im Kontrollgewebe lag bei 1820,8 $\pm 59,5$ Zellen/ $\mathrm{mm}^{2}$ ( $\left.\mathrm{n}=13\right)$, im Gegensatz zu 272,3 $\pm 133,5$ Zellen $/ \mathrm{mm}^{2}(\mathrm{n}=5)$ im Läsionsareal, $518,8 \pm 177,8$ Zellen $/ \mathrm{mm}^{2}(\mathrm{n}=5)$ im Periläsionsareal und 310,8 $\pm 59,0$ Zellen $/ \mathrm{mm}^{2}(\mathrm{n}=7)$ in NAWM. Somit zeigte sich im Kontrollgewebe eine signifikant höhere Dichte von $\mathrm{Olig}^{+} / \mathrm{p} 25^{+}$-Oligodendrozyten im Vergleich zum Läsionsareal $(\mathrm{P} \leq 0,0001)$, Periläsionsareal $(\mathrm{P} \leq 0,0001)$ und der NAWM $(\mathrm{P} \leq 0,0001)$ (zwei-faktorielle Varianzanalyse (2-way-ANOVA)) (Abbildung 7g). Dies deckte sich mit den Resultaten aus der Frühphase der Cuprizon-Behandlung.

Im Gegensatz zur Frühphase zeigte sich nach vier Wochen Cuprizon-Aufnahme jedoch eine signifikante Erhöhung in der Dichte einfach positiver Olig2 $/$ p25-Oligodendrozyten im Läsionsareal mit 472,2 $\pm 42,0$ Zellen $/ \mathrm{mm}^{2}(\mathrm{n}=5)$ im Vergleich zu 152,3 $\pm 27,0$ Zellen $/ \mathrm{mm}^{2}$ $(\mathrm{n}=7)$ in der NAWM $(\mathrm{P} \leq 0,05)$ und 171,2 $\pm 16,63$ Zellen $/ \mathrm{mm}^{2}(\mathrm{n}=13)$ in gesundem Kontrollgewebe $(\mathrm{P} \leq 0,05)$ (zwei-faktorielle Varianzanalyse (2-way-ANOVA)). Die Dichte von Olig $2^{+} /$p25-Oligodendrozyten betrug im Periläsionsareal 255,0 $\pm 25,2$ Zellen $/ \mathrm{mm}^{2}(n=5)$ und wies keinen statistisch signifikanten Unterschied zu den anderen Untersuchungsarealen auf.

Die Dichte von einfach positiven Olig2 $/ \mathrm{p} 25^{+}$-Oligodendrozyten im gesunden Kontrollgewebe lag bei 383,4 $\pm 38,2$ Zellen $/ \mathrm{mm}^{2}(\mathrm{n}=13)$ im Gegensatz zu 384,5 $\pm 89,0$ Zellen/ $\mathrm{mm}^{2}$ $(\mathrm{n}=5)$ im Läsionsareal, 513,3 $\pm 108,5$ Zellen $/ \mathrm{mm}^{2}(\mathrm{n}=5)$ im Periläsionsareal und 932,2 $\pm 123,3$ Zellen $/ \mathrm{mm}^{2}\left(\mathrm{n}=7\right.$ ) in der NAWM. Die Dichte von einfach positiven Olig2 $/ \mathrm{p} 25^{+}$Oligodendrozyten nahm somit auf ein mit dem Kontrollgewebe vergleichbares Niveau ab und lag nun sowohl in Läsionsareal $(\mathrm{P} \leq 0,0001)$, Periläsionsareal $(\mathrm{P} \leq 0,01)$ und Kontrollgewebe $(\mathrm{P} \leq 0,0001)$ signifikant niedriger als in der NAWM (zwei-faktorielle Varianzanalyse (2-way-ANOVA)).

Der prozentuale Gesamtanteil betrug für Olig2 $2^{+} / \mathrm{p} 25^{+}$-Zellen 76,7\% in der Kontrolle, 21,6\% in der NAWM, 38,4\% im Periläsionsareal und 21,3\% im Läsionsareal. Einfach positive Olig2 $2^{+}$p25-Oligodendrozyten machen einen prozentualen Gesamtanteil von 7,3\% im Kontrollgewebe, 10,8\% in der NAWM, 20,2\% im Periläsionsareal und 45,0\% im Läsionsareal aus. Für einfach positive Olig2 $/ \mathrm{p} 25^{+}$-Zellen konnte ein prozentualer Gesamtanteil von 16,0\% in der Kontrolle, 67,7\% in der NAWM, 41,3\% im Periläsionsareal und 33,7\% im Läsionsareal ermittelt werden. 
Cuprizon Woche 4 Olig2 / p25 / MBP /
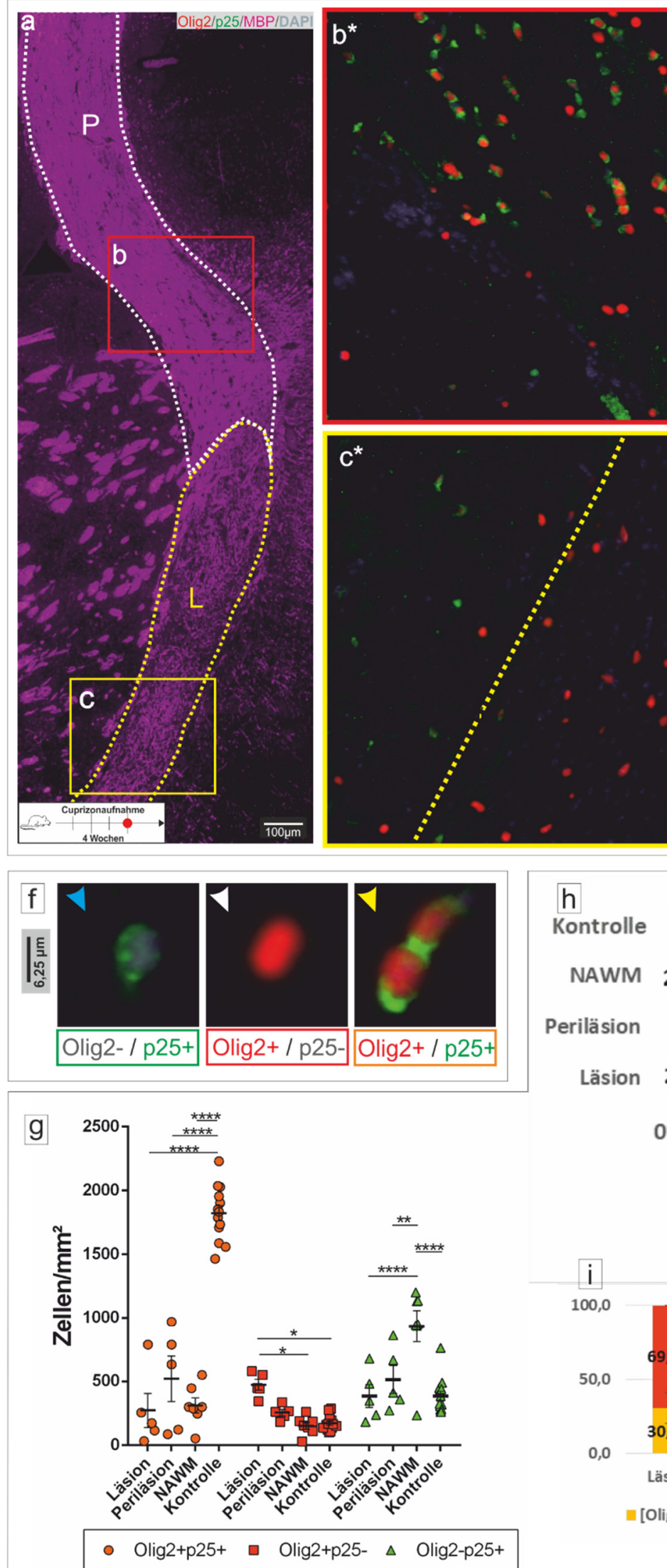

h Kontrolle NAWM

Periläsion Läsion

$0 \%$ $20 \%$

$40 \%$

$60 \%$

$80 \%$

$100 \%$

Gesamtverteilung in Prozent

n Olig2+p25+ $\quad$ Olig2+p25- — Olig2-p25+

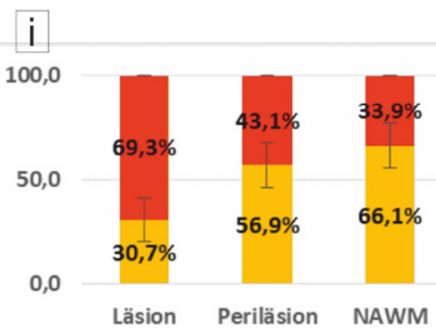

[Olig2] p25+ $\quad$ [Olig2] p25

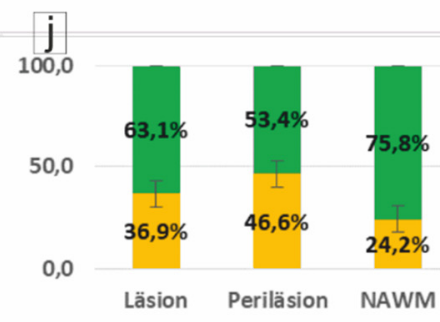

a[p25] Olig2+ $\quad[$ [p25] Olig2-
Prozentuale Anteile in Subpopulationen

\section{Abbildung 7: Cuprizon-Modell Woche 4 Olig2/p25/MBP/DAPI}

Morphologie und Verteilung von Zellen der oligodendroglialen Reihe im Corpus callosum von C57BL/6-Mäusen nach 4 Wochen Cuprizon-Aufnahme über die Nahrung

(a), (d) Übersicht mit Fluoreszenz-Markierungen (Olig2, rot), (p25, grün), (MBP, magenta), (DAPI, hellblau); Maßstabsbalken 100 um; untersuchtes Läsionsareal mit L (gelb) und zusätzlich gelb-gepunkteter Linie umrandet, untersuchtes Periläsionsareal (bzw. Begrenzung Corpus callosum) mit P (weiß) und zusätzlich weiß-gepunkteter Linie umrandet. (b*), (c*) Vergrößerungen von (b), (c). (d) Übersicht mit Fluoreszenz-Markierungen (Olig2, rot), (p25, grün), (MBP, magenta), (DAPI, hellblau); Maßstabsbalken $100 \mu \mathrm{m}$; untersuchtes Läsionsareal mit L (gelb) und zusätzlich gelb-gepunkteter Linie umrandet, untersuchtes Periläsionsareal (bzW. Begrenzung Corpus callosum) mit P (weiß) und zusätzlich weiß-gepunkteter Linie umrandet. ( $\mathbf{e}^{*}$ ) Vergrößerung von (e), gelbe Pfeilspitzen markieren doppelt positive Zellen (Olig2+p25+), weiße Pfeilspitzen markieren nur Olig2-positive Zellen (Olig2+p25-), blaue Pfeilspitzen markieren nur p25-positive Zellen (Olig2-p25+). (f) Übersicht Morphologie und Färbeverhalten der einzelnen Zellpopulationen. (g) Quantifizierung der Zelldichte von verschiedenen Zellen der oligodendroglialen Reihe (Zellen/ $\mathrm{mm}^{2}$ ) anhand der Marker Olig2 und p25. (h) prozentuale Gesamtverteilung der quantifizierten Zellen in Läsion, Periläsion sowie NAWM. (i), (j) prozentuale Aufschlüsselung von Subpopulationen nach Markerprofil, eckige Klammern zeigt übergeordnete Subpopulation an (z.B. [p25] = alle p25+ Zellen). 


\subsubsection{EAE-Modell Frühphase (1-5 Tage)}

Die Gesamtdichte von Zellen der oligodendroglialen Reihe (Olig2 $/ \mathrm{p} 25^{+}$, Olig2 $/ \mathrm{p} 25^{-}$, Olig2 $/ \mathrm{p}^{2} 5^{+}$) betrug in gesundem Kontrollgewebe 482,1 $\pm 338,5$ Zellen $/ \mathrm{mm}^{2}$, im Läsionsareal 214,7 $\pm 37,6$ Zellen $/ \mathrm{mm}^{2}$, im Periläsionsareal 324,6 $\pm 76,2$ Zellen/ $\mathrm{mm}^{2}$ und in der NAWM 308,6 $\pm 75,5$ Zellen $/ \mathrm{mm}^{2}$.

Wie in Abbildung 8c gezeigt, bestand eine signifikante Differenz in der Dichte von Olig2 $2^{+} / \mathrm{p} 25^{+}$-Oligodendrozyten jeweils nur im direkten Vergleich von gesundem Kontrollgewebe zu den anderen Untersuchungsarealen wie Läsionsareal $(\mathrm{P} \leq 0,0001)$, Periläsionsareal $(\mathrm{P} \leq 0,0001)$ und der NAWM $(\mathrm{P} \leq 0,0001)$ (zwei-faktorielle Varianzanalyse (2-way-ANOVA)). Hier lag die Dichte von Olig2 ${ }^{+} / \mathrm{p} 25^{+}$-Oligodendrozyten in der Kontrolle bei 947,5 $\pm 68,1$ Zellen $/ \mathrm{mm}^{2}$ ( $\mathrm{n}=13$ ), im Gegensatz zu 169,6 $\pm 72,9$ Zellen $/ \mathrm{mm}^{2}(\mathrm{n}=5)$ im Läsionsareal, 312,8 $\pm 44,77$ Zellen $/ \mathrm{mm}^{2}(\mathrm{n}=5)$ im Periläsionsareal und 401,6 $\pm 69,9$ Zellen $/ \mathrm{mm}^{2}(\mathrm{n}=5)$ in der NAWM.

Die Dichte einfach positiver Olig2 $2^{+} / \mathrm{p} 25$-Oligodendrozyten wies keinen statistisch signifikanten Unterschied auf und betrug in der Kontrolle 152,2 $\pm 21,5$ Zellen $/ \mathrm{mm}^{2}$ ( $\left.\mathrm{n}=13\right), 261,6$ $\pm 49,8$ Zellen $/ \mathrm{mm}^{2}(\mathrm{n}=5)$ im Läsionsareal, 237,7 $\pm 27,8$ Zellen $/ \mathrm{mm}^{2}(\mathrm{n}=5)$ im Periläsionsareal und 216,7 $\pm 65,3$ Zellen $/ \mathrm{mm}^{2}(\mathrm{n}=5)$ in der NAWM.

Die Dichte einfach positiver Olig2/ $/ \mathrm{p} 25^{+}$-Oligodendrozyten in der Kontrolle lag bei 346,7 $\pm 42,6$ Zellen $/ \mathrm{mm}^{2}$ ( $\mathrm{n}=13$ ) im Gegensatz zu 212,7 $\pm 60,4$ Zellen $/ \mathrm{mm}^{2}(\mathrm{n}=5)$ im Läsionsareal, 423,2 $\pm 123,9$ Zellen $/ \mathrm{mm}^{2}(\mathrm{n}=5)$ im Periläsionsareal und 307,5 $\pm 46,6$ Zellen $/ \mathrm{mm}^{2}(\mathrm{n}=5)$ in der NAWM.

Der prozentuale Gesamtanteil betrug für Olig2 $2^{+} / \mathrm{p} 25^{+}$-Zellen 65,6\% in der Kontrolle, 43,5\% in der NAWM, 33,7\% im Periläsionsareal und 26,0\% im Läsionsareal. Einfach positive Olig2 $2^{+}$p25-Oligodendrozyten machten einen prozentualen Gesamtanteil von 10,2\% in der Kontrolle, 23,1\% in der NAWM, 25,7\% im Periläsionsareal und 40,8\% im Läsionsareal aus. Für einfach positive Olig2 $/ \mathrm{p} 25^{+}$-Oligodendrozyten konnte ein prozentualer Gesamtanteil von 24,2\% in der Kontrolle, 33,4\% in der NAWM, 40,5\% im Periläsionsareal und 33,3\% im Läsionsareal ermittelt werden. 
EAE Frühphase (Tag 1-5) Olig2 / p25 / MBP / DAP
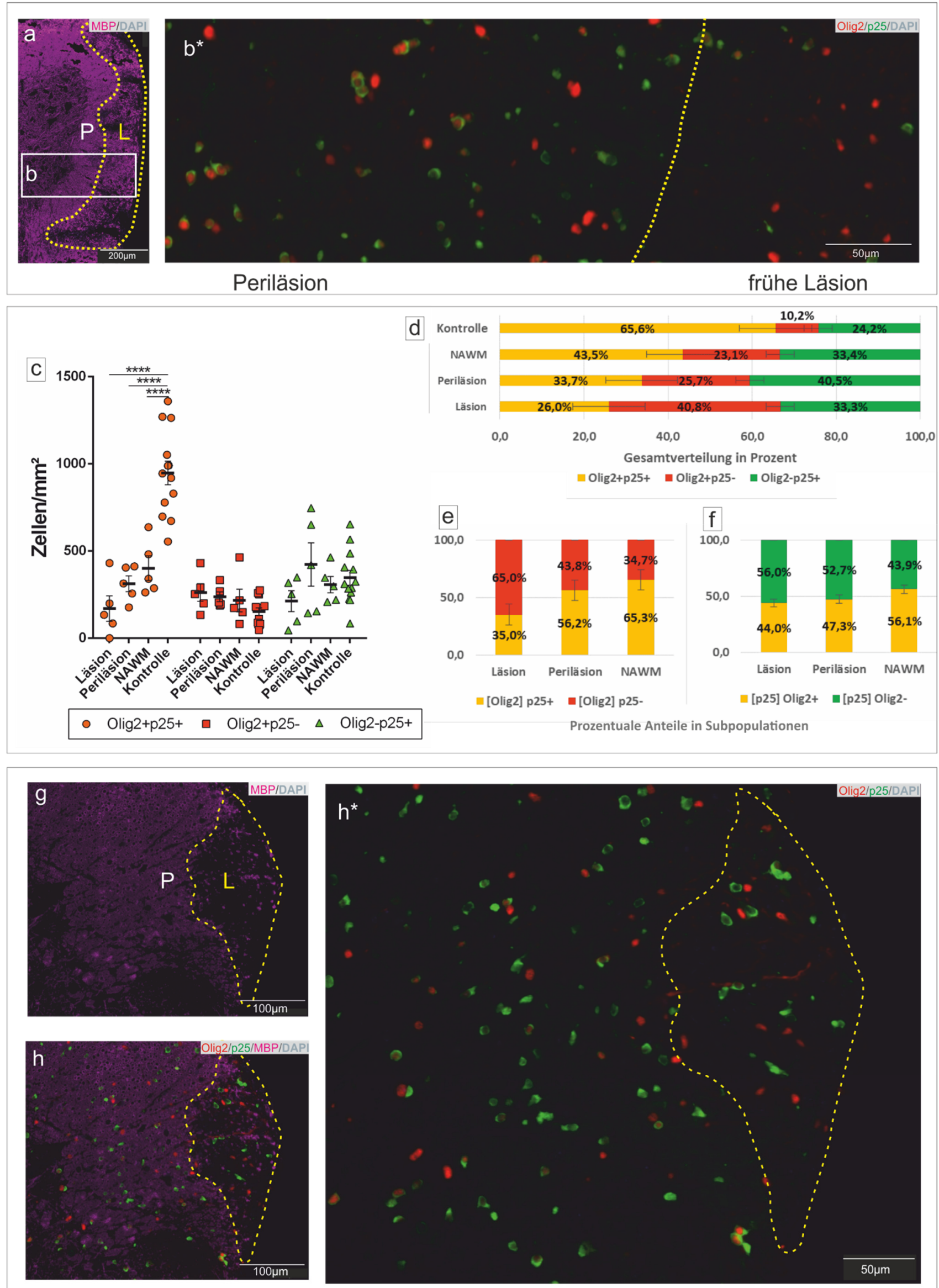

Abbildung 8: EAE-Modell Frühphase (Tag1-5) Olig2/p25/MBP/DAPI

Morphologie und Verteilung von Zellen der oligodendroglialen Reihe im Rückenmark von C57BL/6-Mäusen im EAE-Tiermodell mit einer Erkrankungsdauer von 1-5 Tagen

(a) Übersicht mit Fluoreszenz-Markierungen (MBP, magenta), (DAPI, hellblau); Maßstabsbalken $200 \mu \mathrm{m}$; Läsionsareal mit L (gelb) und zusätzlich gelb-gepunkteter Linie umrandet, Periläsionsareal mit P (weiß) markiert (b*) Vergrößerung von (b) mit Fluoreszenz-Markierungen (Olig2, rot), (p25, grün) und (DAPI, hellblau). (c) Quantifizierung von verschiedenen Zellen der oligodendroglialen Reihe (Zellen/mm²) anhand der Marker Olig2 und p25. (d) prozentuale Gesamtverteilung der quantifizierten Zellen in Läsion, Periläsion sowie NAWM. (e), (f) prozentuale Aufschlüsselung von Subpopulationen nach Markerprofil, eckige Klammern zeigt übergeordnete Subpopulation an (z.B. [p25] = alle p25+ Zellen). (g) Übersicht mit Fluoreszenz-Markierungen (MBP, magenta), (DAPI, hellblau); Maßstabsbalken 100 mm; Läsionsareal mit L (gelb) und zusätzlich gelb-gepunkteter Linie umrandet, Periläsionsareal mit P (weiß) markiert. (h) = (g) mit zusätzlicher Fluoreszenzmarkierung von (Olig2, rot) und (p25, grün); (h*) Vergrößerung von (h) ohne MBP-Markierung; Maßstabsbalken $50 \mu \mathrm{m}$. 


\subsubsection{EAE-Modell Spätphase (6-24 Tage)}

Die Gesamtdichte von Zellen der oligodendroglialen Reihe (Olig2 $/ \mathrm{p} 25^{+}$, Olig2 $/ \mathrm{p} 25^{-}$, Olig2 $/ \mathrm{p}^{2} 5^{+}$) betrug in gesundem Kontrollgewebe 482,1 $\pm 338,5$ Zellen $/ \mathrm{mm}^{2}$, im Läsionsareal 262,4 $\pm 111,2$ Zellen $/ \mathrm{mm}^{2}$, im Periläsionsareal 336,0 $\pm 102,3$ Zellen $/ \mathrm{mm}^{2}$ und in der NAWM 374,5 $\pm 176,6$ Zellen $/ \mathrm{mm}^{2}$.

Wie in Abbildung 9e veranschaulicht, bestätigte sich die bereits in der Frühphase beobachtete hohe Dichte von Olig2 $2^{+}$p $25^{+}$-Oligodendrozyten im gesunden Kontrollgewebe. So war die Dichte hier (Kontrollgewebe) mit 947,5 $\pm 68,1$ Zellen $/ \mathrm{mm}^{2}(\mathrm{n}=13)$ im Vergleich zu 141,5 $\pm 18,2$ Zellen $/ \mathrm{mm}^{2}(\mathrm{n}=14)$ im Läsionsareal $(\mathrm{P} \leq 0,0001), 324,9 \pm 35,9$ Zellen $/ \mathrm{mm}^{2}(\mathrm{n}=14)$ im Periläsionsareal $(\mathrm{P} \leq 0,0001)$ und 539,7 $\pm 72,5$ Zellen $/ \mathrm{mm}^{2}(\mathrm{n}=5)$ in der NAWM $(\mathrm{P} \leq$ 0,0001) weiterhin signifikant erhöht (zwei-faktorielle Varianzanalyse (2-way-ANOVA)). Darüber hinaus zeigte sich eine statistisch signifikante Differenz, mit höherer Dichte in der NAWM im Vergleich zum Läsionsareal $(\mathrm{P} \leq 0,0001)$ und Periläsionsareal $(\mathrm{P} \leq 0,05)$ (zweifaktorielle Varianzanalyse (2-way-ANOVA)). Weiterhin zeigte sich auch eine signifikante Differenz mit niedrigerer Dichte im Läsionsareal und im Vergleich dazu höherer Dichte im Periläsionsareal $(\mathrm{P} \leq 0,05)$ (zwei-faktorielle Varianzanalyse (2-way-ANOVA)).

Die Dichte einfach positiver Olig2 $/ \mathrm{p} 25^{-}$-Oligodendrozyten wies keinen statistisch signifikanten Unterschied auf und betrug 152,2 $\pm 21,5$ Zellen $/ \mathrm{mm}^{2}(\mathrm{n}=13)$ in der Kontrolle, 235,9 $\pm 43,8$ Zellen $/ \mathrm{mm}^{2}$ ( $\mathrm{n}=14$ ) im Läsionsareal, 216,5 $\pm 23,1$ Zellen $/ \mathrm{mm}^{2}$ ( $\left.\mathrm{n}=14\right)$ im Periläsionsareal und 129,8 $\pm 13,4$ Zellen $/ \mathrm{mm}^{2}(\mathrm{n}=5)$ in der NAWM.

Die Dichte einfach positiver Olig2-/p25+-Oligodendrozyten lag im Kontrollgewebe bei 346,7 \pm 42,6 Zellen $/ \mathrm{mm}^{2}$ ( $\mathrm{n}=13$ ) im Gegensatz zu 409,9 $\pm 47,2$ Zellen $/ \mathrm{mm}^{2}$ ( $\mathrm{n}=14$ ) im Läsionsareal, 466,5 $\pm 54,8$ Zellen $/ \mathrm{mm}^{2}(\mathrm{n}=14)$ im Periläsionsareal und 454,2 $\pm 75,7$ Zellen $/ \mathrm{mm}^{2}$ $(\mathrm{n}=5)$ in der NAWM und wies somit keine signifikanten Unterschiede auf.

Der prozentuale Gesamtanteil Olig2 $2^{+} / \mathrm{p} 25^{+}$-Oligodendrozyten betrug 65,6\% in der Kontrolle, 47,6\% in der NAWM, 33,2\% im Periläsionsareal und 18,9\% im Läsionsareal. Einfach positive Olig2 $2^{+}$p 25 -Zellen machten einen prozentualen Gesamtanteil von 10,2\% in der Kontrolle, 12,2\% in der NAWM, 21,3\% im Periläsionsareal und 29,6\% im Läsionsareal aus. Für einfach positive Olig2 $/ \mathrm{p} 25^{+}$-Oligodendrozyten konnte ein prozentualer Gesamtanteil von 24,2\% in der Kontrolle, 40,2\% in der NAWM, 45,4\% im Periläsionsareal und 51,5\% im Läsionsareal ermittelt werden. 
EAE Spätphase (Tag 6-24) Olig2 / p25 / MBP / DAP
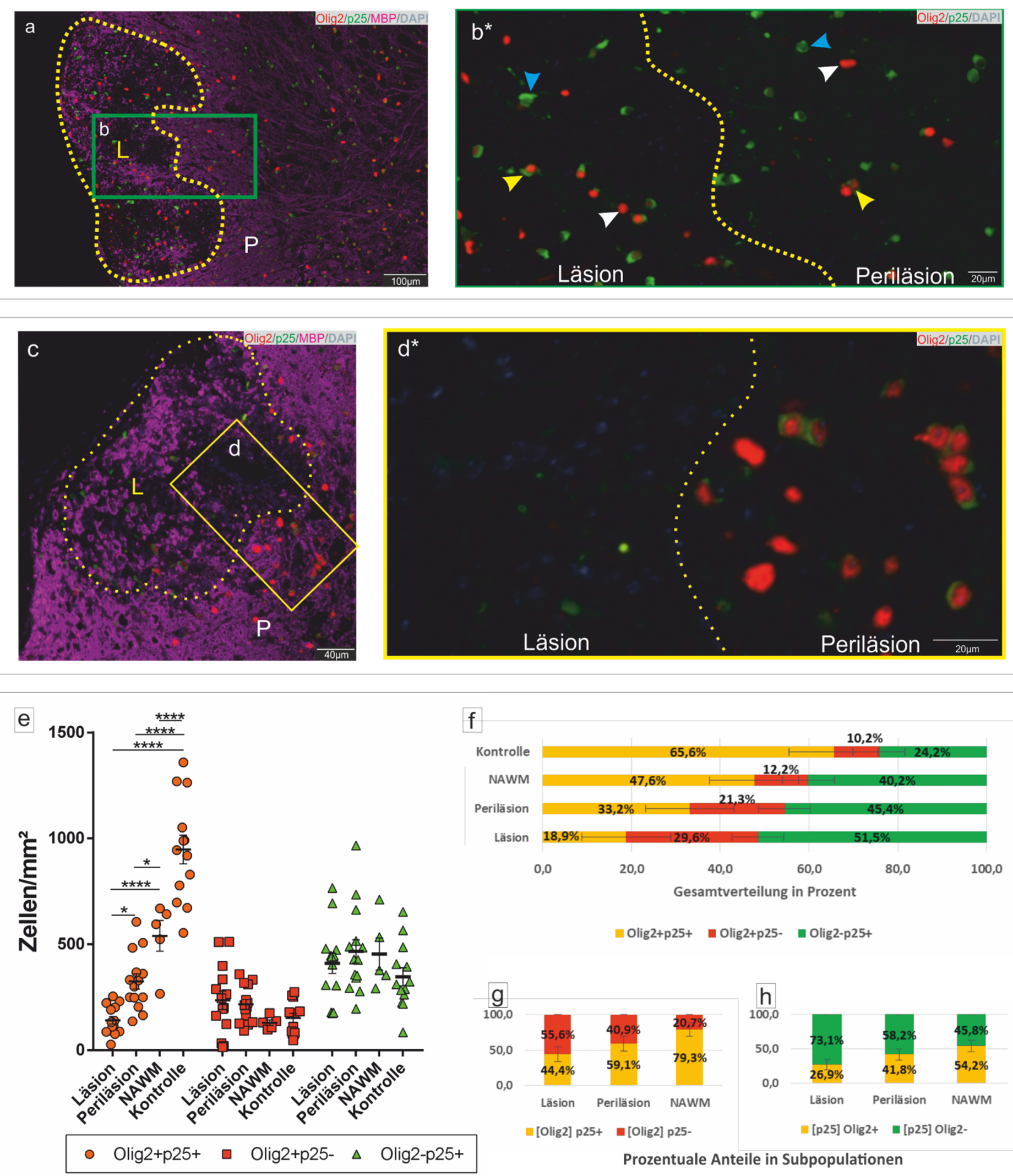

$\Delta \Delta \Delta \quad$ Gesamtverteilung in Prozent

业 $\Delta \quad$ Olig2+p25+ $\square$ Olig2+p25- $\square$ Olig2-p25+

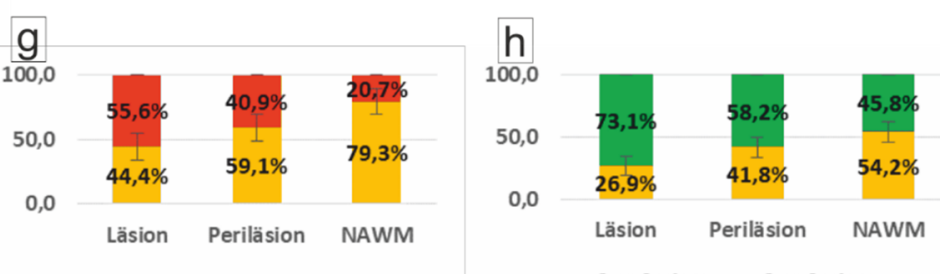

- [Olig2] p25+ - [O [Olig2] p25-

- $[$ p25] Olig2+ $=[$ [p25] Olig2-

Prozentuale Anteile in Subpopulationen

\section{Abbildung 9: EAE-Modell Spätphase (Tag6-24) Olig2/p25/MBP/DAPI}

Morphologie und Verteilung von Zellen der oligodendroglialen Reihe im Rückenmark von C57BL/6-Mäusen im EAE-Tiermodell mit einer Erkrankungsdauer von 6-24 Tagen

(a), (c) Übersicht mit Fluoreszenz-Markierungen (Olig2, rot), (p25, grün), (MBP, magenta), (DAPI, hellblau); Maßstabsbalken (a) $100 \mu \mathrm{m}$, (c) 40 m; Läsionsareal mit L (gelb) und zusätzlich gelb-gepunkteter Linie umrandet, Periläsionsareal P (weiß). ( $\left.\mathbf{b}^{*}\right)$, ( $\left.\mathbf{d}^{*}\right)$ = Vergrößerungen von (b), (d); gelbe Pfeilspitzen markieren doppelt positive Zellen (Olig2+p25+), weiße Pfeilspitzen markieren nur Olig2-positive Zellen (Olig2+p25-), blaue Pfeilspitzen markieren nur p25-positive Zellen (Olig2-p25+). (e) Quantifizierung von verschiedenen Zellen der oligodendroglialen Reihe (Zellen/mm²) anhand der Marker Olig2 und p25. (f) prozentuale Gesamtverteilung der quantifizierten Zellen in Läsion, Periläsion sowie NAWM. (g), (h) prozentuale Aufschlüsselung von Subpopulationen nach Markerprofil (eckige Klammer zeigt übergeordnete Subpopulation an (z.B. [p25] = alle p25+ Zellen)). 


\subsection{5 Übersicht Kontrolltiere}

Im Folgenden sind zur Übersicht die Ergebnisse aus der Analyse der Kontrollkohorte (das sind naive Mäuse ohne Induktion einer Entzündung oder Entmarkung) zusammengefasst:

Die Gesamtdichte für Zellen der oligodendroglialen Reihe (Olig2 ${ }^{+} / \mathrm{p}^{2} 5^{+}$, Olig2 $/ \mathrm{p} 25^{-}$, Olig2$\left./ \mathrm{p} 25^{+}\right)$lag für gesunde Kontrolltiere bei 482,1 $\pm 338,5$ Zellen $/ \mathrm{mm}^{2}$ im Rückenmark und bei $792,1 \pm 732,5$ Zellen $/ \mathrm{mm}^{2}$ im Corpus callosum

Die Dichte von Olig2 ${ }^{+} / \mathrm{p} 25^{+}$-Zellen lag bei $947,5 \pm 68,0$ Zellen $/ \mathrm{mm}^{2}$ ( $\left.\mathrm{n}=13\right)$ im Rückenmark und 1820,8 $\pm 59,5$ Zellen $/ \mathrm{mm}^{2}(\mathrm{n}=13)$ im Corpus callosum. Einfach positive Olig2 ${ }^{+/} \mathrm{p} 25^{-}$-Zellen traten in einer Dichte von 152,2 $\pm 21,5$ Zellen $/ \mathrm{mm}^{2}(\mathrm{n}=13)$ im Rückenmark und 172,0 $\pm 16,7$ Zellen $/ \mathrm{mm}^{2}(\mathrm{n}=13)$ im Corpus callosum auf. Weiterhin ergab die Analyse der Gewebeproben auf einfach positive Olig2 $/ \mathrm{p} 25^{+}$-Oligodendrozyten eine Dichte von 346,7 $\pm 42,6$ Zellen $/ \mathrm{mm}^{2}(\mathrm{n}=13)$ im Rückenmark und 383,4 $\pm 38,2$ Zellen $/ \mathrm{mm}^{2}(\mathrm{n}=13)$ im Corpus callosum (Abbildung 10j).

Weiterhin ergab sich für Olig2 $2^{+} / \mathrm{p} 25^{+}$-Oligodendrozyten ein prozentualer Gesamtanteil von $76,7 \%$ in Corpus callosum und $65,6 \%$ in Rückenmark. Einfach positive Olig2 $/ \mathrm{p} 25$-Zellen machten einen Gesamtanteil von 7,3\% im Corpus callosum und 10,2\% im Rückenmark aus. Olig2 $2^{-1}$ p $25^{+}$-Zellen machten einen Gesamtanteil von 16,0\% im Corpus callosum und 24,42\% im Rückenmark aus. 
Kontrolle Corpus callosum und Rückenmark Olig2 / p25 / MBP / DAP
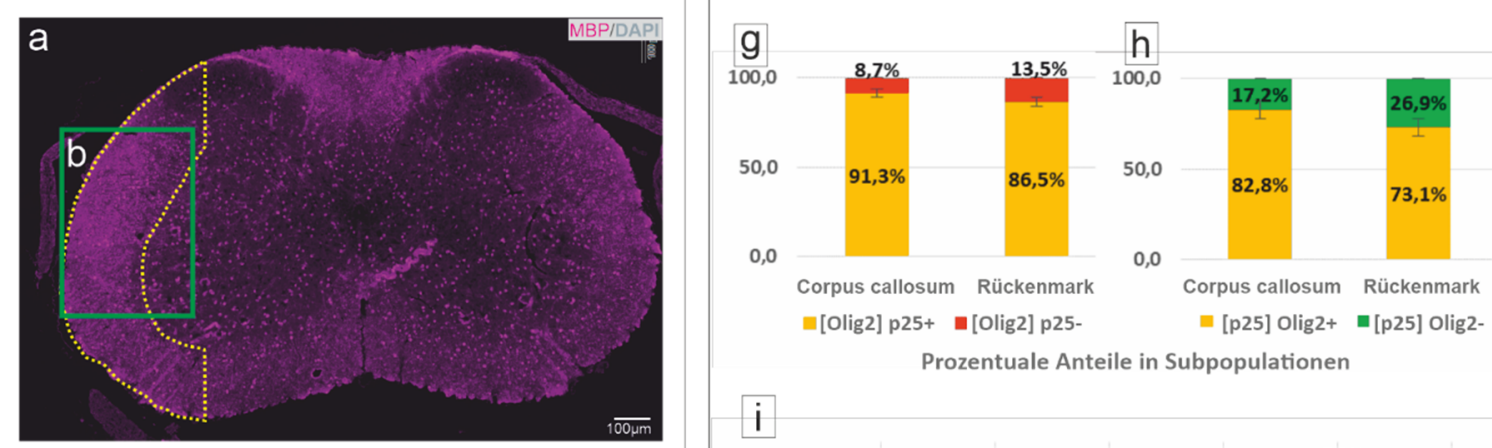

Prozentuale Anteile in Subpopulationen

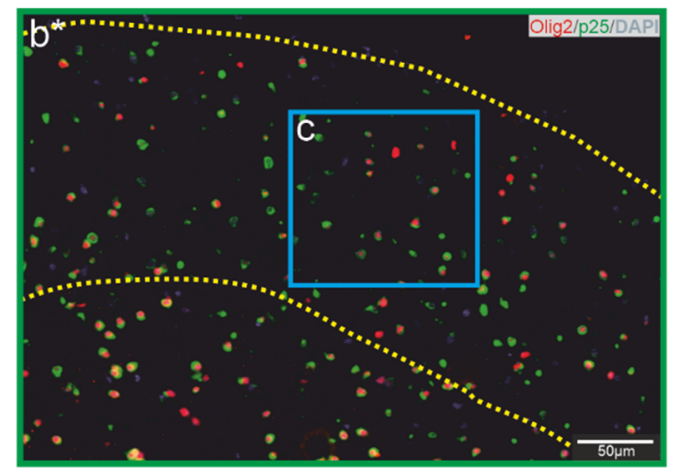

i
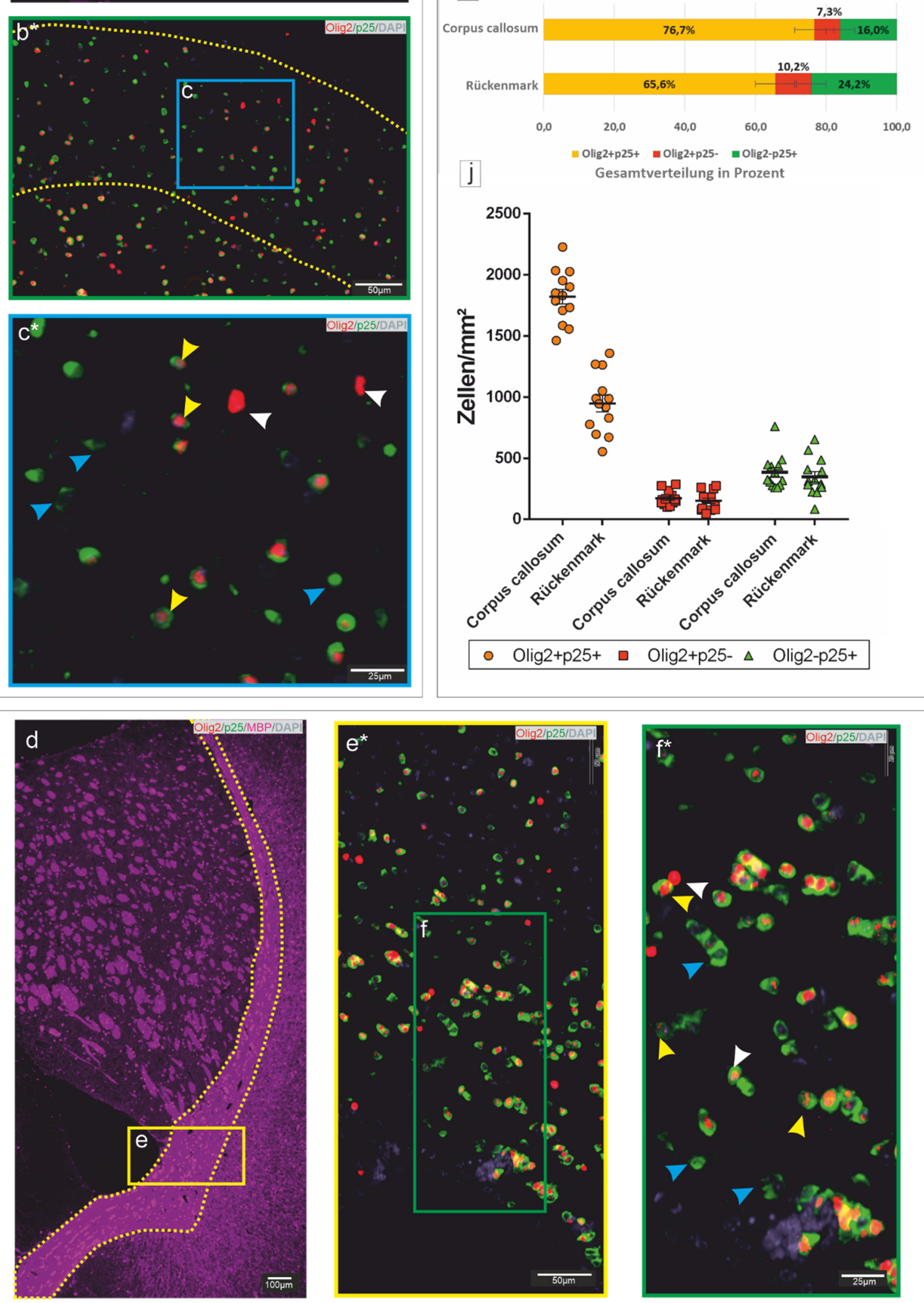


\section{Diskussion}

Die bemerkenswerte Heterogenität der multiplen Sklerose beschränkt sich nicht nur auf ihren Verlauf, sondern gilt ebenso für ihre histologische Präsentation (Lucchinetti et al. 2000; Lucchinetti 2005). Bis zum heutigen Tag ist die Ätiologie der MS nicht eindeutig geklärt (Ascherio und Munger 2007), doch unabhängig von der Verlaufsform oder dem histologischen Typ geht sie früher oder später einher mit einer Zerstörung von Myelin, Axonen und Oligodendrozyten. Letztere rücken als myelinisierende und remyelinisierende Zellen des ZNS immer mehr in den Fokus zellbiologischer Untersuchungen und waren auch Gegenstand unserer Untersuchungen. Mittels Immunfluoreszenz-Mehrfachmarkierungen untersuchten wir die Dichte verschiedener Oligodendrozyten-Subpopulationen in demyelinisierten, ihnen angrenzenden und gesunden Arealen in humanen und tierexperimentell erzeugten Gewebeproben.

Zur Identifizierung von Zellen der oligodendroglialen Reihe verwendeten wir die weitgehend entwicklungsstadiumsunspezifischen Transkriptionsfaktoren Olig2 und Sox10. Weiterhin analysierten wir die Expression des Transkriptionsfaktors Nkx2.2, welcher ähnlich wie Olig2 und Sox10, sowohl von Vorläuferzellen als auch (zeitweise) von reifen Oligodendrozyten exprimiert wird (Suyama et al. 2007). Eine Besonderheit von Nkx2.2 liegt darin, dass seine Expression nach erfolgter Differenzierung zu reifen Oligodendrozyten herunterreguliert wird (Xu et al. 2000; Watanabe et al. 2004). Diese Eigenart deuteten wir bei Doppelmarkierung mit dem Protein p25 als Hinweis auf reife Oligodendrozyten, welche mutmaßlich erst kürzlich ihre Differenzierung abgeschlossen hatten. Das Protein p25 ist hochspezifisch für alle reifen Oligodendrozyten (Skjoerringe et al. 2006) und kann somit in Koexpression mit Olig2, Sox10 oder ggf. Nkx2.2 dazu verwendet werden, um diese zu identifizieren.

Uns war es somit möglich, vier Subpopulationen zu unterscheiden:

1) Zellen mit den Markerkonstellationen: Sox $10^{+} / \mathrm{p} 25^{+}$und Olig2 ${ }^{+} / \mathrm{p} 25^{+}$im Sinne von reifen Oligodendrozyten,

2) Zellen mit der Markerkonstellation: $\mathrm{Nkx} 2.2^{+} / \mathrm{p} 25^{+}$, im Sinne von reifen Oligodendrozyten, welche sich mutmaßlich erst kürzlich zu diesen differenziert hatten,

3) Zellen mit den Markerkonstellationen: $\mathrm{Nkx} 2.2^{+} / \mathrm{p} 25$, Sox $10^{+} / \mathrm{p} 25^{-}$und Olig2 $2^{+} / \mathrm{p} 25^{-}$im Sinne von unreifen Oligodendrozyten bzw. OPCs (Oligodendrozyten-Vorläuferzellen) sowie

4) Zellen mit den Markerkonstellationen: Nkx2.2/ $25^{+}$, Sox $10^{-} / \mathrm{p} 25^{+}$und Olig2 $/ \mathrm{p} 25^{+}$.

Insbesondere die Markerkonstellationen Sox $10^{-} / \mathrm{p} 25^{+}$und Olig2 $/ \mathrm{p} 25^{+}$sind ungewöhnlich, da Sox10 und Olig2 in allen Lebensstadien von Oligodendrozyten exprimiert werden. Wir untersuchten hier die Hypothese, ob eine niedrige Expression bzw. Herunterregulation von Olig2 bzw. Sox10 auf eine Schädigung der Oligodendrozyten hinweist. 


\subsection{Reduktion der Dichte reifer Oligodendrozyten}

In frühen Stadien von per Biopsie gewonnenen MS-Läsionen entsprechend jenen, die wir hier untersucht haben, kann die Dichte von Oligodendrozyten stark variieren und vereinzelt gar höher liegen als in der periläsionalen weißen Substanz (Lassmann et al. 1997). Dies trifft sowohl auf die Dichte reifer Oligodendrozyten (Ozawa et al. 1994; Lucchinetti et al. 1999) als auch von OPCs zu (Wolswijk 1998).

Generell wird jedoch bei demyelinisierenden Läsionen, insbesondere in späteren Läsionsstadien, eine Reduktion insbesondere der Dichte reifer Oligodendrozyten beobachtet, welche in ihrem Ausmaß je nach Läsionsstadium und remyelinisierender Aktivität ebenfalls variieren kann (Ozawa et al. 1994; Lucchinetti et al. 1999). Diese grundlegende Beobachtung bestätigte sich auch bei unseren Untersuchungen von humanen Biopsien sowie teilweise auch in der Untersuchung tierexperimentell erzeugter Proben.

In den untersuchten entmarkten Läsionen ließen sich im Vergleich zur normal erscheinenden weißen Substanz (normal appearing white matter, NAWM) sowohl in den humanen Biopsien als auch im EAE-Modell der autoimmun-induzierten Demyelinisierung signifikant niedrigere Dichten von reifen Oligodendrozyten (Olig2 $/ \mathrm{p} 25^{+}$bzw. Sox $10^{+} / \mathrm{p} 25^{+}$bzw. Nkx $2.2^{+} / \mathrm{p} 25^{+}$) beobachten. Weiterhin war die Zelldichte der reifen Oligodendrozyten in den tierexperimentell erzeugten Gewebeproben (EAE und Cuprizon) stets niedriger als in den untersuchten Kontrollgeweben gesunder Mäuse.

\subsection{Mögliche Gründe für die Abnahme der Dichte reifer Oligodendrozyten}

Grundsätzlich geht man davon aus, dass die beobachtete Abnahme in der Dichte reifer Oligodendrozyten durch einen vermehrten Zelltod von Oligodendrozyten hervorgerufen wird (Chang et al. 2000).

Um dieses Phänomen zu erklären, werden verschiedene Möglichkeiten diskutiert.

Im Allgemeinen sind Oligodendrozyten durch ihren erhöhten Stoffwechsel vulnerabler als andere Zellen des ZNS und dadurch anfällig für eine Vielzahl möglicher Noxen (Bradl und Lassmann 2010). Zahlreiche Mechanismen sind bekannt, welche Oligodendrozyten direkt schädigen und so zu einem Funktionsverlust bzw. Zelluntergang führen können, was dann konsekutiv zu einem sekundären Myelinverlust führt. Diese Schädigungsmechanismen sind vielfältig und können in ihrer Endstrecke vom Sphingomyelinase-Ceramid-Pfad (McTigue und Tripathi 2008) über die exzitotoxische Wirkung von erhöhten Konzentrationen von Glutamat (Sánchez-Gómez und Matute 1999) oder ATP (Matute et al. 2007) bis hin zur direkten Wirkung von Toxinen, wie z. B. Cuprizon, reichen (Kipp et al. 2009). 
In Anbetracht der vielfältigen Funktionen von Oligodendrozyten ist das Absterben von Oligodendrozyten auch mit dem histologischen Befund des Myelinverlusts und der daraus folgenden klinischen Symptomatik von Patienten und Versuchstieren zu vereinbaren. Der Myelinverlust könnte dabei ein sekundäres Phänomen im Rahmen einer primären Oligodendrozytenschädigung sein, wobei dann auch die bei der MS beobachtete Entzündungsreaktion als sekundäres Geschehen im Sinne einer Reaktion auf den vermehrten Zelluntergang interpretiert werden könnte (Nakahara et al. 2010).

Ein Erklärungsansatz, welcher jedoch weitaus breiteren Anklang findet, schreibt der bei der MS zu beobachtenden Entzündungsreaktion selbst eine Schlüsselrolle zu und stellt diese als zugrundeliegende Pathologie in den Vordergrund. Hier wird diskutiert, dass Myelin-Strukturen als Zielantigen eines fehlgeleiteten (Auto)-Immunprozesses erkannt, angegriffen und zerstört werden (Weiner 2004). Der Untergang von Oligodendrozyten wäre damit erst ein sekundäres Geschehen als Folge entzündlich- immunologischer Prozesse und des daraus folgenden für Oligodendrozyten toxischen Milieus (Nakahara et al. 2010).

In der Tat werden im Rahmen von Entzündungsreaktionen vielfältige molekulare Prozesse und zelluläre Interaktionen angestoßen, welche mit weitreichenden Folgen für die Funktion und das Überleben von Oligodendrozyten verbunden sind. Obwohl für das bessere Verständnis der MS ein Schlüsselpunkt - ist es für das Schicksal der Oligodendrozyten vermutlich nachrangig, ob die Entzündung letztendlich ein primäres oder sekundäres Geschehen darstellt, da die in Gang gesetzten Prozesse und involvierten Mediatoren dabei in der Endstrecke sehr ähnlich sind. So sind Läsionen im Zuge der MS gekennzeichnet durch eine massive Infiltration von zellulären und löslichen Mediatoren des Immunsystems, darunter T-Zellen, B-Zellen, Makrophagen und Mikroglia als auch durch die Expression einer breiten Palette von Zytokinen, Chemokinen sowie die Präsenz von Antikörpern, Komplement-Faktoren und anderen toxischen Substanzen (Brück 2005).

\subsection{Erst kürzlich differenzierte reife Oligodendrozyten}

In den humanen Proben wurde zusätzlich zu den „klassischen“ Markern für reife und unreife Oligodendrozyten auch der Transkriptionsfaktor Nkx2.2 untersucht, welcher im Zuge der oligodendroglialen Differenzierung herunterreguliert wird (Xu et al. 2000; Watanabe et al. 2004; Kuhlmann et al. 2008). Daher war es uns möglich, Zellen zu identifizieren, die sich mutmaßlich erst kürzlich zu reifen Oligodendrozyten differenziert hatten und daher sowohl Nkx2.2 als auch p25/TPPP (als Marker für reife Oligodendrozyten) exprimierten.

Bei den in den MS-Biopsieproben untersuchten reifen $\mathrm{Nkx} 2.2^{+} / \mathrm{p} 25^{+}$Oligodendrozyten konnten wir eine signifikant niedrigere Dichte im Läsionsareal verglichen mit der NAWM erkennen. Dieser Befund deckte sich mit dem Bild, welches wir auch bei den Oligodendrozyten im Rahmen der Sox10-Immunfärbungen vorfinden konnten. Mehr noch war bei der 
Dichte der Nkx2.2 $/ \mathrm{p} 25^{+}$-Zellen ein Gradient mit abnehmender Dichte von der NAWM über das Periläsionsareal zum Läsionsareal zu erkennen (siehe Abbildung $5 \mathrm{f}$ ).

Interpretiert man die in den MS-Biopsieproben untersuchten $\mathrm{Nkx} 2.2^{+} / \mathrm{p} 25^{+}$-Zellen als reife Oligodendrozyten, die erst kürzlich differenziert sind, so ergibt sich ein Bild, in welchem die Dichte frisch differenzierter Oligodendrozyten in der Peripherie höher ist als in der Läsion. Daraus könnte man weiter folgern, dass es womöglich ein Konzentrationsgefälle für lokale Faktoren gibt, welche die Reifung von Oligodendrozyten bedingen bzw. in der Läsion verhindern.

Diese besagten Einflussfaktoren könnten dann gleichermaßen auf alle reife Oligodendrozyten wirken - unabhängig vom Zeitpunkt ihrer Differenzierung.

Insoweit wäre eine vornehmlich zytotoxische Komponente mit prolongierter Wirkung als Erklärungsansatz für den zellulären Verlust in den verschiedenen Subpopulationen von reifen Oligodendrozyten in der Tat denkbar. Doch ist es ebenso plausibel, dass die Wirkungen der besagten Faktoren über eine reine Zytotoxizität hinausgehen und es auch zu einer Interferenz mit den Prozessen im Rahmen der Remyelinisierung kommt. Der Begriff der Remyelinisierung beschreibt die Neubildung von Myelinscheiden und bedarf des reibungslosen Ablaufs einer Vielzahl von zeitlich und räumlich festgelegten Prozessen, welche sich auch anhand der von uns untersuchten Dichtewerte der einzelnen Subpopulationen bewerten lassen können.

\subsection{OPCs und Remyelinisierung}

Im Idealfall sollte die Remyelinisierung die prinzipiellen Myelinisierungprozesse in der Entwicklungsphase des ZNS rekapitulieren (Franklin und Goldman 2015) und kann vereinfacht in zwei Phasen unterteilt werden (Franklin 2002).

Die erste umfasst die Rekrutierung oligodendroglialer Vorläuferzellen (OPCs) und setzt sich zusammen aus Proliferation und vermutlich Migration. Die zweite besteht darin, dass die OPCs in Kontakt mit demyelinisierten Axonen treten und sich dann lokal in myelinisierende Oligodendrozyten differenzieren (Franklin 2002).

Beiden Phasen liegen eine Vielzahl störungsanfälliger molekularer Prozesse zugrunde, weswegen ein Scheitern der Remyelinisierung in jeder dieser Phasen bzw. einer ihrer vielzähligen Zwischenschritte denkbar wäre (Franklin 2002).

Damit es zu einer Remyelinisierung kommen kann, müssen OPCs wahrscheinlich in einer ausreichenden Anzahl überleben, sich vermehren und zu den demyelinisierten Läsionen migrieren. Einmal an den entmarkten MS-Läsionen angekommen, müssen diese OPCs sich sodann über zelluläre Zwischenstufen zu reifen Oligodendrozyten differenzieren, um dann anschließend die Myelinscheiden erneuern zu können (Hanafy und Sloane 2011). So gibt es im Prozess der Remyelinisierung viele Meilensteine, an denen der Prozess theoretisch gestört 
werden kann: Überleben der Oligodendrozyten, Aktivierung, Proliferation, Migration, Reifung und letztlich die eigentliche Myelinscheidenbildung (Hanafy und Sloane 2011).

\subsection{Einflussfaktoren auf OPCs: Zytotoxizität vs. Differenzierungsblock}

OPCs können als Reaktion auf pathologische Bedingungen bzw. auf Schädigungsreize in einen aktivierten Phänotyp übergehen (Levine et al. 2001). Diese Aktivierung äußert sich in einer erhöhten Empfindlichkeit gegenüber Mitogenen, Wachstumsfaktoren, Chemokinen und Zytokinen, welche die Proliferation und Mobilisation von OPCs in Richtung des demyelinisierten Areals verstärken.

Eine erhöhte Dichte im Sinne einer solchen Aktivierung und Proliferation (Höftberger et al. 2010) war sowohl bei den MS-Biopsieproben (Sox10) als auch in den Spätphasen des EAEund des Cuprizon-Modells in Ansätzen zu beobachten. Bei Betrachtung der prozentualen Gesamtverteilung der jeweiligen Subpopulationen war der Anteil an OPCs (bis auf die Frühphase des Cuprizon-Models) in den Läsionsarealen aller Gewebe erhöht (siehe Abbildung 4h, Abbildung 5g, Abbildung 6d, Abbildung 7h, Abbildung 8d und Abbildung 9f). Ein resultierender Dichteunterschied mit Erhöhung im Läsionsareal war jedoch nur in der Spätphase des Cuprizon-Modells auch statistisch signifikant (siehe Abbildung 7g).

Somit verblieb die Dichte von OPCs in den verglichenen Arealen wider Erwarten meist auf einem vergleichbaren Niveau. Würde man dies analog zu den reifen Oligodendrozyten als Folge einer direkten Schädigung und dem daraus folgenden Zelluntergang deuten, könnte der mutmaßliche Zelluntergang in seinem Ausmaß dem der reaktiven Zellvermehrung entsprechen und so das Ausbleiben eines statistisch signifikanten Anstieges in der Dichte von OPCs erklären.

Andererseits ist jedoch auch die Möglichkeit zu diskutieren, dass zytotoxische Mechanismen bzw. das Überleben der OPCs möglicherweise nicht die einzigen limitierenden Variablen im Hinblick auf Veränderungen in der Dichte der verschiedenen Oligodendrozytenpopulationen sind.

In Anbetracht unserer Beobachtung, dass trotz einer erniedrigten Dichte von reifen Oligodendrozyten innerhalb von Läsionen weiterhin vergleichbare Dichten für OPCs (Nkx2.2 /p25-Zellen in Humangewebe) in Läsion, Periläsion und NAWM zu beobachten waren (vergleiche hierzu (Wolswijk 1998; Penderis et al. 2003)), könnte die Hypothese diskutiert werden, dass möglicherweise eine ausreichende Menge an Vorläuferzellen für eine Differenzierung zu reifen Oligodendrozyten zur Verfügung stand, diese Differenzierung jedoch in den verschiedenen Untersuchungsarealen nur unterschiedlich effizient ablaufen konnte.

Dies könnte auf eine Störung im Rahmen der OPC-Differenzierung hindeuten (Differenzierungsblock), welche die Reifung zu myelinisierenden Oligodendrozyten verhindern könnte 
(Kuhlmann et al. 2008). Insbesondere bei der Betrachtung der Verteilung der jeweiligen Subpopulationen und der prozentualen Anteile scheint eine solche Deutung durchaus plausibel (siehe Abbildung 5g). Es ist naheliegend, dass es in den Läsionen einen oder mehrere Faktoren geben muss, welche die Differenzierung der OPCs inhibieren könnten (Franklin und ffrench-Constant 2008) und deren Konzentration bzw. Einfluss mit zunehmender Entfernung zur Läsion abnimmt.

Insoweit könnte insbesondere der erwähnte Dichteunterschied von mutmaßlich erst kürzlich differenzierten reifen Oligodendrozyten $\left(\mathrm{Nkx} 2.2^{+} / \mathrm{p} 25^{+}\right)$in den unterschiedlichen Untersuchungsarealen einen weiteren Hinweis auf die regenerative Kapazität und somit indirekt die Funktionsfähigkeit der OPCs innerhalb des Untersuchungsareals geben. Möglicherweise ist nicht nur das Überleben einer ausreichenden Anzahl von reifen Oligodendrozyten für eine Remyelinisierung notwendig (Yeung et al. 2019), sondern ebenfalls eine intakte Generationsfolge als Voraussetzung für eine adäquate Repopulation mit frischen myelinbildenden Oligodendrozyten (Boyd et al. 2013).

\subsection{Einflussfaktoren auf OPCs: Astrozyten und Mikromilieu}

Wie schon erwähnt geht der Proliferation und Differenzierung von OPCs in der Regel eine Aktvierung voraus, welcher sich dann im Verlauf eine Reihe weiterer Zwischenschritte anschließen müssen, um schließlich eine erfolgreiche Remyelinisierung zu bewirken. Die involvierten Prozesse müssen in einem zeitlich genau festgelegten Rahmen stattfinden und können durch vielzählige Faktoren, z. B. in Gestalt von sezernierten Proteinen, beeinflusst werden (Patel und Klein 2011).

So wird nach Domingues und Kollegen (2016) das Ergebnis glialer Interaktionen bei der Myelinisierung stark durch das umgebende Mikromilieu beeinflusst. In ihrer Arbeit zeigen sie auf, dass der Aktivierungszustand lokaler Astrozyten möglicherweise bestimmt, ob deren Einfluss auf die Entwicklung der Oligodendrozyten förderlicher oder inhibitorischer Natur ist. Als wichtiges Einflusskriterium auf die verschiedenen sich daraus ergebenden Phänotypen für Astrozyten könnte insbesondere deren Entfernung zur Läsion eine wichtige Rolle spielen (Domingues et al. 2016). Ergänzend dazu passt der Vorschlag von Nash und Kollegen (2011), dass weiter distal von der Läsion lokalisierte Astrozyten eher aktivierte Astrozyten darstellen könnten, die zur Regeneration durch die Sekretion von Proteinen, wie Wachstumsfaktoren und Zytokinen, beitragen und dass Astrozyten, die eher in der Nähe der Läsion liegen, eher reaktiv sein könnten und den Remyelinisierungsprozess so behindern (Nash et al. 2011). Astrozyten könnten so eine mögliche Quelle für die zuvor vermuteten lokalen Einflussfaktoren auf Oligodendrozyten sein und deren unterschiedlicher Phänotyp die abweichende Zusammensetzung des lokalen Milieus bzw. den vorgeschlagenen Gradienten der verschiedenen Faktoren bedingen. 
Neben Wachstumsfaktoren und Zytokinen sind zahlreiche weitere Proteine bekannt, welche nicht nur zwingend auf das lokale Milieu wirken sondern ebenfalls als Mediatoren der oligodendroglialen Differenzierung fungieren können. Sie können in Form von Chemokinen (Carbajal et al. 2010; Patel et al. 2010), Signalmolekülen (Nakahara et al. 2009; Aguirre et al. 2010), microRNA (Nave 2010) sowie Transkriptionsfaktoren (Kitada und Rowitch 2006) in Erscheinung treten (Patel und Klein 2011). Ihr Auftreten ist als physiologischer Bestandteil zellulärer Steuerungsmechanismen (z. B. Transkriptionsfaktoren) oder situationsbedingt (z. B. im Rahmen von Entzündungen) zu deuten.

Weiterhin gibt es Hinweise darauf, dass eine unzureichende Abräumung und Akkumulation von Myelinfragmenten, von zuvor untergegangenem Myelin, ebenfalls einen inhibitorischen Einfluss auf die Differenzierung von OPCs zu haben scheint (Kotter et al. 2006; Baer et al. 2009). Ebenso akkumulieren Glykosaminoglykan und Hyaluronsäure in demyelinisierenden MS-Läsionen, welche ebenfalls als mögliche Inhibitoren der Differenzierung von OPCs diskutiert werden (Back et al. 2005; Sloane et al. 2010). Letztendlich ist bekannt, dass die Differenzierung von OPCs zusätzlich von räumlichen Faktoren (Rosenberg et al. 2008) und der Dichte der OPCs selbst abhängig zu sein scheint (Hughes et al. 2013) und auch Pathologien in diesen Beziehungen zu einer insuffizienten Repopulation beitragen können.

\subsection{Die Rolle entzündlicher Prozesse bei Differenzierung und Remyelinisierung}

Wie eingangs erwähnt wird das im Rahmen von demyelinisierenden Prozessen oftmals zu beobachtende Entzündungsgeschehen nicht nur als mögliche Hauptkomponente einer zugrundeliegenden Pathologie diskutiert, sondern ebenfalls eng in Verbindung gebracht mit Störungen in der Funktion und Differenzierung von Oligodendrozyten und dem folgenden Scheitern von Remyelinisierung (Franklin und Goldman 2015).

Im Zuge von Entzündungsreaktionen kommt es so, unter anderem durch die Sezernierung von Mediatoren und reaktiven Sauerstoffspezies (ROS), zu widrigen Bedingungen für das Überleben und die Funktion von Oligodendrozyten.

Oligodendrogliale Vorläuferzellen sind in noch höherem Maße anfällig für Schädigungen im Zusammenhang mit entzündlichen Prozessen als dies ohnehin schon der Fall für reife Oligodendrozyten ist (Back et al. 2001). Begründet ist dies unter anderem darin, dass OPCs im Vergleich zu reifen Oligodendrozyten einen niedrigeren Gehalt an antioxidativen Enzymen und Radikalfängern vorweisen können (French et al. 2009). So besitzen OPCs eine nur geringe Widerstandsfähigkeit gegenüber oxidativem Stress (Thorburne und Juurlink 1996), wie er beispielsweise durch reaktive Sauerstoffspezies, freigesetzt aus aktivierten Mikroglia, erzeugt wird (Pang et al. 2010; Chew et al. 2013). 
Dennoch ist die Rolle der Entzündungsreaktion im Rahmen der MS zwiespältiger Natur. So können involvierte Mediatoren sowohl inhibitorisch als auch förderlich auf Reparaturprozesse im Rahmen der Remyelinsierung wirken (Hanafy und Sloane 2011). Dies gilt sowohl beim Menschen als auch in Tiermodellen der MS (Franklin und Goldman 2015) und zeigt sich unter anderem am Beispiel von Zytokinen.

So kann TNF- $\alpha$ beispielsweise stark zytotoxische Einflüsse ausüben (Hehlgans und Pfeffer 2005) und Oligodendrozyten schädigen (Jurewicz et al. 2005), ebenfalls jedoch die Myelinisierung durch Oligodendrozyten und deren Proliferation fördern (Arnett et al. 2001). Ähnliches trifft beispielsweise auf Interleukine wie IL2 und IL4 zu. Die unterschiedlichen Wirkungen erklären sich in den meisten Fällen durch das zeitliche Auftreten der Zytokine in Bezug auf das Entzündungsstadium, deren Produktionsort sowie durch den Aktivierungszustand und die Rezeptorexpression der Zielzelle (Merrill und Benveniste 1996).

\subsection{Die mögliche Rolle molekularer Signalwege in der Beeinflussung von Oligodendrozyten und ihrer Funktion}

Entzündungsreaktionen induzieren im betroffenen Organismus wie erwähnt eine große Zahl von Prozessen, welche meist parallel ablaufen. In die Steuerung dieser Prozesse sind unter anderem auch zytokinabhängige Signalpfade involviert. Man geht davon aus, dass die Pathogenese der MS mit Veränderungen multipler solcher Signalpfade und dazugehöriger Prozesse verbunden sein könnte. So wurden bei der MS Anomalien in zahlreichen solch zytokinabhängigen Signalpfaden sowie assoziierten Immunrezeptoren identifiziert (Kotelnikova et al. 2015). Beispielsweise ist der NF- $x$ B-Pfad in die Steuerung von Immunzellen involviert und hat einen verstärkenden Einfluss auf entzündliche Prozesse, wie sie bei der MS beobachtet werden. NF- $x$ B induziert auch die Produktion von Entzündungsmediatoren durch dendritische Zellen, beeinflusst die Antigenverarbeitung und -präsentation in Makrophagen und bewirkt die Produktion von proinflammatorischen Zytokinen sowie neurotoxischen Mediatoren in Mikroglia und Astrozyten (Yan und Greer 2008).

So wird beispielsweise deutlich, dass durch eine übermäßige Expression von NF- $\varkappa$ B ein proinflammatorisches Milieu begünstigt werden könnte, in dem sich Autoimmunerkrankungen wie die MS entwickeln könnten (Leibowitz und Yan 2016). Ähnlich wie bei der MS ist auch die Induktion des EAE-Modells abhängig von der Aktivierung proinflammatorischer Mediatoren, von denen ebenfalls viele unter der Kontrolle von NF- $x$ B stehen (Pahan und Schmid 2000).

Ferner werden verschiedene Signalwege direkt mit der Regulation von Remyelinisierung und OPC-Differenzierung in Verbindung gebracht. Beispielsweise ist bekannt, dass pathologische Veränderungen im Wnt-Signalweg Remyelinisierungprozesse stören (Fancy et al. 2009) 
und dass eine Dysregulation im Notch-Signalweg inhibitorisch auf Differenzierung von OPCs wirken kann (Brosnan und John 2009; Tognatta und Miller 2016).

\subsection{Herunterregulation der Transkriptionsfaktoren Olig2 und Sox10 in MS-Läsionen}

Die Reifung und Differenzierung einer oligodendroglialen Vorläuferzelle zum reifen Oligodendrozyten ist abhängig von der regelrechten Funktion einer Reihe von Transkriptionsfaktoren, die sich in ihrer Funktion synergistisch ergänzen und beeinflussen können (Emery und Lu 2015). So gibt es Hinweise darauf, dass es dosisabhängige Wechselwirkungen zwischen den von uns untersuchten Transkriptionsfaktoren Sox10, Nkx2.2 und Olig2 gibt (Liu et al. 2007). Gerade eine verminderte Expression von Transkriptionsfaktoren wie Olig2 und Sox10 ist im Hinblick auf den Remyelinisierungsprozess als kritisch anzusehen. Dies liegt darin begründet, dass insbesondere der Myelin-Regulationsfaktor (MyRF), welchem im Rahmen der Oligodendrozytenreifung und Myelinbildung eine Schlüsselrolle zugeschrieben wird (Emery et al. 2009; Franklin und Ffrench-Constant 2017), unter dem regulatorischen Einfluss von Sox10 und Olig2 steht (Hornig et al. 2013; Yu et al. 2013).

Wegener und Kollegen (2015) zeigten in ihrer Arbeit, dass Olig2 in MS-Läsionen ein unphysiologisches Expressionsmuster aufweist, welches in der Regel mit der Läsionsaktivität korreliert. In ihren Untersuchungen konnten sie weiterhin aufzeigen, dass wiederum eine erhöhte Aktivität von Olig2 zu einer erhöhten Migrationsrate von OPCs, deren Differenzierung zu reifen Oligodendrozyten und einer verbesserten Myelinisierung im ZNS führen kann (Wegener et al. 2015).

So ist der Schluss zulässig, dass Pathologien, beispielsweise in Form einer verminderten Expression der genannten Transkriptionsfaktoren, weitreichende Folgen für die OPCs haben können (Stolt et al. 2002; Zhu et al. 2012; Mei et al. 2013). In noch unveröffentlichten Vorarbeiten unserer Arbeitsgruppe sowie den hier durchgeführten Tierexperimenten konnten wir z. T. eine Minderexpression von Olig2 beobachten, was möglicherweise die Regeneration in entmarkten Läsionen beeinträchtigen könnte.

Insbesondere der im Rahmen von Entzündungsreaktionen induzierte oxidative Stress führt nicht nur zu einer Herunterregulation der Expression von Sox10 und Olig2 (French et al. 2009), sondern ebenfalls zu einer Zunahme der Expression von für eine OPC-Differenzierung inhibitorischen Genen (wie z.B. Id2 und Id4) (Gokhan et al. 2005). 


\subsection{Vorkommen und mögliche Bedeutung von Olig2 $/ \mathrm{p} 25^{+}-$Zellen}

Geht man - wie für die MS vorgeschlagen und in Tiermodellen gezeigt - primär von einer selektiven Myelinzerstörung durch Autoantikörper aus, könnten reife Oligodendrozyten zunächst überleben und im Läsionsgebiet intakt verbleiben (Romanelli et al. 2016). Yeung und Kollegen (2019) sowie Duncan und Kollegen (2018) verwiesen in diesem Zusammenhang auf die Möglichkeit, dass eine Remyelinisierung primär von diesen verbliebenen Oligodendrozyten ausgehen könnte und nicht unbedingt von OPCs, wie in der Regel postuliert wird (Duncan et al. 2018; Yeung et al. 2019). Demzufolge könnte eine Remyelinisierung stattfinden, solange diese adulten, geschädigten Oligodendrozyten nicht untergehen (Cui et al. 2017).

Aufbauend auf bislang noch unveröffentlichten Arbeiten unserer Arbeitsgruppe wurden in dieser Arbeit ebenfalls Zellen untersucht, welche zwar p25 als spezifischen Marker für reife Oligodendrozyten exprimierten, in denen jedoch weitere wichtige oligodendrogliale Marker wie die Transkriptionsfaktoren Olig2 und Sox10 nicht oder nur sehr schwach nachzuweisen waren. Zellen mit diesen Markerkonstellationen sind bisher noch wenig untersucht und könnten möglicherweise einen Beitrag zu einem besseren Verständnis der in die frühe Pathogenese der MS involvierten Prozesse führen.

Es wäre denkbar, dass diese Zellen reife Oligodendrozyten darstellen, welche durch noch ungeklärte und möglicherweise vielfältige Mechanismen eine pathologische Genregulation der Expression der untersuchten Transkriptionsfaktoren erfahren haben und so in ihrer Funktion eingeschränkt sind.

In der Tat waren entsprechende Zellen sowohl in humanen MS-Biopsieproben als auch in den Tiermodellen in teils stark variierenden Verteilungen und Dichten nachzuweisen. In den untersuchten humanen Gewebeproben war beispielsweise der prozentuale Gesamtanteil für Sox10\%/p25 -Zellen im Läsionsareal höher als in den Periläsionsarealen oder der NAWM (Abbildung 4h).

Besonders in den Tiermodellen waren unsere Beobachtungen teils sehr heterogener Natur. Hier waren die Entwicklungen in den prozentualen Anteilen im EAE-Modell und im Cuprizon-Modell entgegengesetzter Natur. Während sich in der Spätphase des EAE-Modells beispielsweise der prozentuale Anteil der Olig2 $/ \mathrm{p} 25^{+}$-Zellen leicht vergrößerte, schien er sich in der Spätphase des Cuprizon-Modells zu verringern. Auch im Hinblick auf die Dichte dieser Zellen herrschte kein einheitliches Bild.

Weiterhin war beispielsweise in der Frühphase des Cuprizon-Modells eine im Vergleich zu den anderen Subpopulationen allgemein erhöhte Dichte von Olig2 $/ \mathrm{p} 25^{+}$-Zellen zu beobachten und lag dabei signifikant höher als im gesunden Kontrollgewebe. Dies könnte die spezifische oligodendrogliatoxische Pathogenese dieses Modells reflektieren. 
Interessanterweise waren die entsprechenden Dichtewerte für Olig2 $/ \mathrm{p} 25^{+}$-Zellen im Tiermodell auch stets vergleichbar oder gar höher als die von OPCs in den untersuchten Geweben.

Dies ist erwähnenswert, da Olig2 $/ \mathrm{p} 25^{+}$-Zellen auch in den Kontrollgeweben von gesunden Mäusen anzutreffen waren und dieses auch hier in teils höheren Dichten als OPCs. Diese Beobachtung lässt die Vermutung zu, dass Olig2 $/ \mathrm{p} 25^{+}$-Zellen bei Mäusen eine physiologische Zellpopulation darstellen könnten und nicht zwingend das Ergebnis pathologischer Einflüsse sein müssen.

So bleibt zu hinterfragen, inwieweit die beobachteten Zellen im Mausmodell mit denen im menschlichen Organismus verglichen werden können. Die Zellbiologie von Oligodendrozyten bei Mensch und Nagetier lässt sich nicht in jedem Aspekt vergleichen und ist teilweise recht unterschiedlicher Natur (Menge und Hörste 2013; Fard et al. 2017).

Dennoch bleibt auch beim Menschen die Möglichkeit zu diskutieren, ob es sich hier womöglich ebenfalls nur um ein transientes Phänomen im Sinne einer vorübergehenden Herunterregulation von Transkriptionsfaktoren als Teilaspekt einer physiologischen Reaktion auf Schädigungen handeln könnte.

\subsection{Epigenetische Regulationsmechanismen als möglicher Erklärungsansatz für Olig2 $/ \mathrm{p}^{2} 5^{+}$-Zellen}

Gesetzt den Fall, diese undefinierten Zellen stellen tatsächlich reife Oligodendrozyten dar, in denen Transkriptionsfaktoren möglicherweise pathologisch reguliert wurden: Welche Mechanismen könnten eine reduzierte Expression der untersuchten Transkriptionsfaktoren erklären?

Das Zusammenspiel von Transkriptionsfaktoren und epigenetischen Modifikatoren, einschließlich Histonmodifikationen, DNA-Methylierung und microRNAs, ist während der Entwicklung und für die Ausbildung spezifischer Zellreihen, wie die der Oligodendrozyten, unerlässlich (Liu und Casaccia 2010).

Epigenetische Regulationsmechanismen involvieren verschiedene hochgradig miteinander verschränkte Prozesse, wie beispielsweise die der enzymatischen Histonmodifikationen (Hsieh und Gage 2004). Solche Histonmodifikationen können durch Methylierung, Acetylierung, Phosphorylierung sowie Ubiquitylierung erfolgen und modulieren die Gentranskription an spezifischen Gen-Loci, wodurch Genprodukte wie Transkriptionsfaktoren reguliert werden können (Kouzarides 2007; Emery und Lu 2015).

Eine der am besten charakterisierten Histonmodifikationen ist die Histonacetylierung an Lysinresten, die durch Histonacetyltransferasen (HATs) und Histondeacetylasen (HDACs) 
realisiert wird. Die Histondeacylierung durch HDACs bewirkt zum Beispiel eine lokale Chromatinverdichtung, was zu einer Blockade des Zugangs zur Nukleotidsequenz und somit zu einer spezifischen Genabschaltung (Gen-Silencing) führt (Bachl et al. 2017).

Vieles deutet darauf hin, dass die Expression von Myelin-Genen eine solche Genabschaltung von Transkriptionsinhibitoren und die anschließende Zunahme in der Expression von Transkriptionsaktivatoren erfordert (Liu und Casaccia 2010).

So werden mehrere Mitglieder der HDAC-Familie in vivo in Oligodendrozyten exprimiert und sind wohl für deren Differenzierung, Myelinisierung sowie Remyelinisierung unerlässlich (Shen et al. 2005; Shen et al. 2008).

Beispielsweise führt eine Blockierung von HDAC1 und HDAC2 unter experimentellen Bedingungen zu einer fehlerhaften OPC-Differenzierung, da HDACs Komplexe mit Transkriptionsfaktoren bilden, welche wiederum inhibitorisch auf oligodendrogliale Differenzierung und Myelinisierung wirken können (Shen et al. 2008).

Beeinträchtigungen in der Funktion von HDACs könnten also so zur Akkumulation inhibitorischer Faktoren führen und damit ihren Einfluss auf ein möglicherweise pathologisches Niveau verstärken (McKinsey et al. 2000; Gao et al. 2002; Shen et al. 2008) und in der Folge zu einer Behinderung der Differenzierung von Oligodendrozyten führen (Ye et al. 2009).

Die Entdeckung solch enzymatischer Prozesse mit der Fähigkeit, epigenetische Modifikationen sowohl zu bewirken als auch rückgängig zu machen (Shi 2007; Cloos et al. 2008), stellt das Konzept der Differenzierung als ein "bidirektionales" Ereignis vor (Liu und Casaccia 2010). Störungen in epigenetischen Regulationsmechanismen könnten beispielsweise einen Hinweis auf die Herkunft der beobachteten Olig2 $/ \mathrm{p} 25^{+}$-Zellen geben, und sie möglicherweise als Korrelat einer pathologischen Regulation des Transkriptionsfaktors Olig2 identifizieren.

\subsection{Limitationen der vorliegenden Arbeit}

Die Deutung der Ergebnisse und Beobachtungen dieser Arbeit sollten unter Berücksichtigung folgender Aspekte erfolgen.

Zur Auswertung der immunfluoreszenzmarkierten Gewebeschnitte wurden diese gescannt und digitalisiert. Dies ermöglichte uns nicht nur eine Konservierung des frischen Färberesultats, sondern auch eine Dokumentation und spätere Evaluation der Analyseergebnisse.

Je höher die Anzahl der zu detektierenden Strukturen, umso höher liegt auch die Zahl der notwendigen Antikörper und der mit ihrer Anwendung verbundenen Zwischenschritte im Färbeprozess. 
In Färbungen mit mehreren Antikörpern können Wechselwirkungen nicht ausgeschlossen werden. Vereinzelte Präparate waren beispielsweise durch eine starke Hintergrundfärbung gekennzeichnet, welches eine Abgrenzung der Zielzellen von der Umgebung und möglichen Färbeartefakten erschwerte. Weiterhin untersuchten wir verhältnismäßig große GewebeAreale, welches mitunter zu einem unterschiedlichen Färberesultat auch innerhalb einer einzelnen Gewebeprobe führen konnte.

Insofern war eine akkurate Abbildung mehrerer Farbsignale auf einer Zielzelle, auch unter Anwendung digitaler Bildoptimierungstechniken sehr anspruchsvoll. Insbesondere in Geweben mit großen Untersuchungsarealen konnte das lokale Optimum für Parameter wie Kontrast und Helligkeit zu einer beeinträchtigten Darstellung an anderen Stellen des Scans führen. Daher wurden notwendige Bildoptimierungen vor dem Datenexport und stets nur anhand der digitalen Rohdaten in einer vom Scanner-Hersteller dafür entwickelten Softwareumgebung durchgeführt (Computer-Programm cellSens ${ }^{\text {TM }}$ (Olympus Europa SE \& CO. KG, Hamburg, Deutschland)).

Die Quantifizierung der Zellen musste unter Berücksichtigung mehrerer Subpopulationen in teilweise verschiedenen Arealen innerhalb eines einzelnen Gewebepräparats erfolgen. Um dies zu realisieren, war es notwendig die Scans zur weiteren Analyse in ein anderes Dateiformat zu überführen. Durch diesen notwendigen Datenexport war es jedoch, beispielsweise bei Präparaten mit starker Hintergrundfärbung, nicht mehr möglich einzelne Farb-Signale auszublenden, um im seltenen Zweifelsfall ein möglicherweise überstrahltes Signal bei Doppelfärbung noch zu unterscheiden.

Ein Alleinstellungsmerkmal dieser Studie war sicherlich die Möglichkeit, Gewebe von erst vor kurzem diagnostizierten MS-Patienten in einem noch sehr frühen Stadium der Erkrankung zu untersuchen. Eine Biopsie bei Verdacht auf MS ist nicht üblich und Biopsien solcher Patienten dementsprechend auch in nur in sehr begrenzter Anzahl verfügbar. Daraus erklärt sich auch, dass die untersuchte Stichprobengröße nur vergleichsweise klein ausfallen konnte. Hier bleibt weiterhin zu bedenken, dass Biopsien sehr unterschiedlich ausfallen können und daher nur unterschiedlich große Anteile der jeweiligen Areale angeschnitten und entnommen worden sind (vergleiche hierzu Abbildung 4a und Abbildung 5a)

In den Untersuchungen der toxisch-induzierten Demyelinisierung im Tiermodell (CuprizonModell) ist (wie beim EAE-Modell) eine beachtlich hohe Differenz in der Dichte von OPCs und reifen Oligodendrozyten zu den korrespondierenden Populationen im entsprechenden ZNS-Gewebe gesunder Mäuse zu beobachten. Neben der bereits erwähnten Möglichkeit, dass es hier zu einer Transformation von reifen Oligodendrozyten, also möglicherweise einer Verschiebung in der Dichte der Oligodendrozyten gekommen ist, ist auch eine weitere Erklärung für diese Beobachtung möglich. Die Identifikation des Läsionsareals und die Unterscheidung von Periläsion und NAWM erfolgte durch Beurteilung des immunfluoreszenzmarkierten Myelinproteins MBP. Bekanntermaßen ist Cuprizon, als Gift der zellulären Atmungskette, insbesondere für metabolisch hochaktive Oligodendrozyten toxisch und 
führt sehr rasch zum Zelltod dieser. So sind die vergleichbaren Dichtewerte für die reifen Oligodendrozyten oder OPCs in Läsionsarealen, der NAWM und in Periläsionsarealen womöglich durch den Umstand zu erklären, dass es bereits früh zu einer toxischen Wirkung und dem konsekutiven Zelluntergang von reifen Oligodendrozyten in den erwähnten Arealen gekommen, jedoch die verzögerte Abräumung von Myelinfragmenten noch nicht erfolgt war. Somit hätte es zu einer (fälschlichen) Zuordnung von toxisch entvölkerten Arealen als Periläsionsareal oder NAWM und so zu einer fehlerhaften Quantifizierung der Zellen kommen können.

\subsection{Fazit}

Die vorliegende Arbeit konnte zuvor gemachte Beobachtungen in Bezug auf Veränderungen in der Dichte reifer Oligodendrozyten in ihren Ergebnissen größtenteils reproduzieren. So war auch in unseren Untersuchungen die Dichte von reifen und somit myelinsierenden oder Myelin erhaltenden Oligodendrozyten in den untersuchten Läsionen zumeist niedriger als in umgebendem (mutmaßlich gesundem) Gewebe und darüber hinaus immer signifikant niedriger als in gesundem Kontrollgewebe. Diese Beobachtung traf sowohl auf humane Oligodendrozyten als auch auf Oligodendrozyten im EAE-Maus-Modell zu und wurde als Korrelat einer sekundären oder womöglich gar primären Zellschädigung von Oligodendrozyten gedeutet.

Bei Betrachtung der prozentualen Anteile der jeweiligen Subpopulationen war zwar der Anteil von OPCs bis auf die Frühphase des Cuprizon-Models in allen Geweben erhöht (siehe Abbildung 4h, Abbildung 5g, Abbildung 6d, Abbildung 7h, Abbildung 8d und Abbildung 9f), bildete jedoch in den meisten Fällen keinen statistisch relevanten Dichteunterschied aus. Wir deuteten dies einerseits als mögliches Ergebnis eines zytotoxischen Einflusses auf OPCs, welcher in seinem zellschädigenden Ausmaß dem der reaktiven Proliferation entspricht und daher keinen signifikanten Dichtezuwachs in den verschiedenen Untersuchungsarealen verzeichnen lässt. Andererseits kann die fehlende Ausbildung eines statistisch relevanten Dichteunterschiedes in den jeweiligen Geweben auch das Ergebnis eines Differenzierungsblockes sein.

Darüber hinaus konnten wir die bisher noch wenig definierten und in Vorarbeiten gesehenen Olig2 $/ \mathrm{p} 25^{+}$-Zellen sowohl in humanen als auch tierexperimentell erzeugten Geweben nachweisen. Wir konnten zeigen, dass oligodendrogliale Zellpopulationen mit der Expression von für reife Oligodendrozyten spezifischem p25, jedoch ohne oder nur mit geringer Expression der funktions- und zellreihenspezifischen Transkriptionsfaktoren Olig2 oder Sox10 sowohl in humanen als auch tierexperimentell erzeugten Gewebeproben anzutreffen waren und dass deren Dichtewerte je nach den koexprimierten Transkriptionsfaktoren in den unterschiedli- 
chen Arealen stark variierten. Eine belastbare Deutung oder gar das Ableiten einer Gesetzmäßigkeit für das Auftreten dieser Zellen war aufgrund der ausgeprägten Heterogenität in den beobachteten Dichtewerten nur eingeschränkt möglich. Insbesondere im Hinblick auf den hohen Anteil dieser Zellpopulationen in gesundem Kontrollgewebe von Mäusen scheint eine speziesübergreifende Einordnung dieser Zellen als Ergebnis einer zugrundeliegenden Pathologie nicht zulässig. Gewiss ist es möglich, dass es sich bei diesen Zellen um reife Oligodendrozyten handelt, welche eine pathologische Regulation funktionsspezifischer Transkriptionsfaktoren erfahren haben und somit in ihrer Funktion eingeschränkt sind. Diese Deutung würde sich in Anbetracht der vielfältigen möglichen Schädigungsmechanismen für Oligodendrozyten mit dem Bild eines generell zellschädigenden Milieus im Rahmen der MS decken. Tatsächlich muss aber auch die Möglichkeit berücksichtigt werden, dass es sich bei diesen Zellen unter Umständen um ein transientes Zwischenstadium im Rahmen der oligodendroglialen Reifung oder sogar eine physiologische Subpopulation von Oligodendrozyten handeln könnte.

Das übergeordnete Ziel dieser Arbeit war es, ein besseres Verständnis für das Schicksal verschiedener Zellpopulationen der oligodendroglialen Reihe im Rahmen der MS bzw. entmarkender Tiermodelle zu erlangen.

Die Ergebnisse der durchgeführten Untersuchungen lieferten zum Teil überraschende Ergebnisse und deckten sich zum Teil mit unseren Erwartungen.

Insbesondere im Hinblick auf die Erkenntnis des häufigen Auftretens von Olig2 / p25 -Zellen hoffen wir den Grundstein für weiterführende Studien gelegt zu haben. Durch Verfeinerung methodischer Aspekte und unter Berücksichtigung einer größeren Zahl von wissenschaftlich quantifizierbaren Merkmalen scheint die weitergehende Untersuchung dieser Zellpopulation ein Weg, um ein besseres Verständnis für das Krankheitsgeschehen im Rahmen von demyelinisierenden Erkrankungen zu erlangen. Für die Zukunft wäre es sicherlich interessant zu untersuchen, ob und in welcher Dichte Olig2 $/ \mathrm{p} 25^{+}$-Zellen auch in gesundem Humangewebe vorzufinden sind. 


\section{$5 \quad$ Zusammenfassung}

Die multiple Sklerose (MS), auch als Enzephalomyelitis disseminata bezeichnet, ist eine demyelinisierende Erkrankung des zentralen Nervensystems (ZNS) und die häufigste nichttraumatische Ursache für eine Behinderung im jungen Erwachsenenalter. Sie ist gekennzeichnet durch Entmarkungsherde, die im gesamten ZNS auftreten können, sowie einer variablen Zerstörung von Oligodendrozyten, Myelin und Axonen. Nach heutigem Stand der Forschung gilt die MS als nicht heilbar und ihre Ätiologie ist nicht eindeutig geklärt. Diskutiert wird neben einer autoimmunen Genese ebenfalls eine primäre Schädigung von Oligodendrozyten.

Ziel der vorliegenden Arbeit war es, die Dichte von Zellen der oligodendroglialen Reihe in frühen Läsionen von MS-Patienten sowie in tierexperimentell erzeugten Gewebeproben zu untersuchen. Tierexperimentell induzierte Demyelinisierungen wurden im Rahmen des Cuprizon-Modells (toxische Demyelinisierung) sowie im Rahmen des EAE-Modells (autoimmun-induzierte Demyelinisierung) im ZNS der Maus untersucht. Mit Hilfe von Immunfluoreszenz-Mehrfachmarkierungen wurden oligodendrogliale Subpopulationen identifiziert, in definierten Untersuchungsarealen lokalisiert und anschließend quantifiziert.

Die Veränderungen in der Dichte verschiedener Oligodendrozytenpopulationen stellten sich in unseren Untersuchungen je nach Gewebe und Krankheitsmodell heterogen dar. Im Vergleich von entmarkten Läsionsarealen zu gesundem Gewebe (NAWM) beim Menschen bzw. Kontrollgewebe im Tiermodell war in der Regel eine reduzierte Dichte reifer Oligodendrozyten zu beobachten. Ähnliches galt für mutmaßlich erst kürzlich differenzierte, reife Oligodendrozyten in den untersuchten Gewebeproben von MS-Patienten.

In Vorarbeiten unserer Arbeitsgruppe wurden vor allem in Läsionsarealen oligodendrogliale Zellpopulationen beobachtet, in denen zwar p25 als Marker für reife Oligodendrozyten, jedoch nicht oder nur schwach Olig2 als oligodendrozytenspezifischer Transkriptionsfaktor exprimiert war. Solche Zellen mit schwacher bzw. herunterregulierter Expression von Olig2 konnten wir unter Berücksichtigung weiterer oligodendrozytenspezifischer Markerproteine auch in den vorliegenden Untersuchungen nachweisen. Zwar waren die Dichten für diese Zellen je nach Modell und untersuchtem Areal sehr variabel, doch waren sie in allen Geweben sowohl von Maus als auch Mensch nachzuweisen. Interessanterweise konnten wir Olig2/p25+-Zellen auch im ZNS-Gewebe gesunder Mäuse nachweisen, was somit eine speziesübergreifende Attribuierung als Korrelat einer Pathologie nicht ohne Weiteres zulässt.

Zusammenfassend zeigt sich in unseren Untersuchungen eine ausgeprägte Heterogenität in der Auswirkung demyelinisierender Prozesse auf die oligodendrogliale Zelldichte, sowohl beim Menschen als auch im Tiermodell. Dabei ist der Verlust von reifen p25+-Oligodendrozyten der über die verschiedenen Modelle reproduzierbarste Befund. Hier vermuten wir ein mögliches Zusammenspiel aus Zellschädigung und konsekutivem Zelluntergang und einer möglichen Störung in der Differenzierung von OPCs zu reifen Oligodendrozyten. 


\section{$6 \quad$ Literaturverzeichnis}

Acs P, Kalman B (2012): Pathogenesis of Multiple Sclerosis: What Can We Learn from the Cuprizone Model, Methods Mol Biol $\underline{900}$, 403-431

Aguirre A, Rubio ME, Gallo V (2010): Notch and EGFR pathway interaction regulates neural stem cell number and self-renewal. Nature $\underline{467}, 323-327$

Arnett HA, Mason J, Marino M, Suzuki K, Matsushima GK, Ting JP (2001): TNF alpha promotes proliferation of oligodendrocyte progenitors and remyelination. Nat Neurosci $\underline{4}, 1116$ 1122

Ascherio A, Munger KL (2007): Environmental risk factors for multiple sclerosis. Part I: The role of infection. Ann Neurol 61, 288-299

Aubin F (2003): Mechanisms involved in ultraviolet light-induced immunosuppression. Eur J Dermatol $\underline{13}, 515-523$

Bachl N, Löllgen H, Tschan H, Wackerhage H, Wessner B (Hrsg.): Molekulare Sport- und Leistungsphysiologie: Molekulare, zellbiologische und genetische Aspekte der körperlichen Leistungsfähigkeit. Springer, Heidelberg 2017

Back SA, Luo NL, Borenstein NS, Levine JM, Volpe JJ, Kinney HC (2001): Late Oligodendrocyte Progenitors Coincide with the Developmental Window of Vulnerability for Human Perinatal White Matter Injury. J Neurosci 21, 1302-1312

Back SA, Tuohy TMF, Chen H, Wallingford N, Craig A, Struve J, Luo NL, Banine F, Liu Y, Chang A, et al. (2005): Hyaluronan accumulates in demyelinated lesions and inhibits oligodendrocyte progenitor maturation. Nat Med 11, 966

Baer AS, Syed YA, Kang SU, Mitteregger D, Vig R, ffrench-Constant C, Franklin RJM, Altmann F, Lubec G, Kotter MR (2009): Myelin-mediated inhibition of oligodendrocyte precursor differentiation can be overcome by pharmacological modulation of Fyn-RhoA and protein kinase C signalling. Brain 132, 465-481

Bakshi R, Hutton GJ, Miller JR, Radue E-W (2004): The use of magnetic resonance imaging in the diagnosis and long-term management of multiple sclerosis. Neurology $\underline{63}$, S3-11

Barnett MH, Prineas JW (2004): Relapsing and remitting multiple sclerosis: Pathology of the newly forming lesion. Ann Neurol $\underline{55}, 458-468$

Bartholomäus I, Kawakami N, Odoardi F, Schläger C, Milikovic D, Ellwart JW, Klinkert WEF, Flügel-Koch C, Issekutz TB, Wekerle H, Flügel A (2009): Effector T cell interactions with meningeal vascular structures in nascent autoimmune CNS lesions. Nature $\underline{462}, 94-98$

Baumann N, Pham-Dinh D (2001): Biology of Oligodendrocyte and Myelin in the Mammalian Central Nervous System. Physiol Rev $\underline{81}, 871-927$

Baxter AG (2007): The origin and application of experimental autoimmune encephalomyelitis. Nat Rev Immunol 7, 904-912 
Beecham AH, Consortium (IMSGC) IMSG, Patsopoulos NA, Xifara DK, Davis MF, Kemppinen A, Cotsapas C, Shah TS, Spencer C, Booth D, et al. (2013): Analysis of immune-related loci identifies 48 new susceptibility variants for multiple sclerosis. Nat Genet $\underline{45}, 1353-1360$

Blakemore WF (1972): Observations on oligodendrocyte degeneration, the resolution of status spongiosus and remyelination in cuprizone intoxication in mice. J Neurocytol $\underline{1}, 413-426$

Boyd A, Zhang H, Williams A (2013): Insufficient OPC migration into demyelinated lesions is a cause of poor remyelination in MS and mouse models. Acta Neuropathol $\underline{125}, 841-859$

Bradl M, Lassmann H (2010): Oligodendrocytes: biology and pathology. Acta Neuropathol 119 , $37-53$

Brandt T, Diener H-C, Gerloff C (Hrsg.): Therapie und Verlauf neurologischer Erkrankungen. 6. Auflage; Kohlhammer, Stuttgart 2012

Brogi A, Strazza M, Melli M, Costantino-Ceccarini E (1997): Induction of intracellular ceramide by interleukin- $1 \beta$ in oligodendrocytes. J Cell Biochem $\underline{66}, 532-541$

Brosnan CF, John GR (2009): Revisiting Notch in remyelination of multiple sclerosis lesions. J Clin Invest $\underline{119}, 10-13$

Brück W (2005): The pathology of multiple sclerosis is the result of focal inflammatory demyelination with axonal damage. J Neurol $\underline{252}$, v3-v9

Brück W, Porada P, Poser S, Rieckmann P, Hanefeld F, Kretzschmarch HA, Lassmann H (1995): Monocyte/macrophage differentiation in early multiple sclerosis lesions: Macrophages in MS. Ann Neurol 38, 788-796

Brück W, Sommermeier N, Bergmann M, Zettl U, Goebel HH, Kretzschmar HA, Lassmann H (1996): Macrophages in Multiple Sclerosis. J Immunobiol 195, 588-600

Brunner C, Lassmann H, Waehneldt TV, Matthieu J-M, Linington C (1989): Differential Ultrastructural Localization of Myelin Basic Protein, Myelin/Oligodendroglial Glycoprotein, and 2',3'-Cyclic Nucleotide 3'-Phosphodiesterase in the CNS of Adult Rats. J Neurochem $\underline{52}$, 296-304

Buffo A, Vosko MR, Ertürk D, Hamann GF, Jucker M, Rowitch D, Götz M (2005): Expression pattern of the transcription factor Olig2 in response to brain injuries: Implications for neuronal repair. Proc Natl Acad Sci U S A 102, 18183-18188

Carbajal KS, Schaumburg C, Strieter R, Kane J, Lane TE (2010): Migration of engrafted neural stem cells is mediated by CXCL12 signaling through CXCR4 in a viral model of multiple sclerosis. Proc Natl Acad Sci U S A 107, 11068-11073

Carlton WW (1966): Response of mice to the chelating agents sodium diethyldithiocarbamate, $\alpha$ benzoinoxime, and biscyclohexanone oxaldihydrazone. Toxicol Appl Pharmacol $\underline{8}, 512$ 521

Chang A, Nishiyama A, Peterson J, Prineas J, Trapp BD (2000): NG2-Positive Oligodendrocyte Progenitor Cells in Adult Human Brain and Multiple Sclerosis Lesions. J Neurosci 20, 6404-6412

Chew L-J, Fusar-Poli P, Schmitz T (2013): Oligodendroglial Alterations and the Role of Microglia in White Matter Injury: Relevance to Schizophrenia. Dev Neurosci 35, 102-129 
Chiaravalloti ND, DeLuca J (2008): Cognitive impairment in multiple sclerosis. Lancet Neurol 7 , 1139-1151

Chwastiak L, Ehde DM, Gibbons LE, Sullivan M, Bowen JD, Kraft GH (2002): Depressive Symptoms and Severity of Illness in Multiple Sclerosis: Epidemiologic Study of a Large Community Sample. Am J Psychiatry 159, 1862-1868

Cloos PAC, Christensen J, Agger K, Helin K (2008): Erasing the methyl mark: histone demethylases at the center of cellular differentiation and disease. Genes Dev 22, 1115-1140

Compston A, Coles A (2002): Multiple sclerosis. Lancet $\underline{359}, 1221-1231$

Compston A, McDonald I, Noseworthy J, Lassmann H, Miller D, Smith K, Wekerle H, Confavreux (Hrsg.): McAlpine's Multiple Sclerosis. 4. Auflage; Elsevier, Philadelphia 2006

Copray JCVM, Küst BM, Mantingh-Otter I, Boddeke HWGM (2005): p75NTR independent oligodendrocyte death in cuprizone-induced demyelination in C57BL/6 mice. Neuropathol Appl Neurobiol 31, 600-609

Crawford JD, McIvor GP (1985): Group psychotherapy: Benefits in multiple sclerosis. Arch Phys Med Rehabil 66, 810-813

Cua DJ, Sherlock J, Chen Y, Murphy CA, Joyce B, Seymour B, Lucian L, To W, Kwan S, Churakova T, et al. (2003): Interleukin-23 rather than interleukin-12 is the critical cytokine for autoimmune inflammation of the brain. Nature $\underline{421}, 744-748$

Cui Q-L, Khan D, Rone M, Rao VTS, Johnson RM, Lin YH, Bilodeau P-A, Hall JA, Rodriguez M, Kennedy TE, et al. (2017): Sublethal oligodendrocyte injury: A reversible condition in multiple sclerosis? Ann Neurol $\underline{81}, 811-824$

Dean G, Elian M (1997): Age at immigration to England of Asian and Caribbean immigrants and the risk of developing multiple sclerosis. J Neurol Neurosurg Psychiatry $\underline{63}, 565-568$

Denic A, Johnson AJ, Bieber AJ, Warrington AE, Rodriguez M, Pirko I (2011): The relevance of animal models in multiple sclerosis research. Pathophysiology $\underline{18}, 21-29$

Domercq M, Sánchez-Gómez MV, Sherwin C, Etxebarria E, Fern R, Matute C (2007): System xcand Glutamate Transporter Inhibition Mediates Microglial Toxicity to Oligodendrocytes. J Immunol $\underline{178}, 6549-6556$

Domingues HS, Portugal CC, Socodato R, Relvas JB (2016): Oligodendrocyte, Astrocyte, and Microglia Crosstalk in Myelin Development, Damage, and Repair. Front Cell Dev Biol 4, 71

Döring A, Paul F, Dörr J (2013): Vitamin D und Multiple Sklerose. Nervenarzt 또, 173-189

Duncan ID, Radcliff AB, Heidari M, Kidd G, August BK, Wierenga LA (2018): The adult oligodendrocyte can participate in remyelination. Proc Natl Acad Sci USA 115, E11807E11816

Dziembowska M, Tham TN, Lau P, Vitry S, Lazarini F, Dubois-Dalcq M (2005): A role for CXCR4 signaling in survival and migration of neural and oligodendrocyte precursors. Glia $\underline{50}, 258-269$

Einstein ER, Robertson DM, DiCaprio JM, Moore W (1962): The Isolation from Bovine Spinal Cord of a Homogeneous Protein with Encephalitogenic Activity*. J Neurochem 9, 353361 
Emery B (2010): Regulation of Oligodendrocyte Differentiation and Myelination. Science $\underline{330}$, 779_ 782

Emery B, Lu QR (2015): Transcriptional and Epigenetic Regulation of Oligodendrocyte Development and Myelination in the Central Nervous System. Cold Spring Harb Perspect Biol 7, a020461

Emery B, Agalliu D, Cahoy JD, Watkins TA, Dugas JC, Mulinyawe SB, Ibrahim A, Ligon KL, Rowitch DH, Barres BA (2009): Myelin Gene Regulatory Factor Is a Critical Transcriptional Regulator Required for CNS Myelination. Cell 138, 172-185

Fancy SPJ, Zhao C, Franklin RJM (2004): Increased expression of Nkx2.2 and Olig2 identifies reactive oligodendrocyte progenitor cells responding to demyelination in the adult CNS. Mol Cell Neurosci 27, 247-254

Fancy SPJ, Baranzini SE, Zhao C, Yuk D-I, Irvine K-A, Kaing S, Sanai N, Franklin RJM, Rowitch DH (2009): Dysregulation of the Wnt pathway inhibits timely myelination and remyelination in the mammalian CNS. Genes Dev $\underline{23}, 1571-1585$

Fancy SPJ, Kotter MR, Harrington EP, Huang JK, Zhao C, Rowitch DH, Franklin RJM (2010): Overcoming remyelination failure in multiple sclerosis and other myelin disorders. Exp Neurol 225, $18-23$

Fard MK, van der Meer F, Sánchez P, Cantuti-Castelvetri L, Mandad S, Jäkel S, Fornasiero EF, Schmitt S, Ehrlich M, Starost L, et al. (2017): BCAS1 expression defines a population of early myelinating oligodendrocytes in multiple sclerosis lesions. Sci Transl med $\underline{9}$, eaam7816

Franklin RJM (2002): Why does remyelination fail in multiple sclerosis? Nat Rev Neurosci $\underline{3}$, 705714

Franklin RJM, ffrench-Constant C (2008): Remyelination in the CNS: from biology to therapy. Nat Rev Neurosci $\underline{9}$, 839-855

Franklin RJM, Goldman SA (2015): Glia Disease and Repair-Remyelination. Cold Spring Harb Perspect Biol a020594

Franklin RJM, Ffrench-Constant C (2017): Regenerating CNS myelin - from mechanisms to experimental medicines. Nat Rev Neurosci $\underline{18}, 753-769$

French HM, Reid M, Mamontov P, Simmons RA, Grinspan JB (2009): Oxidative stress disrupts oligodendrocyte maturation. J Neurosci Res $\underline{87}, 3076-3087$

Freund J, McDermott K (1942): Sensitization to Horse Serum by Means of Adjuvants. Proc Soc Exp Biol Med 49, 548-553

Fünfschilling U, Supplie LM, Mahad D, Boretius S, Saab AS, Edgar J, Brinkmann BG, Kassmann CM, Tzvetanova ID, Möbius W, et al. (2012): Glycolytic oligodendrocytes maintain myelin and long-term axonal integrity. Nature $\underline{485}, 517-521$

Furtado GC, Marcondes MCG, Latkowski J-A, Tsai J, Wensky A, Lafaille JJ (2008): Swift Entry of Myelin-Specific T Lymphocytes into the Central Nervous System in Spontaneous Autoimmune Encephalomyelitis. J Immunol 181, 4648-4655

Gao L, Cueto MA, Asselbergs F, Atadja P (2002): Cloning and Functional Characterization of HDAC11, a Novel Member of the Human Histone Deacetylase Family. J Biol Chem 277, 25748-25755 
Giovannoni G, Cutter GR, Lunemann J, Martin R, Münz C, Sriram S, Steiner I, Hammerschlag MR, Gaydos CA (2006): Infectious causes of multiple sclerosis. Lancet Neurol $\underline{5}$, 887-894

Glezer I, Lapointe A, Rivest S (2006): Innate immunity triggers oligodendrocyte progenitor reactivity and confines damages to brain injuries. FASEB J 20, 750-752

Gokhan S, Marin-Husstege M, Yung SY, Fontanez D, Casaccia-Bonnefil P, Mehler MF (2005): Combinatorial Profiles of Oligodendrocyte-Selective Classes of Transcriptional Regulators Differentially Modulate Myelin Basic Protein Gene Expression. J Neurosci 25, 8311-8321

Gold R, Linington C, Lassmann H (2006): Understanding pathogenesis and therapy of multiple sclerosis via animal models: 70 years of merits and culprits in experimental autoimmune encephalomyelitis research. Brain $\underline{129}$, 1953-1971

Gudz TI, Komuro H, Macklin WB (2006): Glutamate Stimulates Oligodendrocyte Progenitor Migration Mediated via an $\alpha \mathrm{v}$ Integrin/Myelin Proteolipid Protein Complex. J Neurosci 26, $2458-2466$

Hanafy KA, Sloane JA (2011): Regulation of remyelination in multiple sclerosis. FEBS Lett $\underline{585}$, 3821-3828

Hantschke M, Palmedo G: Immunhistologische Techniken. In: Cerroni L, Garbe C, Metze D, Kutzner H, Kerl H (Hrsg.): Histopathologie der Haut. 2. Auflage Springer, Berlin 2016, $15-35$

Harauz G, Boggs JM (2013): Myelin management by the 18.5-kDa and 21.5-kDa classic myelin basic protein isoforms. J Neurochem $\underline{125}, 334-361$

Hartung H-P, Kieseier BC, Hemmer B (2005): Purely systemically active anti-inflammatory treatments are adequate to control multiple sclerosis. J Neurol 252, v30-v37

Hauk A (2014): Der Unterschied zwischen mono- und polyklonalen Antikörpern. Biol unserer Zeit 44, 156-156

Hehlgans T, Pfeffer K (2005): The intriguing biology of the tumour necrosis factor/tumour necrosis factor receptor superfamily: players, rules and the games. Immunology $\underline{115}, 1-20$

Hein T, Hopfenmüller W (2000): Hochrechnung der Zahl an Multiple Sklerose erkrankten Patienten in Deutschland. Nervenarzt $\underline{71}, 288-294$

Henze T, Pette M, Rieckmann P, V. Toyka K, Behandlung S (2004): Symptomatische Therapie der Multiplen Sklerose. Psychoneuro $\underline{30}$, 393-400

Hoffmann S, Vitzthum K, Mache S, Spallek M, Quarcoo D, Groneberg DA, Uibel S (2009): Multiple Sklerose: Epidemiologie, Pathophysiologie, Diagnostik und Therapie. Multiple Sklerose $\underline{10}, 143$

Höftberger R, Fink S, Aboul-Enein F, Botond G, Olah J, Berki T, Ovadi J, Lassmann H, Budka H, Kovacs GG (2010): Tubulin polymerization promoting protein (TPPP/p25) as a marker for oligodendroglial changes in multiple sclerosis. Glia $\underline{58}, 1847-1857$

Holstiege J, Steffen A, Goffrier B, Bätzing J (2017): Epidemiologie der Multiplen Sklerose - Eine populationsbasierte deutschlandweite Studie. Versorgungsatlas - Bericht 17/09, Verorgungsatlas.de, Berlin 2017. https://www.versorgungsatlas.de/themen/alle-analysen-nach-datum-sortiert/?tab=6\&uid=86; zuletzt abgerufen am 19.09.19 
Horiuchi M, Itoh A, Pleasure D, Itoh T (2006): MEK-ERK Signaling Is Involved in Interferon- $\gamma-$ induced Death of Oligodendroglial Progenitor Cells. J Biol Chem 281, 20095-20106

Hornig J, Fröb F, Vogl MR, Hermans-Borgmeyer I, Tamm ER, Wegner M (2013): The Transcription Factors Sox10 and Myrf Define an Essential Regulatory Network Module in Differentiating Oligodendrocytes. PloS Genet $\underline{9}$, e1003907

Hsieh J, Gage FH (2004): Epigenetic control of neural stem cell fate. Curr Opin Genet Dev 14 , $461-469$

Hughes EG, Kang SH, Fukaya M, Bergles DE (2013): Oligodendrocyte progenitors balance growth with self-repulsion to achieve homeostasis in the adult brain. Nat Neurosci $\underline{16}, 668-676$

Irvine K-A, Blakemore WF (2006): Age increases axon loss associated with primary demyelination in cuprizone-induced demyelination in C57BL/ 6 mice. J Neuroimmunol 175, 69-76

Jakovcevski I, Zecevic N (2005): Olig Transcription Factors Are Expressed in Oligodendrocyte and Neuronal Cells in Human Fetal CNS. J Neurosci 25, 10064-10073

Jakovcevski I, Filipovic R, Mo Z, Rakic S, Zecevic N (2009): Oligodendrocyte development and the onset of myelination in the human fetal brain. Front Neuroanat $\underline{3}, 5$

Jana A, Pahan K (2007): Oxidative Stress Kills Human Primary Oligodendrocytes Via Neutral Sphingomyelinase: Implications for Multiple Sclerosis. J Neuroimmune Pharm 2 2, 184-193

Jurewicz A, Matysiak M, Tybor K, Kilianek L, Raine CS, Selmaj K (2005): Tumour necrosis factorinduced death of adult human oligodendrocytes is mediated by apoptosis inducing factor. Brain 128, 2675-2688

Juurlink BHJ (1997): Response of Glial Cells to Ischemia: Roles of Reactive Oxygen Species and Glutathione. Neurosci Biobehav Rev 21, 151-166

Káradóttir R, Cavelier P, Bergersen LH, Attwell D (2005): NMDA receptors are expressed in oligodendrocytes and activated in ischaemia. Nature $\underline{438}, 1162-1166$

Kettenmann H, Verkhratsky A (2011): Neuroglia, der lebende Nervenkitt. Fortschr Neurol Psychiatrie $\underline{79}, 588-597$

Kipp M, Clarner T, Dang J, Copray S, Beyer C (2009): The cuprizone animal model: new insights into an old story. Acta Neuropathol $\underline{118}, 723-736$

Kitada M, Rowitch DH (2006): Transcription factor co-expression patterns indicate heterogeneity of oligodendroglial subpopulations in adult spinal cord. Glia $\underline{54}, 35-46$

Kotelnikova E, Bernardo-Faura M, Silberberg G, Kiani NA, Messinis D, Melas IN, Artigas L, Schwartz E, Mazo I, Masso M, et al. (2015): Signaling networks in MS: A systems-based approach to developing new pharmacological therapies. Mult Scler 21, 138-146

Kotter MR, Li W-W, Zhao C, Franklin RJM (2006): Myelin Impairs CNS Remyelination by Inhibiting Oligodendrocyte Precursor Cell Differentiation. J Neurosci 26, 328-332

Kouzarides T (2007): Chromatin Modifications and Their Function. Cell 128, 693-705

Kucenas S, SNELL H, APPEL B (2008): nkx2.2a promotes specification and differentiation of a myelinating subset of oligodendrocyte lineage cells in zebrafish. Neuron Glia Biol 4, 71 
Kuhlmann T, Miron V, Cuo Q, Wegner C, Antel J, Brück W (2008): Differentiation block of oligodendroglial progenitor cells as a cause for remyelination failure in chronic multiple sclerosis. Brain 131, 1749-1758

Kuhlmann T, Goldschmidt T, Antel J, Wegner C, König F, Metz I, Brück W (2009): Gender differences in the histopathology of MS? J Neurol Sci 286, 86-91

Laatsch RH, Kies MW, Gordon S, Alvord EC (1962): The Encephalomyelitic Activity of Myelin Isolated by Ultracentrifugation. J Exp Med $\underline{115}, 777-788$

Lang G: Histotechnik: Praxislehrbuch für die biomedizinische Analytik. 2 Auflage; Springer, Wien 2013

Lassmann H: The Pathology of Inflammatory Demyelinating Lesions; in: (Lassmann H (Hrsg.) Comparative Neuropathology of Chronic Experimental Allergic Encephalomyelitis and Multiple Sclerosis. Springer, Berlin 1983, 9-95

Lassmann H, Brück W, Lucchinetti C, Rodriguez M (1997): Remyelination in multiple sclerosis. Mult Scler $\underline{3}, 133-136$

Lebar R, Lubetzki C, Vincent C, Lombrail P, Boutry JM (1986): The M2 autoantigen of central nervous system myelin, a glycoprotein present in oligodendrocyte membrane. Clin Exp Immunol 66, 423-434

Lee Y, Morrison BM, Li Y, Lengacher S, Farah MH, Hoffman PN, Liu Y, Tsingalia A, Jin L, Zhang P-W, et al. (2012): Oligodendroglia metabolically support axons and contribute to neurodegeneration. Nature $\underline{487}, 443-448$

Lehotzky A, Tőkési N, Gonzalez-Alvarez I, Merino V, Bermejo M, Orosz F, Lau P, Kovacs GG, Ovádi J (2008): Progress in the development of early diagnosis and a drug with unique pharmacology to improve cancer therapy. Philos Trans R Soc Lond B Biol Sci $\underline{366}$, 3599_ 3617

Leibowitz SM, Yan J (2016): NF- $x$ B Pathways in the Pathogenesis of Multiple Sclerosis and the Therapeutic Implications. Front Mol Neurosci $\underline{9}, 84$

Levine JM, Reynolds R, Fawcett JW (2001): The oligodendrocyte precursor cell in health and disease. Trends Neurosci $24,39-47$

Liebetanz D, Merkler D (2006): Effects of commissural de- and remyelination on motor skill behaviour in the cuprizone mouse model of multiple sclerosis. Exp Neurol 202, 217-224

Ligon KL, Alberta JA, Kho AT, Weiss J, Kwaan MR, Nutt CL, Louis DN, Stiles CD, Rowitch DH (2004): The oligodendroglial lineage marker OLIG2 is universally expressed in diffuse gliomas. J Neuropathol Exp Neurol $\underline{63}$, 499-509

Limmroth V, Sindern E (Hrsg.): Multiple Sklerose. Thieme, Stuttgart 2004

Lindsey JW (2017): Antibodies to the Epstein-Barr virus proteins BFRF3 and BRRF2 cross-react with human proteins. J Neuroimmunol $\underline{310}$, 131-134

Lisak RP, Benjamins JA, Bealmear B, Nedelkoska L, Studzinski D, Retland E, Yao B, Land S (2009): Differential effects of Th1, monocyte/macrophage and Th2 cytokine mixtures on early gene expression for molecules associated with metabolism, signaling and regulation in central nervous system mixed glial cell cultures. J of Neuroinflammation $\underline{6}, 4$ 
Liu J, Casaccia P (2010): Epigenetic regulation of oligodendrocyte identity. Trends Neurosci $\underline{33}$, 193-201

Liu J, Dietz K, DeLoyht JM, Pedre X, Kelkar D, Kaur J, Vialou V, Lobo MK, Dietz DM, Nestler EJ, et al. (2012): Impaired adult myelination in the prefrontal cortex of socially isolated mice. Nat Neurosci 15, 1621-1623

Liu Z, Hu X, Cai J, Liu B, Peng X, Wegner M, Qiu M (2007): Induction of oligodendrocyte differentiation by Olig2 and Sox10: evidence for reciprocal interactions and dosage-dependent mechanisms. Dev Biol 302, 683-693

Lublin FD, Reingold SC (1996): Defining the clinical course of multiple sclerosis. Neurology $\underline{46}$, 907

Lublin FD, Reingold SC, Cohen JA, Cutter GR, Sorensen PS, Thompson AJ, Wolinsky JS, Balcer LJ, Banwell B, Barkhof F, et al. (2014): Defining the clinical course of multiple sclerosis: The 2013 revisions. Neurology $\underline{83}, 278-286$

Lucchinetti CF (2005): Update on the International Project on Pathologic Correlates in MS. Mult Scler 11, 99-100

Lucchinetti CF, Brück W, Rodriguez M, Lassmann H (1996): Distinct Patterns of Multiple Sclerosis Pathology Indicates Heterogeneity in Pathogenesis. Brain Pathol 6, 259-274

Lucchinetti CF, Brück W, Parisi J, Scheithauer B, Rodriguez M, Lassmann H (1999): A quantitative analysis of oligodendrocytes in multiple sclerosis lesions. A study of 113 cases. Brain $\underline{122}$, 2279-2295

Lucchinetti CF, Brück W, Parisi J, Scheithauer B, Rodriguez M, Lassmann H (2000): Heterogeneity of multiple sclerosis lesions: Implications for the pathogenesis of demyelination. Ann Neurol $\underline{47}, 707-717$

Lucchinetti CF, Gavrilova RH, Metz I, Parisi JE, Scheithauer BW, Weigand S, Thomsen K, Mandrekar J, Altintas A, Erickson BJ, et al. (2008): Clinical and radiographic spectrum of pathologically confirmed tumefactive multiple sclerosis. Brain 131, 1759-1775

Lucchinetti CF, Popescu BFG, Bunyan RF, Moll NM, Roemer SF, Lassmann H, Brück W, Parisi JE, Scheithauer BW, Giannini C, et al. (2011): Inflammatory Cortical Demyelination in Early Multiple Sclerosis. N Engl J Med $\underline{365}$, 2188-2197

Ludwin SK (1978): Central nervous system demyelination and remyelination in the mouse: an ultrastructural study of cuprizone toxicity. Lab Invest $\underline{39}$, 597-612

Lüllmann-Rauch R, Asan E: Taschenbuch Histologie. 5. Auflage; Thieme, Stuttgart 2015

Luttmann W, Bratke K, Küpper M, Myrtek D: Der Experimentator: Immunologie. Springer, Berlin 2014

Maeda Y, Solanky M, Menonna J, Chapin J, Li W, Dowling P (2001): Platelet-derived growth factor- $\alpha$ receptor-positive oligodendroglia are frequent in multiple sclerosis lesions. Ann Neurol $\underline{49}, 776-785$

Mahad D, Lassmann H, Turnbull D (2008): Review: Mitochondria and disease progression in multiple sclerosis. Neuropathol Appl Neurobiol 34, 577-589

Marrie RA (2004): Environmental risk factors in multiple sclerosis aetiology. Lancet Neurol $\underline{3}, 709$ 718 
Matsushima GK, Morell P (2001): The Neurotoxicant, Cuprizone, as a Model to Study Demyelination and Remyelination in the Central Nervous System. Brain Pathol 11, 107-116

Matute C, Torre I, Pérez-Cerdá F, Pérez-Samartín A, Alberdi E, Etxebarria E, Arranz AM, Ravid R, Rodríguez-Antigüedad A, Sánchez-Gómez M, Domercq M (2007): P2X(7) receptor blockade prevents ATP excitotoxicity in oligodendrocytes and ameliorates experimental autoimmune encephalomyelitis. J Neurosci 27, 9525-9533

Mcdonald JW, Althomsons SP, Hyrc KL, Choi DW, Goldberg MP (1998): Oligodendrocytes from forebrain are highly vulnerable to AMPA/kainate receptor-mediated excitotoxicity. Nat Med 4, 291-297

McDonald WI, Compston A, Edan G, Goodkin D, Hartung HP, Lublin FD, McFarland HF, Paty DW, Polman CH, Reingold SC, et al. (2001): Recommended diagnostic criteria for multiple sclerosis: guidelines from the International Panel on the diagnosis of multiple sclerosis. Ann Neurol 50, 121-127

McKinsey TA, Zhang C-L, Lu J, Olson EN (2000): Signal-dependent nuclear export of a histone deacetylase regulates muscle differentiation. Nature $\underline{408}, 106$

McTigue DM, Tripathi RB (2008): The life, death, and replacement of oligodendrocytes in the adult CNS. J Neurochem 107, 1-19

Mecollari V, Nieuwenhuis B, Verhaagen J (2014): A perspective on the role of class III semaphorin signaling in central nervous system trauma. Front Cell Neurosci $\underline{8}, 9$

Mei F, Wang H, Liu S, Niu J, Wang L, He Y, Etxeberria A, Chan JR, Xiao L (2013): Stage-Specific Deletion of Olig2 Conveys Opposing Functions on Differentiation and Maturation of Oligodendrocytes. J Neurosci $\underline{33}, 8454-8462$

Menge T, Hörste GM zu (2013): Aktuelles aus der Forschung. Akt Neurol 40, 410-411

Merrill JE, Benveniste EN (1996): Cytokines in inflammatory brain lesions: helpful and harmful. Trends Neurosci 19, 331-338

Messori L, Casini A, Gabbiani C, Sorace L, Muniz-Miranda M, Zatta P (2007): Unravelling the chemical nature of copper cuprizone. Dalton Trans 21, 2112-2114

Micu I, Jiang Q, Coderre E, Ridsdale A, Zhang L, Woulfe J, Yin X, Trapp BD, McRory JE, Rehak $\mathrm{R}$, et al. (2006): NMDA receptors mediate calcium accumulation in myelin during chemical ischaemia. Nature $\underline{439}, 988-992$

Miron VE, Kuhlmann T, Antel JP (2011): Cells of the oligodendroglial lineage, myelination, and remyelination. Biochim Biophys Acta Mol Basis Dis 1812, 184-193

Mix E, Meyer-Rienecker H, Hartung H-P, Zettl UK (2010): Animal models of multiple sclerosis-

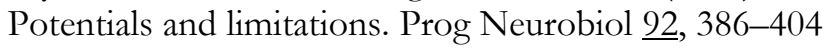

Montalban X, Gold R, Thompson AJ, Otero-Romero S, Amato MP, Chandraratna D, Clanet M, Comi G, Derfuss T, Fazekas F, et al. (2018): ECTRIMS/EAN guideline on the pharmacological treatment of people with multiple sclerosis. Eur J Neurol 25, 215-237

Moreno MA, Or-Geva N, Aftab BT, Khanna R, Croze E, Steinman L, Han MH (2018): Molecular signature of Epstein-Barr virus infection in MS brain lesions. Neurol Neuroimmunol Neuroinflamm $\underline{5}, 5: e 466$ 
Morrison BM, Lee Y, Rothstein JD (2013): Oligodendroglia: metabolic supporters of axons. Trends Cell Biol 23, 644-651

Munoz JJ, Bernard CCA, Mackay IR (1984): Elicitation of experimental allergic encephalomyelitis (EAE) in mice with the aid of pertussigen. Cellular Immunology $\underline{83}, 92-100$

Nakahara J, Kanekura K, Nawa M, Aiso S, Suzuki N (2009): Abnormal expression of TIP30 and arrested nucleocytoplasmic transport within oligodendrocyte precursor cells in multiple sclerosis. J Clin Invest 119, 169-181

Nakahara J, Aiso S, Suzuki N (2010): Autoimmune Versus Oligodendrogliopathy: The Pathogenesis of Multiple Sclerosis. Arch Immunol Ther Exp (Warsz) 58, 325-333

Nash B, Thomson CE, Linington C, Arthur AT, McClure JD, McBride MW, Barnett SC (2011): Functional Duality of Astrocytes in Myelination. J Neurosci 31, 13028-13038

Nave K-A (2010): Oligodendrocytes and the "Micro Brake" of Progenitor Cell Proliferation. Neu$\operatorname{ron} \underline{65}, 577-579$

Nave K-A, Trapp BD (2008): Axon-Glial Signaling and the Glial Support of Axon Function. Annu Rev Neurosci 31, 535-561

Nave K-A, Werner HB (2014): Myelination of the Nervous System: Mechanisms and Functions. Annu Rev Cell Dev Biol 30, 503-533

Noseworthy JH, Lucchinetti C, Rodriguez M, Weinshenker BG (2000): Multiple sclerosis. N Engl J Med $\underline{343}, 938-952$

Olsson T, Dahlman I, Wallström E, Weissert R, Piehl F (2000): Genetics of rat neuroinflammation. J Neuroimmunol $\underline{107}, 191-200$

Olsson T, Barcellos LF, Alfredsson L (2017): Interactions between genetic, lifestyle and environmental risk factors for multiple sclerosis. Nat Rev Neurol 13, 25-36

Ou Z, Sun Y, Lin L, You N, Liu X, Li H, Ma Y, Cao L, Han Y, Liu M, et al. (2016): Olig2-Targeted G-Protein-Coupled Receptor Gpr17 Regulates Oligodendrocyte Survival in Response to Lysolecithin-Induced Demyelination. J Neurosci 36, 10560-10573

Ozawa K, Suchanek G, Breitschopf H, Brück W, Budka H, Jellinger K, Lassmann H (1994): Patterns of oligodendroglia pathology in multiple sclerosis. Brain 117, 1311-1322

Pahan K, Schmid M (2000): Activation of nuclear factor-kB in the spinal cord of experimental allergic encephalomyelitis. Neurosci Lett 287, 17-20

Pang Y, Campbell L, Zheng B, Fan L, Cai Z, Rhodes P (2010): Lipopolysaccharide-activated microglia induce death of oligodendrocyte progenitor cells and impede their development. Neuroscience $166,464-475$

Parnell GP, Booth DR (2017): The Multiple Sclerosis (MS) Genetic Risk Factors Indicate both Acquired and Innate Immune Cell Subsets Contribute to MS Pathogenesis and Identify Novel Therapeutic Opportunities. Front Immunol $\underline{8}, 415$

Patel JR, Klein RS (2011): Mediators of oligodendrocyte differentiation during remyelination. FEBS Lett $\underline{585}, 3730-3737$

Patel JR, McCandless EE, Dorsey D, Klein RS (2010): CXCR4 promotes differentiation of oligodendrocyte progenitors and remyelination. Proc Natl Acad Sci U S A 107, 11062-11067 
Peferoen L, Kipp M, Valk P van der, Noort JM van, Amor S (2014): Oligodendrocyte-microglia cross-talk in the central nervous system. Immunology 141, 302-313

Penderis J, Shields SA, Franklin RJM (2003): Impaired remyelination and depletion of oligodendrocyte progenitors does not occur following repeated episodes of focal demyelination in the rat central nervous system. Brain $\underline{126}, 1382-1391$

Petersen G, Wittmann R, Arndt V, Göpffarth D (2014): Epidemiologie der Multiplen Sklerose in Deutschland: Regionale Unterschiede und Versorgungsstruktur in Abrechnungsdaten der gesetzlichen Krankenversicherung. Nervenarzt 모, 990-998

Piaton G, Williams A, Seilhean D, Lubetzki C: Remyelination in multiple sclerosis, In: Verhaagen J, Hol EM, Huitenga I, Wijnholds J, Bergen AB, Boer GJ, Swaab DF (Hrsg.): Progress in Brain Research, Elsevier, Amsterdam 2009, 453-464

Pittock SJ, McClelland RL, Achenbach SJ, Konig F, Bitsch A, Brück W, Lassmann H, Parisi JE, Scheithauer BW, Rodriguez M, et al. (2005): Clinical course, pathological correlations, and outcome of biopsy proved inflammatory demyelinating disease. J Neurol Neurosurg Psychiatry $\underline{76}, 1693-1697$

Polman CH, Reingold SC, Edan G, Filippi M, Hartung H-P, Kappos L, Lublin FD, Metz LM, McFarland HF, O'Connor PW, et al. (2005): Diagnostic criteria for multiple sclerosis: 2005 revisions to the „McDonald Criteria“. Ann Neurol 58 , 840-846

Polman CH, Reingold SC, Banwell B, Clanet M, Cohen JA, Filippi M, Fujihara K, Havrdova E, Hutchinson M, Kappos L, et al. (2011): Diagnostic criteria for multiple sclerosis: 2010 revisions to the McDonald criteria. Ann Neurol 69, 292-302

Poser CM, Paty DW, Scheinberg L, McDonald WI, Davis FA, Ebers GC, Johnson KP, Sibley WA, Silberberg DH, Tourtellotte WW (1983): New diagnostic criteria for multiple sclerosis: guidelines for research protocols. Ann Neurol 13, 227-231

Ramagopalan SV, Dyment DA, Ebers GC (2008): Genetic epidemiology: the use of old and new tools for multiple sclerosis. Trends Neurosci $31,645-652$

Reboldi A, Coisne C, Baumjohann D, Benvenuto F, Bottinelli D, Lira S, Uccelli A, Lanzavecchia A, Engelhardt B, Sallusto F (2009): C-C chemokine receptor 6-regulated entry of $\mathrm{T}_{\mathrm{H}}-17$ cells into the CNS through the choroid plexus is required for the initiation of EAE. Nat Immunol $10,514-523$

Redwine JM, Armstrong RC (1998): In vivo proliferation of oligodendrocyte progenitors expressing $\mathrm{PDGF} \alpha \mathrm{R}$ during early remyelination. J Neurobiol $\underline{37}, 413-428$

Rhodes KE, Raivich G, Fawcett JW (2006): The injury response of oligodendrocyte precursor cells is induced by platelets, macrophages and inflammation-associated cytokines. Neuroscience $\underline{140}, 87-100$

Rivers TM, Sprunt DH, Berry GP (1933): Observations on Attempts to Produce Acute Disseminated Encephalomyelitis in Monkeys. J Exp Med 묘, 39-53

Rodriguez M, Warrington AE, Pease LR (2009): Invited Article: Human natural autoantibodies in the treatment of neurologic disease. Neurology $\underline{72}, 1269-1276$

Romanelli E, Merkler D, Mezydlo A, Weil M-T, Weber MS, Nikić I, Potz S, Meinl E, Matznick FEH, Kreutzfeldt M, et al. (2016): Myelinosome formation represents an early stage of oligodendrocyte damage in multiple sclerosis and its animal model. Nat Commun $\mathbf{7}, 13275$ 
Rose AS, Ellison GW, Myers LW, Tourtellotte WW (1976): Criteria for the clinical diagnosis of multiple sclerosis. Neurology $\underline{26}, 20-22$

Rosenberg SS, Kelland EE, Tokar E, Torre ARDL, Chan JR (2008): The geometric and spatial constraints of the microenvironment induce oligodendrocyte differentiation. Proc Natl Acad Sci U S A $\underline{105}, 14662-14667$

Sampaio-Baptista C, Johansen-Berg H (2017): White Matter Plasticity in the Adult Brain. Neuron 96, 1239-1251

Sánchez-Gómez MV, Matute C (1999): AMPA and Kainate Receptors Each Mediate Excitotoxicity in Oligodendroglial Cultures. Neurobiol Dis $\underline{6}, 475-485$

Sawcer S, Consortium 2 TIMSGC\& TWTCC, Hellenthal G, Pirinen M, Spencer CCA, Patsopoulos NA, Moutsianas L, Dilthey A, Su Z, Freeman C, et al. (2011): Genetic risk and a primary role for cell-mediated immune mechanisms in multiple sclerosis. Nature $\underline{476}, 214-219$

Schenck M, Carpinteiro A, Grassmé H, Lang F, Gulbins E (2007): Ceramide: Physiological and pathophysiological aspects. Arch Biochem Biophys $\underline{462}, 171-175$

Scholz J, Klein MC, Behrens TEJ, Johansen-Berg H (2009): Training induces changes in white-matter architecture. Nat Neurosci $\underline{12}, 1370-1371$

Schumacher GA, Beebe G, Kibler RF, Kurland LT, Kurtzke JF, McDowell F, Nagler B, Sibley WA, Tourtellotte WW, Willmon TL (1965): Problems of Experimental Trials of Therapy in Multiple Sclerosis: Report by the Panel on the Evaluation of Experimental Trials of Therapy in Multiple Sclerosis. Ann N Y Acad Sci 122, 552-568

Setzu A, Lathia JD, Zhao C, Wells K, Rao MS, ffrench-Constant C, Franklin RJM (2006): Inflammation stimulates myelination by transplanted oligodendrocyte precursor cells. Glia $\underline{54}$, 297-303

Shen S, Li J, Casaccia-Bonnefil P (2005): Histone modifications affect timing of oligodendrocyte progenitor differentiation in the developing rat brain. J Cell Biol $\underline{169}, 577-589$

Shen S, Sandoval J, Swiss VA, Li J, Dupree J, Franklin RJM, Casaccia-Bonnefil P (2008): Age-dependent epigenetic control of differentiation inhibitors is critical for remyelination efficiency. Nat Neurosci 11, 1024-1034

Shi Y (2007): Histone lysine demethylases: emerging roles in development, physiology and disease. Nat Rev Genet $\underline{8}, 829-833$

Simons M, Nave K-A (2016): Oligodendrocytes: Myelination and Axonal Support. Cold Spring Harb Perspect Biol $\underline{8}$, a020479

Simpson S, Blizzard L, Otahal P, Van der Mei I, Taylor B (2011): Latitude is significantly associated with the prevalence of multiple sclerosis: a meta-analysis. J Neurol Neurosurg Psychiatry $\underline{82}, 1132-1141$

Singh I, Pahan K, Khan M, Singh AK (1998): Cytokine-mediated Induction of Ceramide Production Is Redox-sensitive - Implications To Proinflammatory Cytokine-Mediated Apoptosis in Demyelinating Diseases. J Biol Chem $\underline{273}$, 20354-20362

Skjoerringe T, Lundvig DMS, Jensen PH, Moos T (2006): P25 /Tubulin polymerization promoting protein expression by myelinating oligodendrocytes of the developing rat brain. J Neurochem 99, 333-342 
Sloane JA, Batt C, Ma Y, Harris ZM, Trapp B, Vartanian T (2010): Hyaluronan blocks oligodendrocyte progenitor maturation and remyelination through TLR2. Proc Natl Acad Sci U S A $\underline{107}, 11555-11560$

Smith KJ, Lassmann H (2002): The role of nitric oxide in multiple sclerosis. Lancet Neurol 1 , 232 241

Smith KJ, Blakemore WF, Mcdonald WI (1979): Central remyelination restores secure conduction. Nature 280, 395-396

Song YJC, Lundvig DMS, Huang Y, Gai WP, Blumbergs PC, Højrup P, Otzen D, Halliday GM, Jensen PH (2007): p25 $\alpha$ Relocalizes in Oligodendroglia from Myelin to Cytoplasmic Inclusions in Multiple System Atrophy. Am J Pathol 171, 1291-1303

Sospedra M, Martin R (2005): Immunology of Multiple Sclerosis. Ann Rev Immunol 233, 683-747

Stangel M, Kleinschnitz C, Mäurer M, Raab P, Sühs K-W, Trebst C: Multiple Sklerose und andere autoimmune ZNS-Erkrankungen. In: Stangel M, Mäurer M (Hrsg.): Autoimmunerkrankungen in der Neurologie: Diagnostik und Therapie. Springer, Berlin 2018, 1-103

Stegemeyer H-R, Stegemeyer H (2004): "Finally, I propose the medullary substance to be named Myelin". Dtsch Med Wochenschr 129, 2784-2787

Stolt CC, Rehberg S, Ader M, Lommes P, Riethmacher D, Schachner M, Bartsch U, Wegner M (2002): Terminal differentiation of myelin-forming oligodendrocytes depends on the transcription factor Sox10. Genes Dev 16, 165-170

Suyama K, Watanabe M, Sakai D, Osada T, Imai M, Mochida J (2007): Nkx2.2 Expression in Differentiation of Oligodendrocyte Precursor Cells and Inhibitory Factors for Differentiation of Oligodendrocytes after Traumatic Spinal Cord Injury. J Neurotrauma 24, 1013-1025

Takahashi M, Tomizawa K, Fujita SC, Sato K, Uchida T, Imahori K (1993): A Brain-Specific Protein p25 Is Localized and Associated with Oligodendrocytes, Neuropil, and Fiber-Like Structures of the CA3 Hippocampal Region in the Rat Brain. J Neurochem 60, 228-235

Takebayashi H, Nabeshima Y, Yoshida S, Chisaka O, Ikenaka K, Nabeshima Y (2002): The basic helix-loop-helix factor olig2 is essential for the development of motoneuron and oligodendrocyte lineages. Curr Biol 12, 1157-1163

Tanaka H, Grooms SY, Bennett MVL, Zukin RS (2000): The AMPAR subunit GluR2: still front and center-stage11Published on the World Wide Web on 30 October 2000. Brain Res $\underline{886}$, 190-207

Testai FD, Landek MA, Dawson G (2004): Regulation of sphingomyelinases in cells of the oligodendrocyte lineage. J Neurosci Res $\underline{75}$, 66-74

Thompson AJ, Banwell BL, Barkhof F, Carroll WM, Coetzee T, Comi G, Correale J, Fazekas F, Filippi M, Freedman MS, et al. (2018): Diagnosis of multiple sclerosis: 2017 revisions of the McDonald criteria. Lancet Neurol 17, 162-173

Thorburne SK, Juurlink BHJ (1996): Low Glutathione and High Iron Govern the Susceptibility of Oligodendroglial Precursors to Oxidative Stress. J Neurochem 7, 1014-1022

Tognatta R, Miller RH (2016): Contribution of the oligodendrocyte lineage to CNS repair and neurodegenerative pathologies. Neuropharmacology $\underline{110}, 539-547$ 
Torkildsen Ø, Brunborg LA, Myhr K-M, Bø L (2008): The cuprizone model for demyelination. Acta Neurol Scand $\underline{117}, 72-76$

Trapp BD, Kidd GJ: Structure of the Myelinated Axon. In: Lazzarini RA, Griffin JW, Lassman H, Nave K-A, Miller R, Trapp BD (Hrsg.): Myelin Biology and Disorders. Academic Press, San Diego 2004, 3-27

Tuohy VK, Lu ZJ, Sobel RA, Laursen RA, Lees MB (1988): A synthetic peptide from myelin proteolipid protein induces experimental allergic encephalomyelitis. J Immunol 141, 1126

Tzartos JS, Friese MA, Craner MJ, Palace J, Newcombe J, Esiri MM, Fugger L (2008): Interleukin17 Production in Central Nervous System-Infiltrating T Cells and Glial Cells Is Associated with Active Disease in Multiple Sclerosis. Am J Pathol 172, 146-155

Vassall KA, Bamm VV, Harauz G (2015): MyelStones: the executive roles of myelin basic protein in myelin assembly and destabilization in multiple sclerosis. Biochem J 472, 17-32

Venturini G (1973): Enzymic Activities and Sodium, Potassium and Copper Concentrations in Mouse Brain and Liver After Cuprizone Treatment in Vivo. J Neurochem 21, 1147-1151

Wang S, Sdrulla AD, diSibio G, Bush G, Nofziger D, Hicks C, Weinmaster G, Barres BA (1998): Notch Receptor Activation Inhibits Oligodendrocyte Differentiation. Neuron 21, 63-75

Watanabe M, Hadzic T, Nishiyama A (2004): Transient upregulation of Nkx2.2 expression in oligodendrocyte lineage cells during remyelination. Glia $\underline{46}, 311-322$

Wegener A, Deboux C, Bachelin C, Frah M, Kerninon C, Seilhean D, Weider M, Wegner M, NaitOumesmar B (2015): Gain of Olig2 function in oligodendrocyte progenitors promotes remyelination. Brain $\underline{138}, 120-135$

Weiner HL (2004): Multiple Sclerosis Is an Inflammatory T-Cell-Mediated Autoimmune Disease. Arch Neurol 61, 1613-1615

Wolswijk G (1998): Chronic Stage Multiple Sclerosis Lesions Contain a Relatively Quiescent Population of Oligodendrocyte Precursor Cells. J Neurosci 18, 601-609

Xu X, Cai J, Fu H, Wu R, Qi Y, Modderman G, Liu R, Qiu M (2000): Selective Expression of Nkx2.2 Transcription Factor in Chicken Oligodendrocyte Progenitors and Implications for the Embryonic Origin of Oligodendrocytes. Mol Cell Neurosci 16, 740-753

Yan J, Greer JM (2008): NF- B, a Potential Therapeutic Target for the Treatment of Multiple Sclerosis. CNS Neurol Disord Drug Targets $\underline{7}, 536-557$

Ye F, Chen Y, Hoang T, Montgomery RL, Zhao X, Bu H, Hu T, Taketo MM, van Es JH, Clevers $\mathrm{H}$, et al. (2009): HDAC1 and HDAC2 regulate oligodendrocyte differentiation by disrupting the $\beta$-catenin-TCF interaction. Nat Neurosci 12, 829-838

Yeung MSY, Djelloul M, Steiner E, Bernard S, Salehpour M, Possnert G, Brundin L, Frisén J (2019): Dynamics of oligodendrocyte generation in multiple sclerosis. Nature $\underline{566}, 538-542$

Yu Y, Chen Y, Kim B, Wang H, Zhao C, He X, Liu L, Liu W, Wu LMN, Mao M, et al. (2013): Olig2 Targets Chromatin Remodelers to Enhancers to Initiate Oligodendrocyte Differentiation. Cell $152,248-261$

Zhou Q, Choi G, Anderson DJ (2001): The bHLH Transcription Factor Olig2 Promotes Oligodendrocyte Differentiation in Collaboration with Nkx2.2. Neuron $\underline{31}, 791-807$ 
Zhou Y, Simpson S, Charlesworth JC, van der Mei I, Lucas RM, Ponsonby A-L, AUSLONG Investigators Group, Taylor BV (2017): Variation within MBP gene predicts disease course in multiple sclerosis. Brain Behav 7 , e00670

Zhu X, Zuo H, Maher BJ, Serwanski DR, Lo'Turco JJ, Lu QR, Nishiyama A (2012): Olig2-dependent developmental fate switch of NG2 cells. Development 139, 2299-2307 


\section{Danksagung}

Mein Dank gilt besonders Frau Prof. Dr. C. Stadelmann-Nessler für die freundliche Überlassung des interessanten Dissertationsthemas und für die Möglichkeit, in Ihrer Abteilung zu promovieren. Als Doktormutter hat sie mich über den gesamten Zeitraum hervorragend betreut und trug mit ihrer ausdauernden und unkomplizierten Unterstützung zum Gelingen dieser Arbeit bei. Durch die immerwährende Diskussionsbereitschaft und ihre motivierenden Anregungen konnte die Arbeit zu einem erfolgreichen Ende gebracht werden.

Darüber hinaus gilt mein Dank ebenfalls Herrn Dr. med. Alonso Barrantes-Freer und Frau Melanie Lohrberg, als ebenfalls ausdauernde und hilfsbereite Betreuer*innen.

Auch bedanken möchte ich mich bei Frau Olga Kowatsch und den anderen Mitarbeitern des Labors, welche mir bei methodischen Fragen stets helfend zur Seite standen. 